Research

Elsevier Editorial System(tm) for Gondwana

Manuscript Draft

Manuscript Number: GR-D-16-00192R3

Title: Insights from recent gravity satellite missions in the density structure of continental margins - with focus on the passive margins of the South Atlantic

Article Type: SI: Rifting to Passive Margins

Keywords: continental margins; satellite gravity missions; spatial resolution; omission error; interpretation gravity effects; interpretation gravity gradients.

Corresponding Author: Dr. Hans-Juergen Goetze, Prof. Dr.

Corresponding Author's Institution:

First Author: Hans-Juergen Goetze, Prof. Dr.

Order of Authors: Hans-Juergen Goetze, Prof. Dr.

Abstract: We focus on new gravity and gravity gradient data sets from modern satellite missions GOCE, GRACE and CHAMP, and their geophysical interpretation at passive continental margins of the South Atlantic. Both sides, South Africa and South America, have been targets of hydrocarbon exploration and academic research of the German Priority Program SAMPLE (South Atlantic Margin Processes and Links with onshore Evolution). The achievable spatial resolution, driven by GOCE, is 70 - $80 \mathrm{~km}$. Therefore, most of the geological structures, which cause a significant gravity effect (by both size and density contrast), can be resolved. However, one of the most important aspects is the evaluation of the omission error, which is not always in the focus of interpreters. It results from highfrequency signals of very rough topographic and bathymetric structures, which cannot be resolved by satellite gravimetry due to the exponential signal attenuation with altitude. The omission error is estimated from the difference of the combined gravity model EIGEN-6C4 and the satelliteonly model Goco05S. It can be significantly reduced by topographic reductions. Simple $2 \mathrm{D}$ density models and their related mathematical formulas provide insights in the magnitude of the gravity effect of masses that form a passive continental margin. They are contrasted with results from satellite-only and combined gravity models. Example geophysical interpretations are given for the western and eastern margin of the South Atlantic Ocean, where standard deviations vary from $25-16$ mGal and 21 - 11 mGal, respectively. It could be demonstrated, that modern satellite gravity data provide significant added value in the geophysical gravity data processing domain and in the validation of heterogeneous terrestrial data bases. Combined models derived from highresolution terrestrial gravity and homogeneous satellite data will lead to more detailed and better constrained lithospheric density models, and hence will improve our knowledge about structure, evolution and state of stress in the lithosphere.

Response to Reviewers: 
- Combine terrestrial and satellite gravity to provide insights into passive margins.

- Satellite gravity and gradients were used to validate terrestrial gravity databases.

- 2 2nd derivations of satellite gravity can re-examine the continent-ocean boundaries. 
Click here to download high resolution image

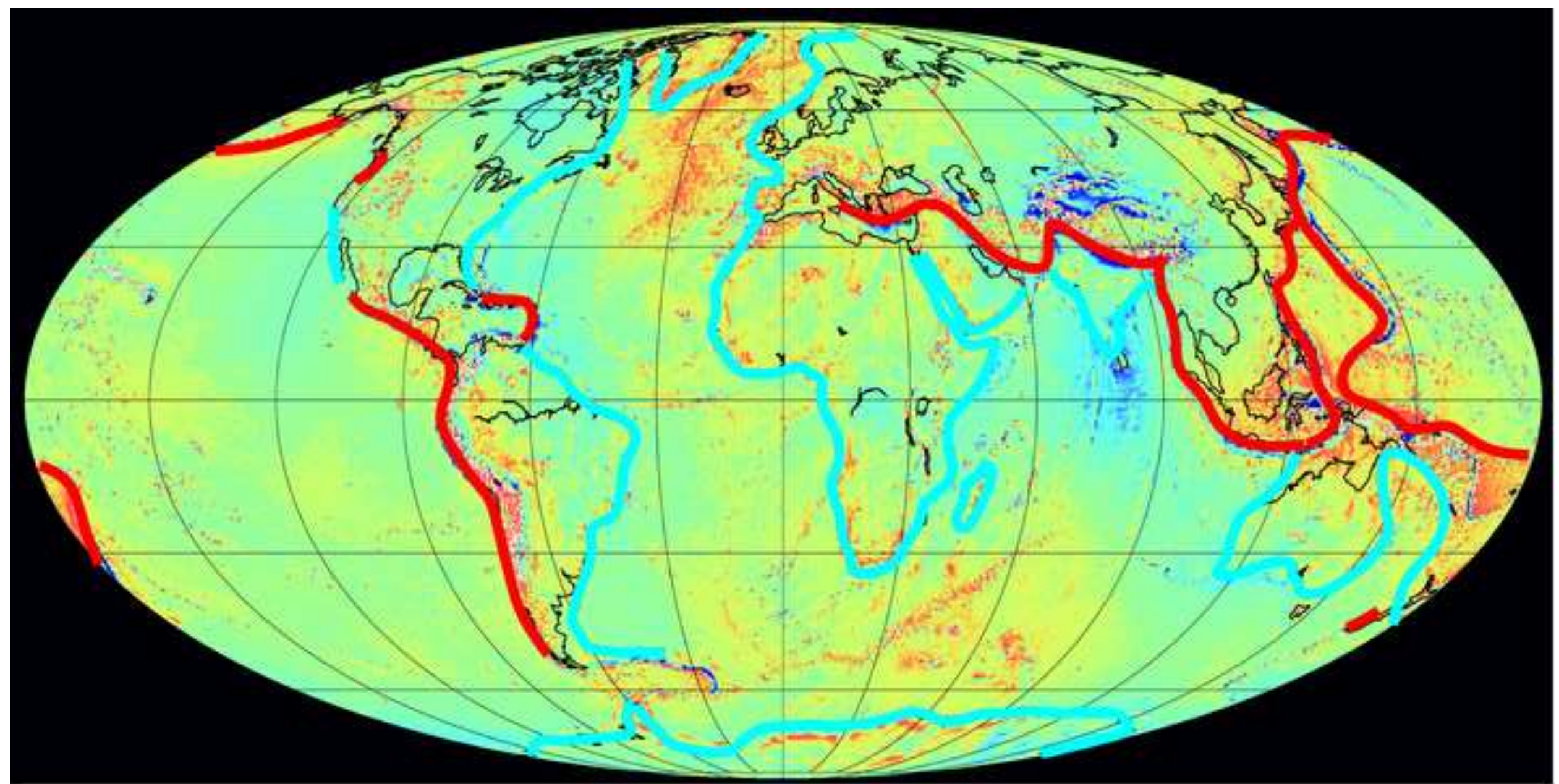

Passive continental margins

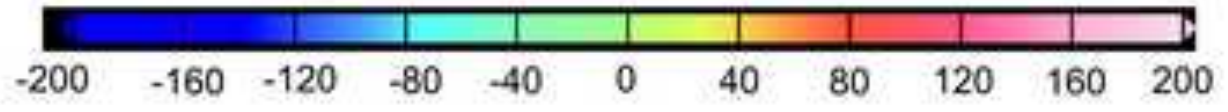

Active continental margins

Gobal field of gravity disturbance, units: $10^{s} \mathrm{~m} / \mathrm{s}^{2}$ 


\section{Distribution of observations}

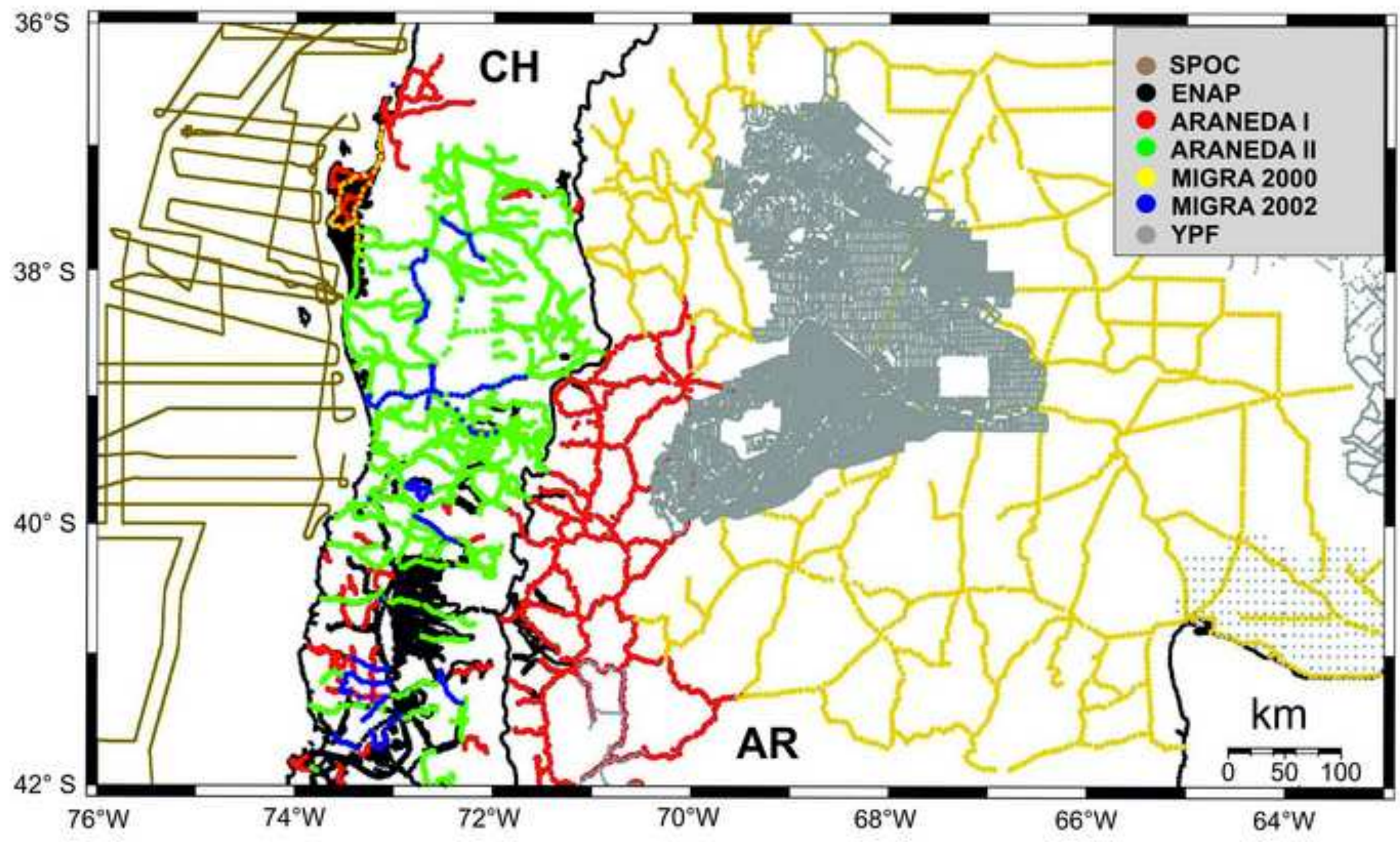




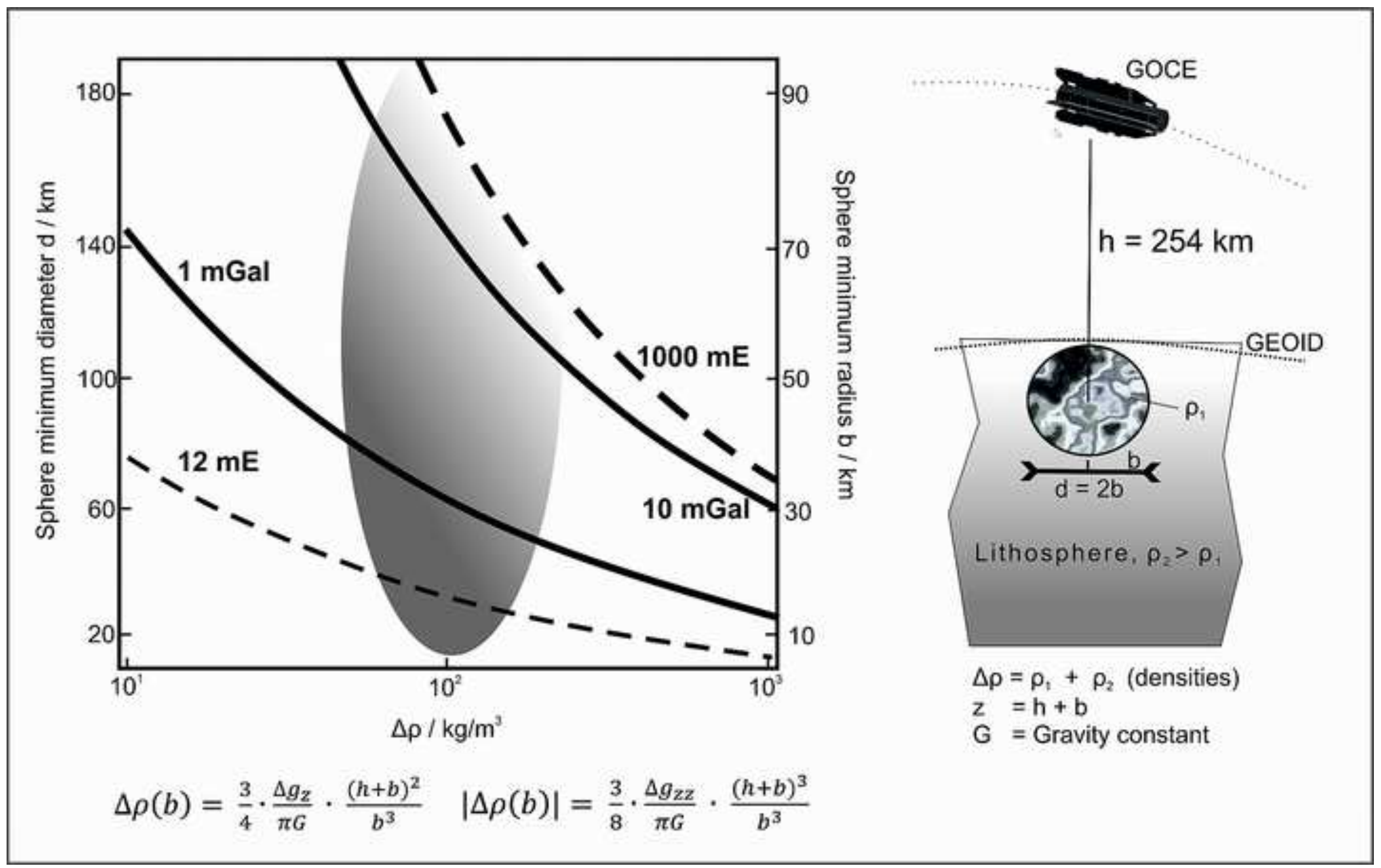


0 deg. I $90 \operatorname{deg} \mathrm{N}$

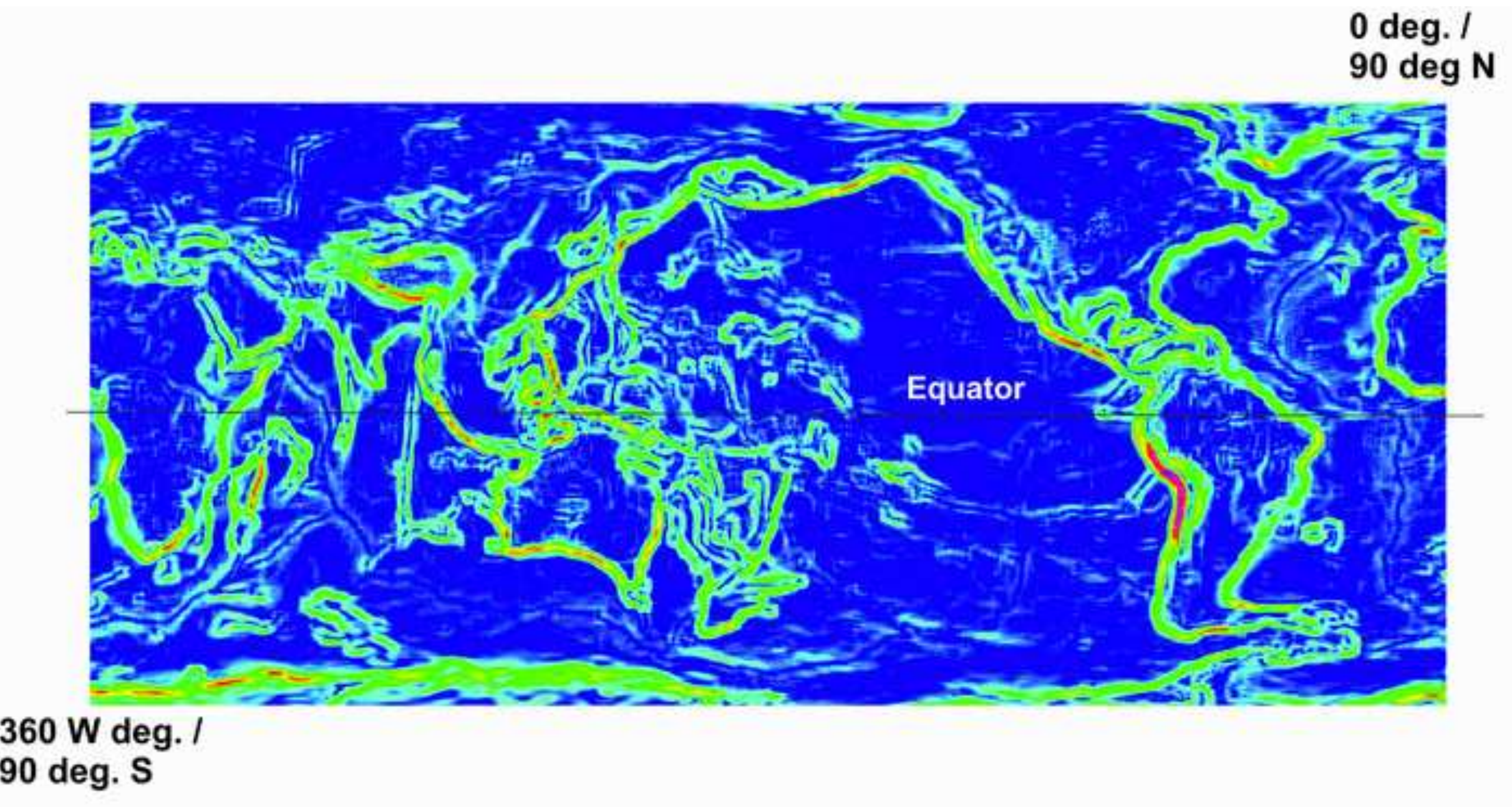

$360 \mathrm{~W}$ deg. I

90 deg. $\mathrm{S}$

90 deg.

tan



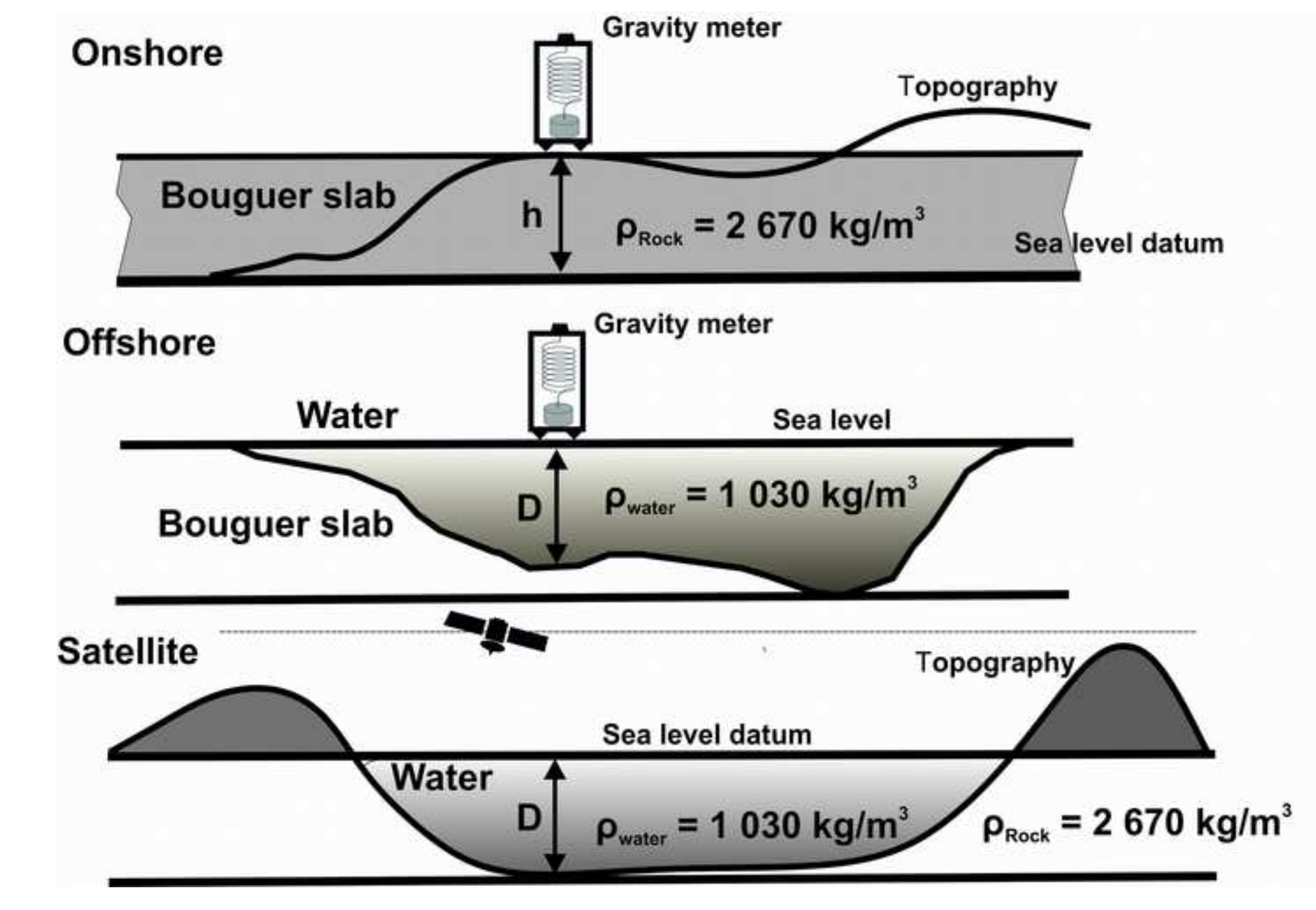

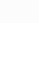

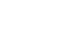

(1)

(1)

(1)

.

.

.

(1)

(1)

(1)

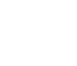

(1)
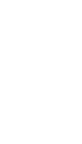


\section{Continent}

Crustal Thickness ${ }_{\text {continent }}$ $=31,8 \mathrm{~km}$

\section{Ocean}

Crustal Thickness $_{\text {ocean }}=8 \mathrm{~km}$

Water: $\rho=1030 \mathrm{~kg} / \mathrm{m}^{3}$, depth $=5 \mathrm{~km}$

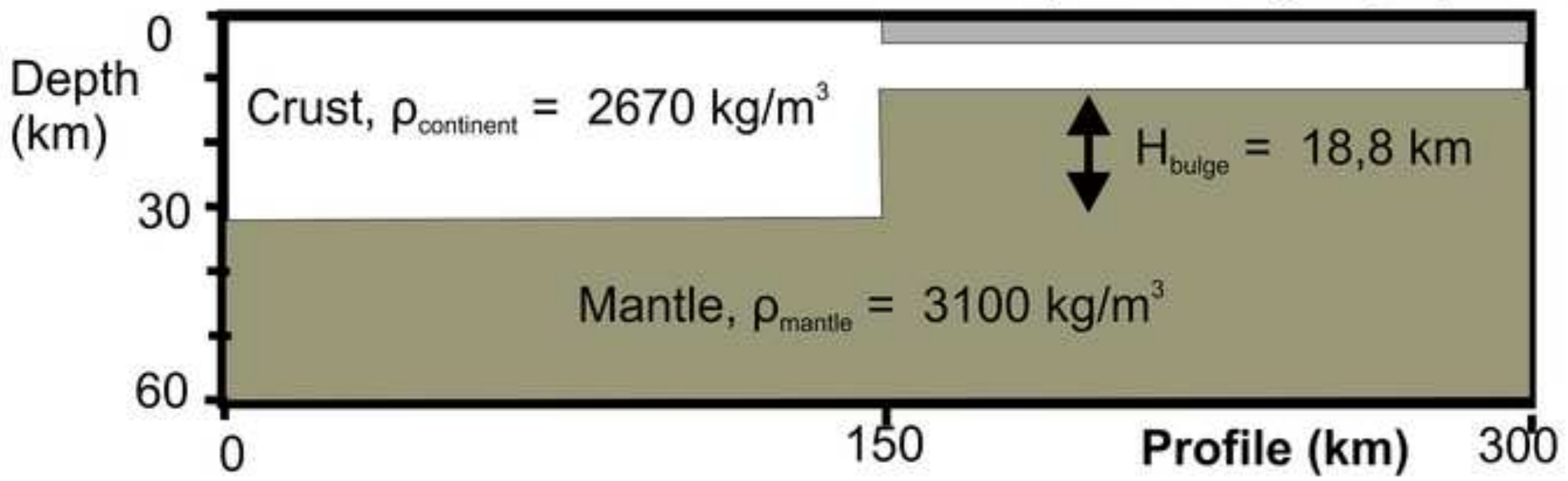


(A)

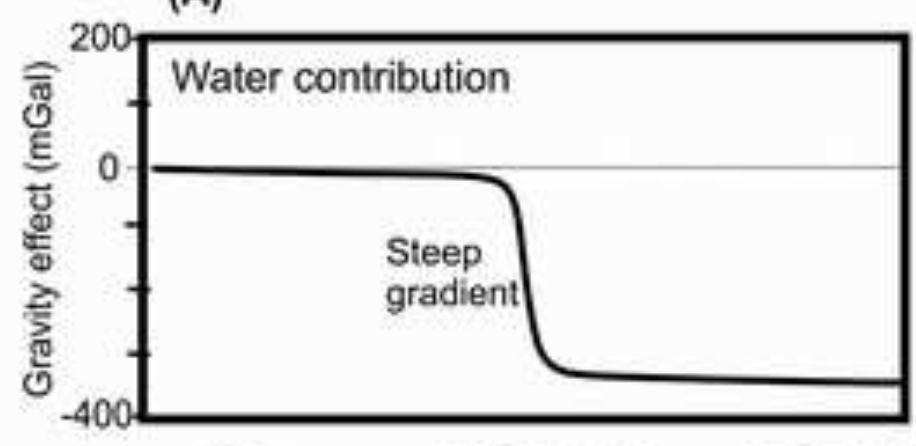

Water, $\rho_{\text {min }}=1030 \mathrm{~kg} / \mathrm{m}^{3} \Delta \rho=-1640 \mathrm{~kg} / \mathrm{m}^{3}$

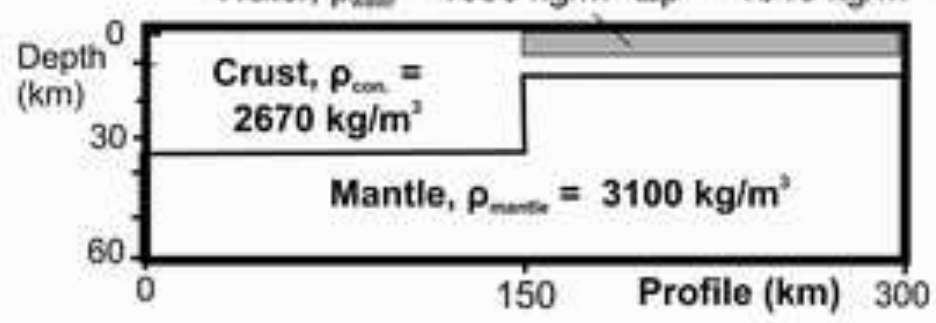

(B)
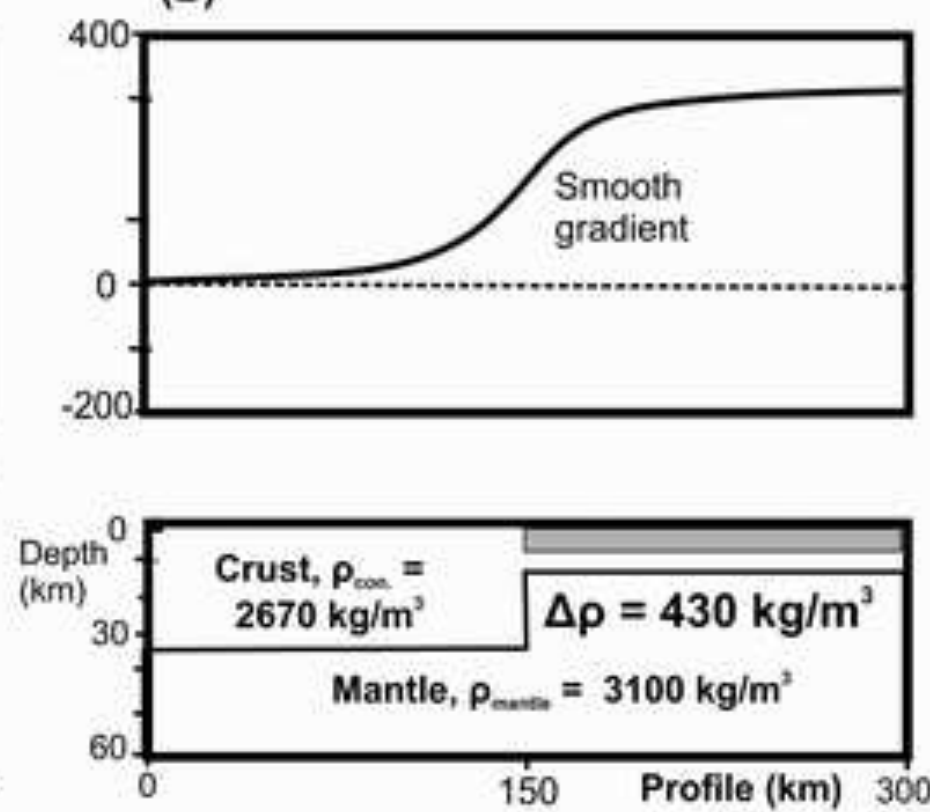

(C)

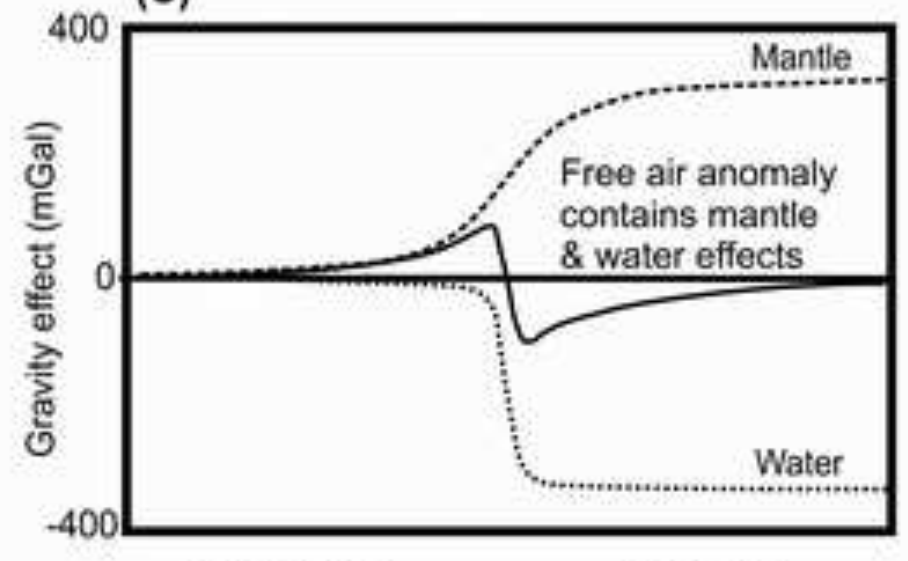

Continent

Ocean

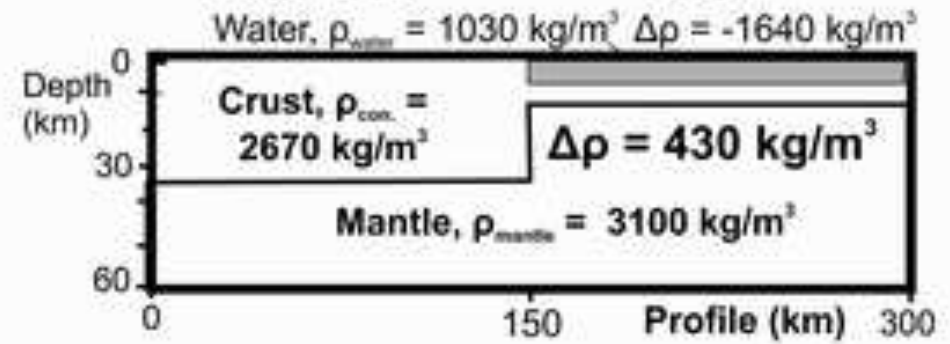


(A)

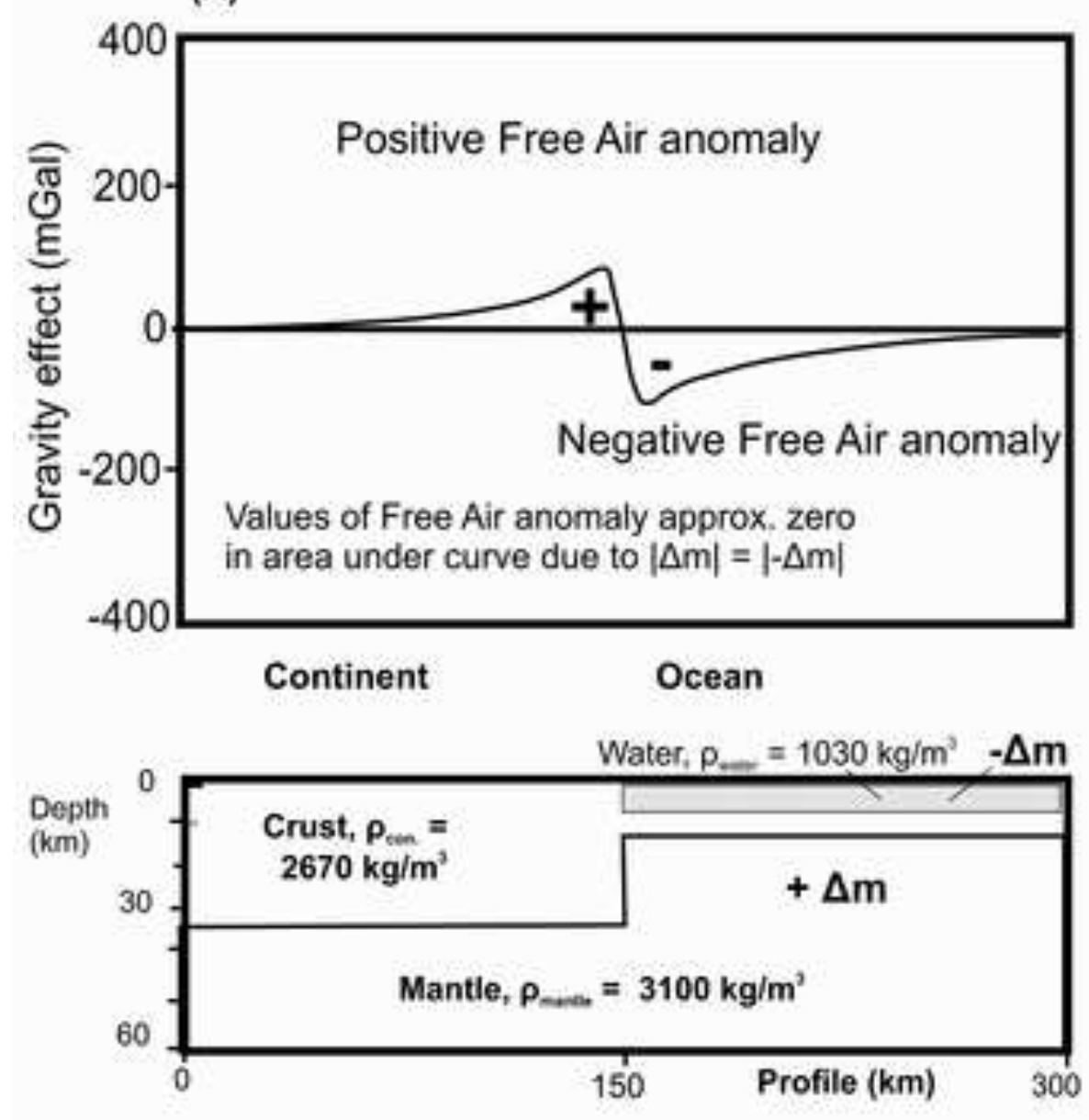

(B)

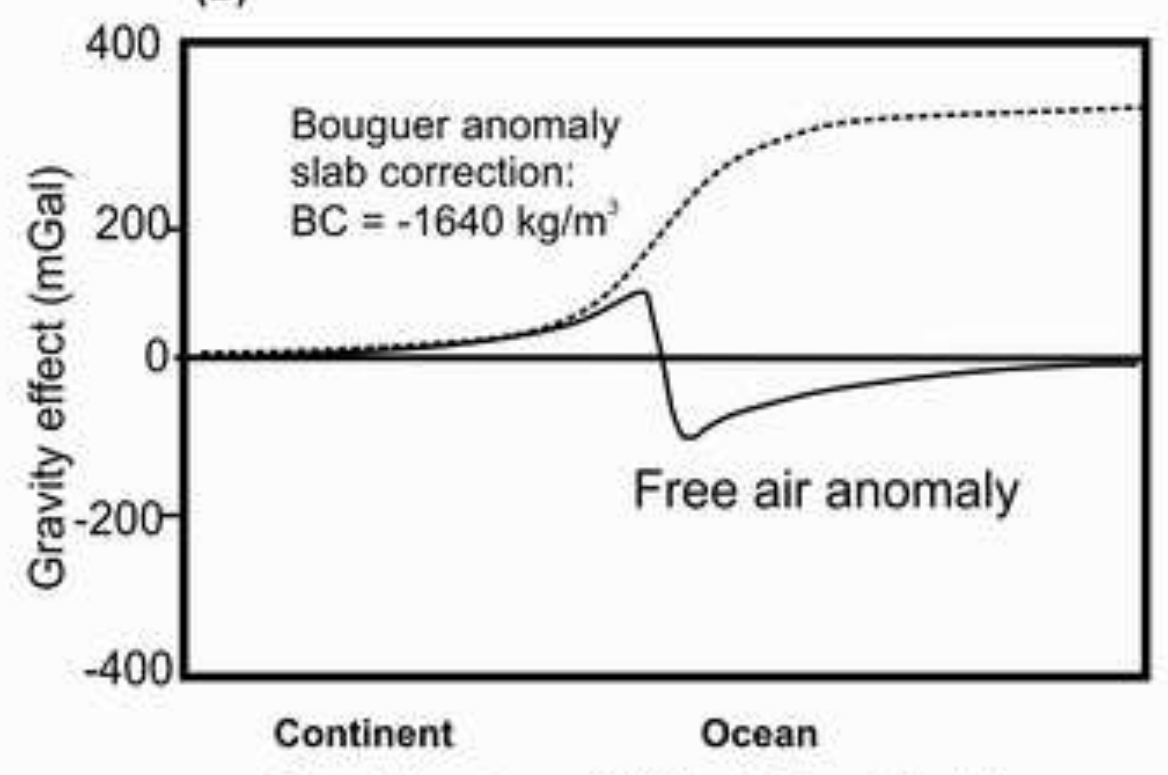

Corrected water, $\rho=2670 \mathrm{~kg} / \mathrm{m}^{2} \Delta \rho=0 \mathrm{~kg} / \mathrm{m}^{2}$.

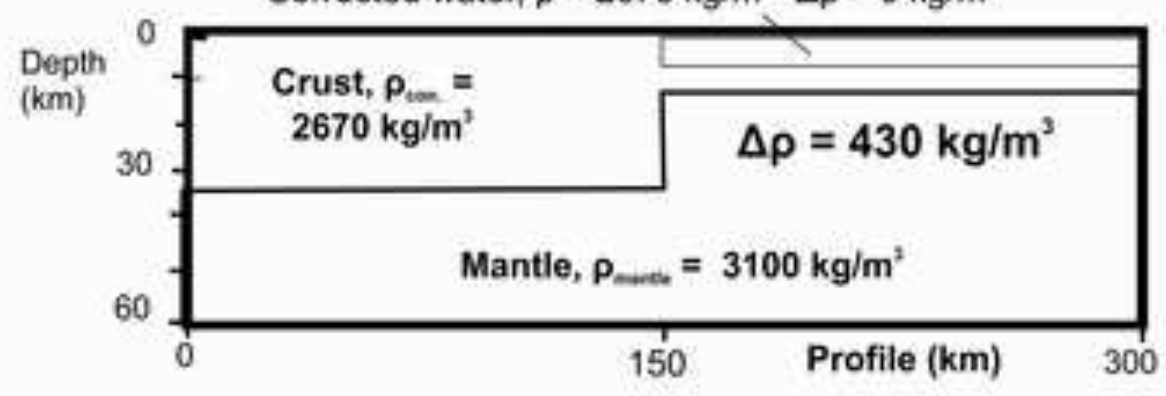


Figure

Click here to download high resolution image

C)

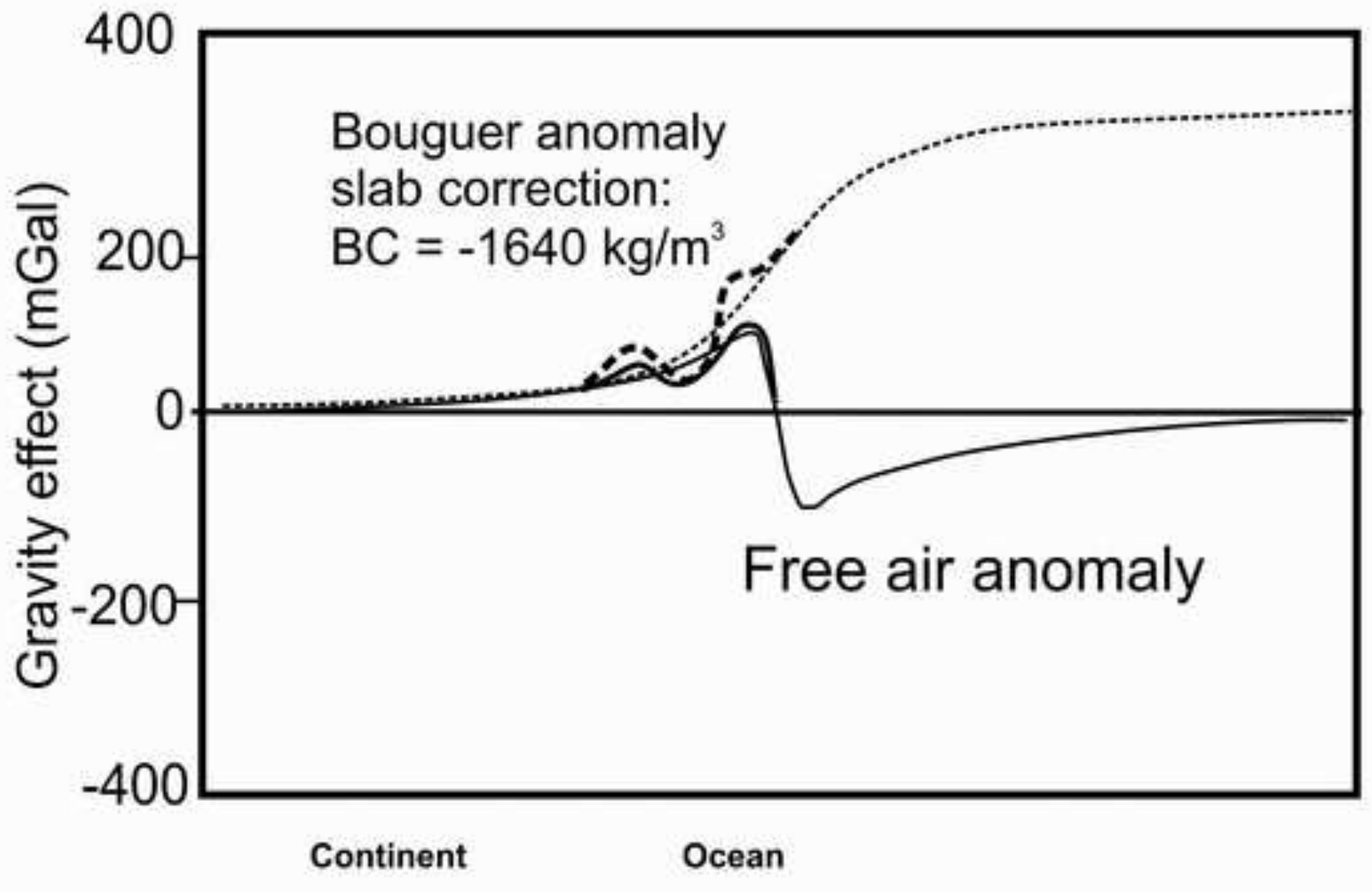

Corrected water, $\rho=2670 \mathrm{~kg} / \mathrm{m}^{3} \quad \Delta \rho=0 \mathrm{~kg} / \mathrm{m}^{3}$

Depth

$(\mathrm{km})$

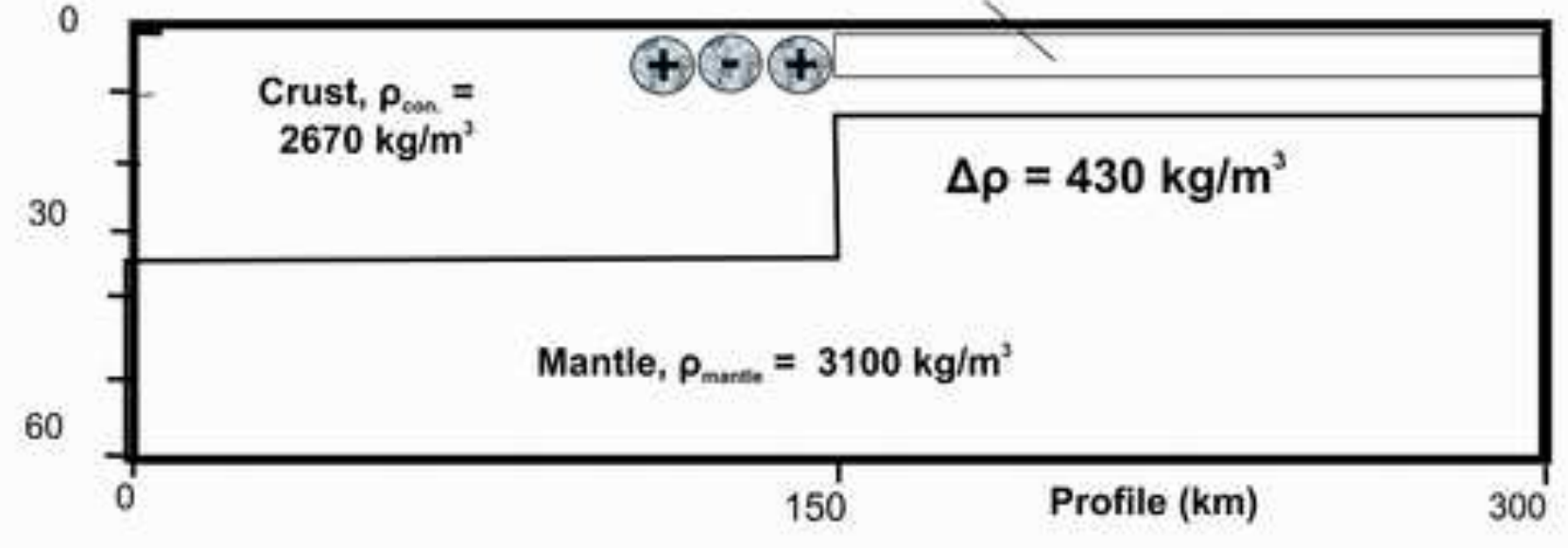


Click here to download high resolution image

- Sea water

\section{- Cenozoic}

- Upper Cretaceous (base Turonian)base Cenozoic interval

- Lower Cretaceous (base Aptian)Upper Cretaceous (base Turonian) interval

- pre-Aptian sodiments

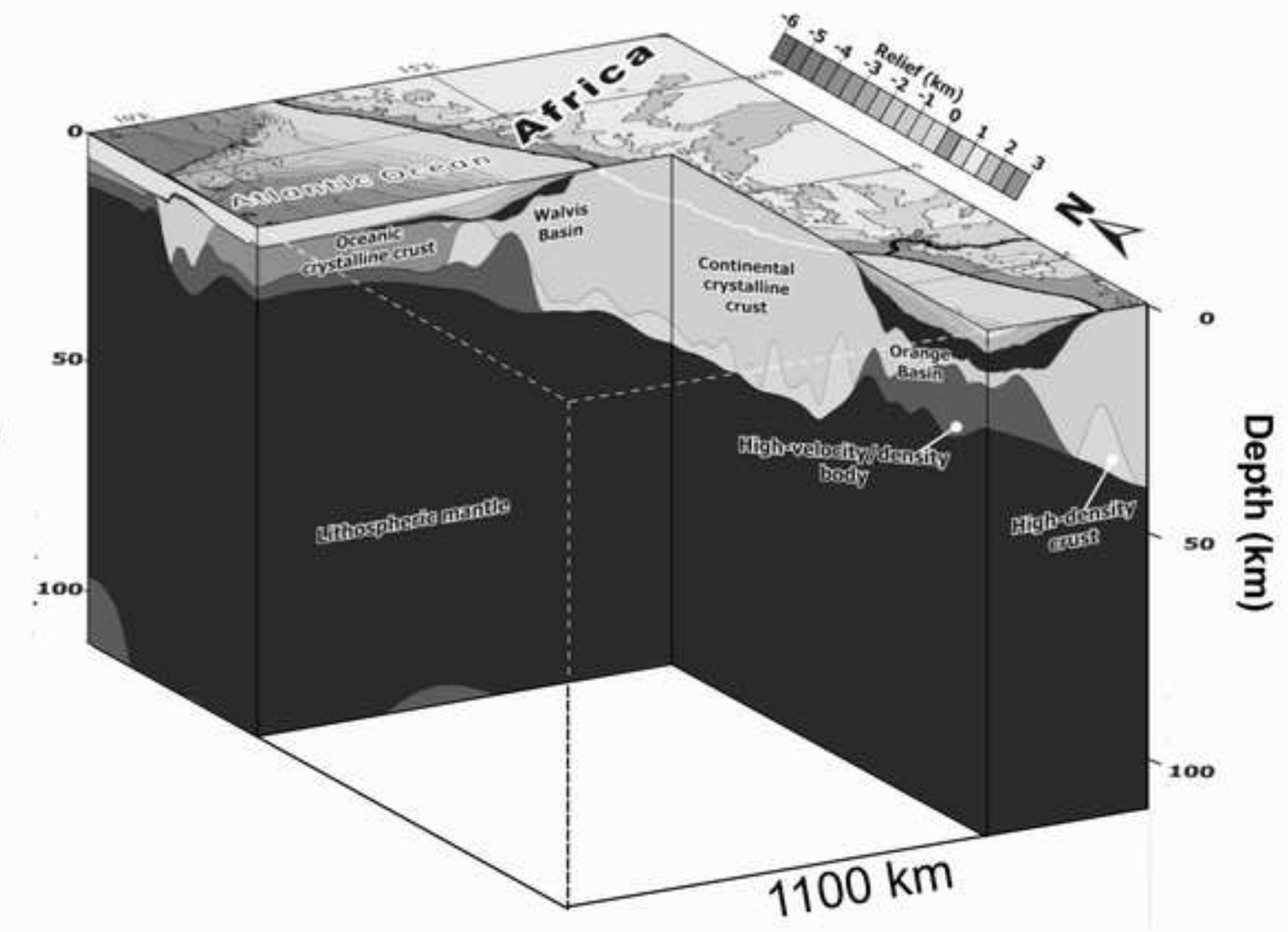




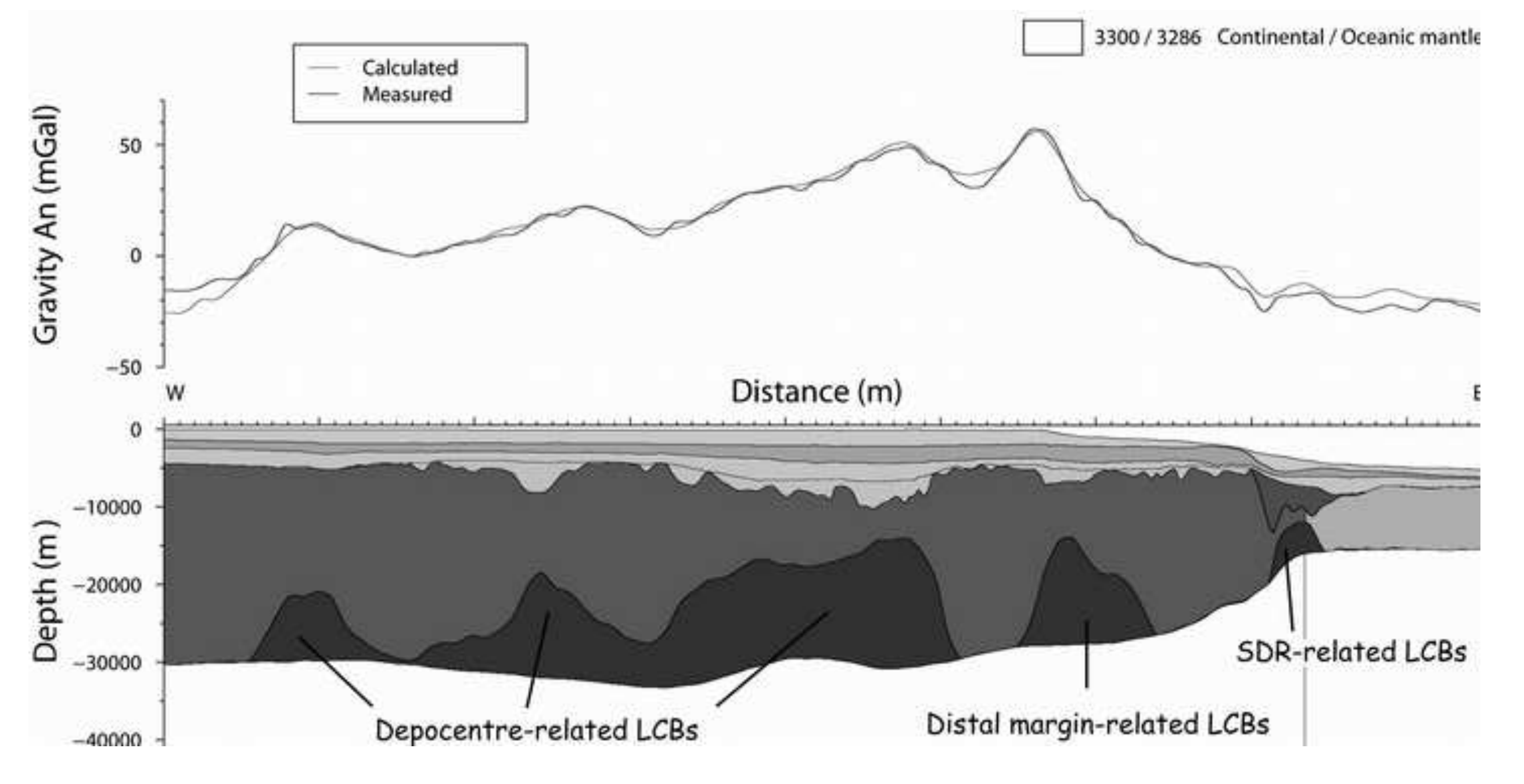

.
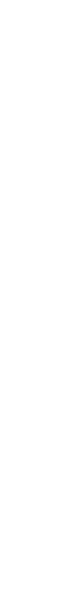


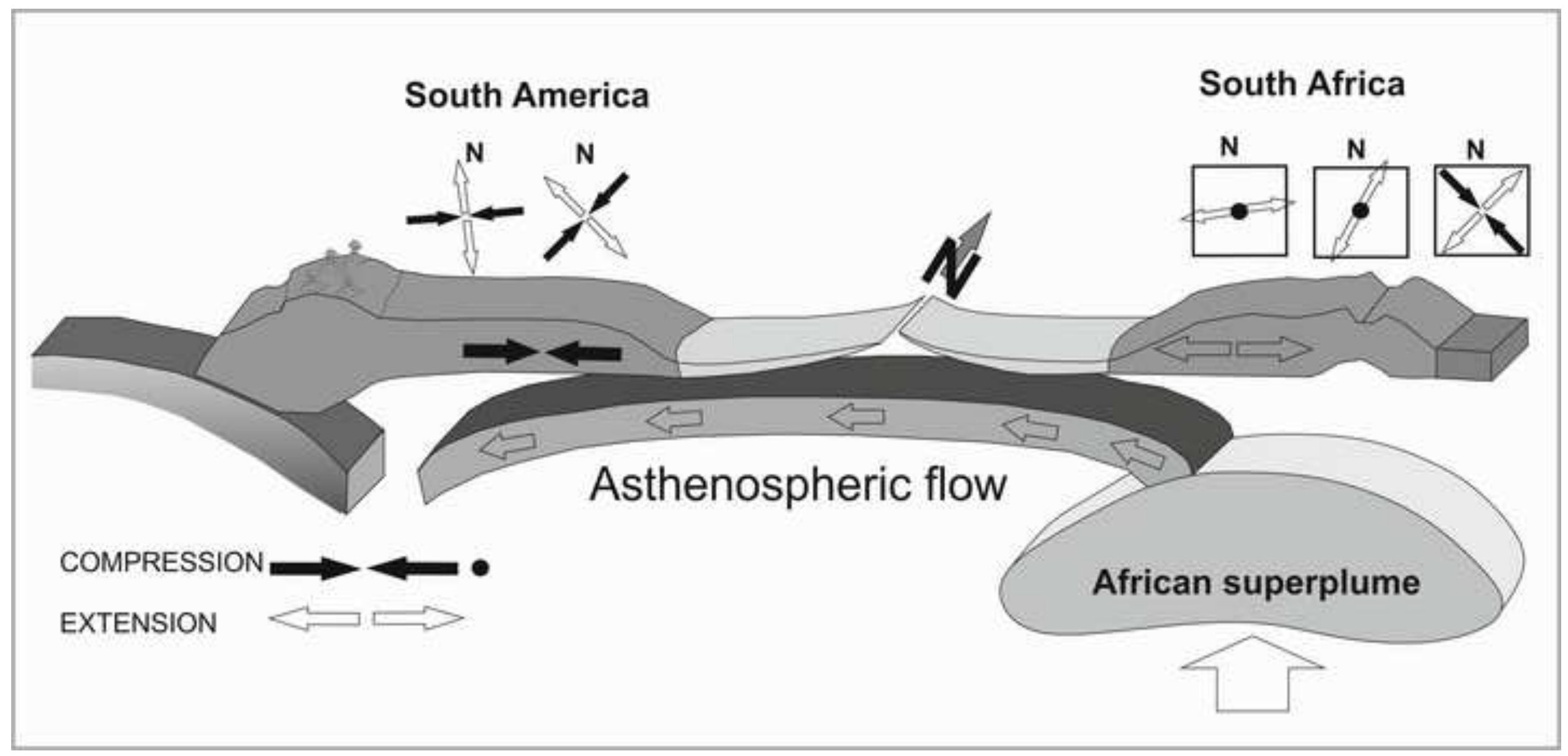

South America 
Click here to download high resolution image
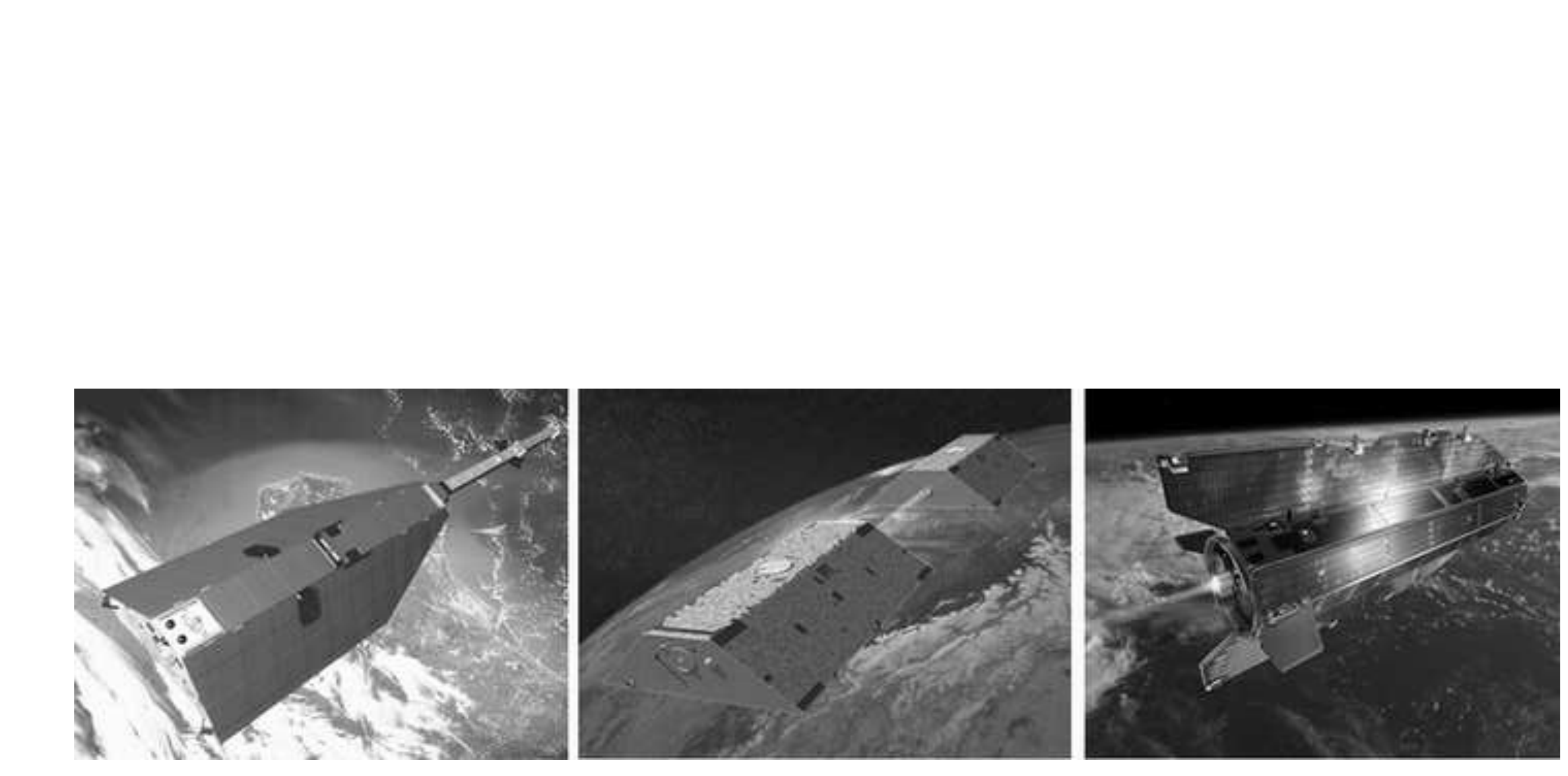
wavelength in $\mathrm{km}$

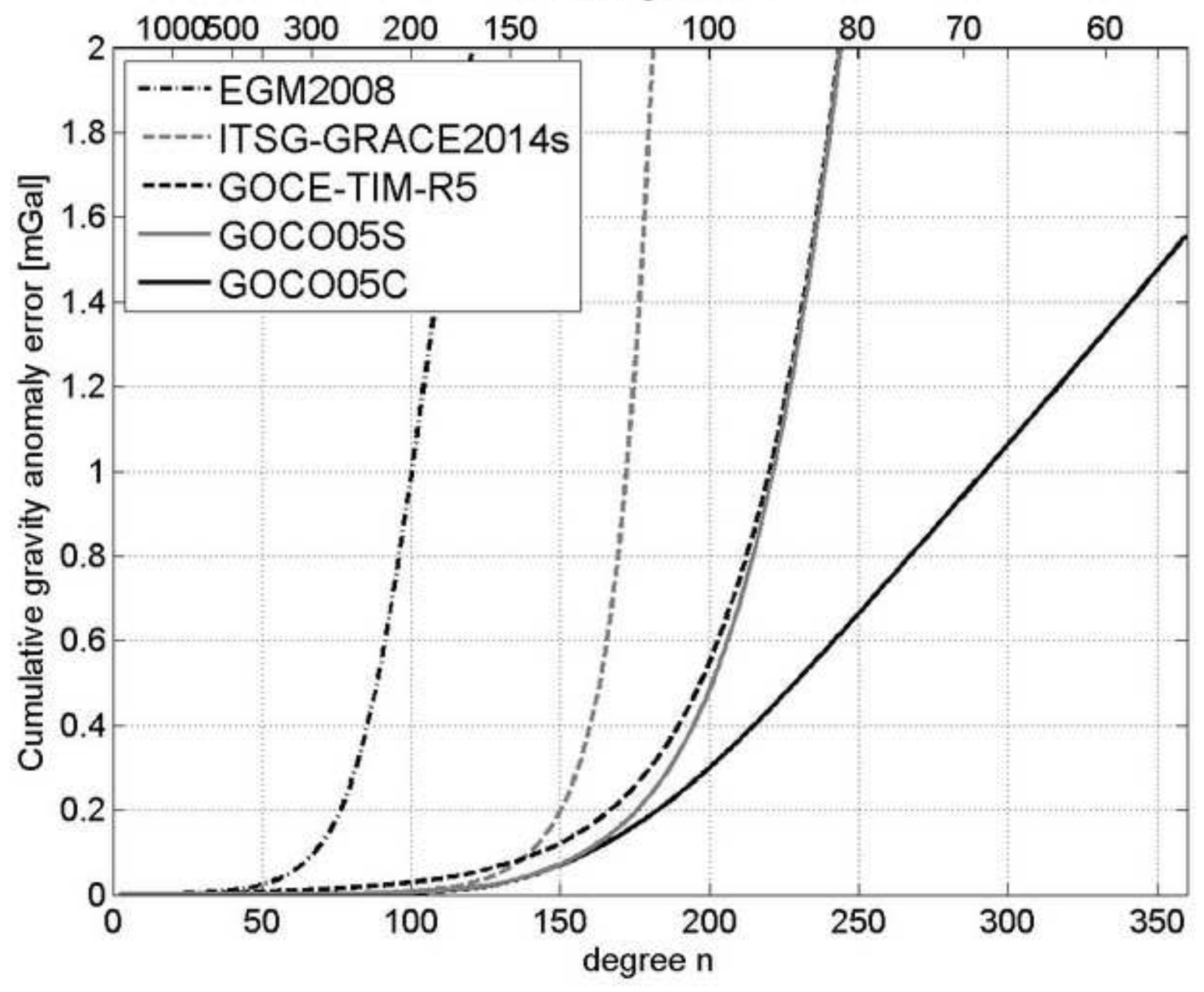


Figure

Click here to download high resolution image
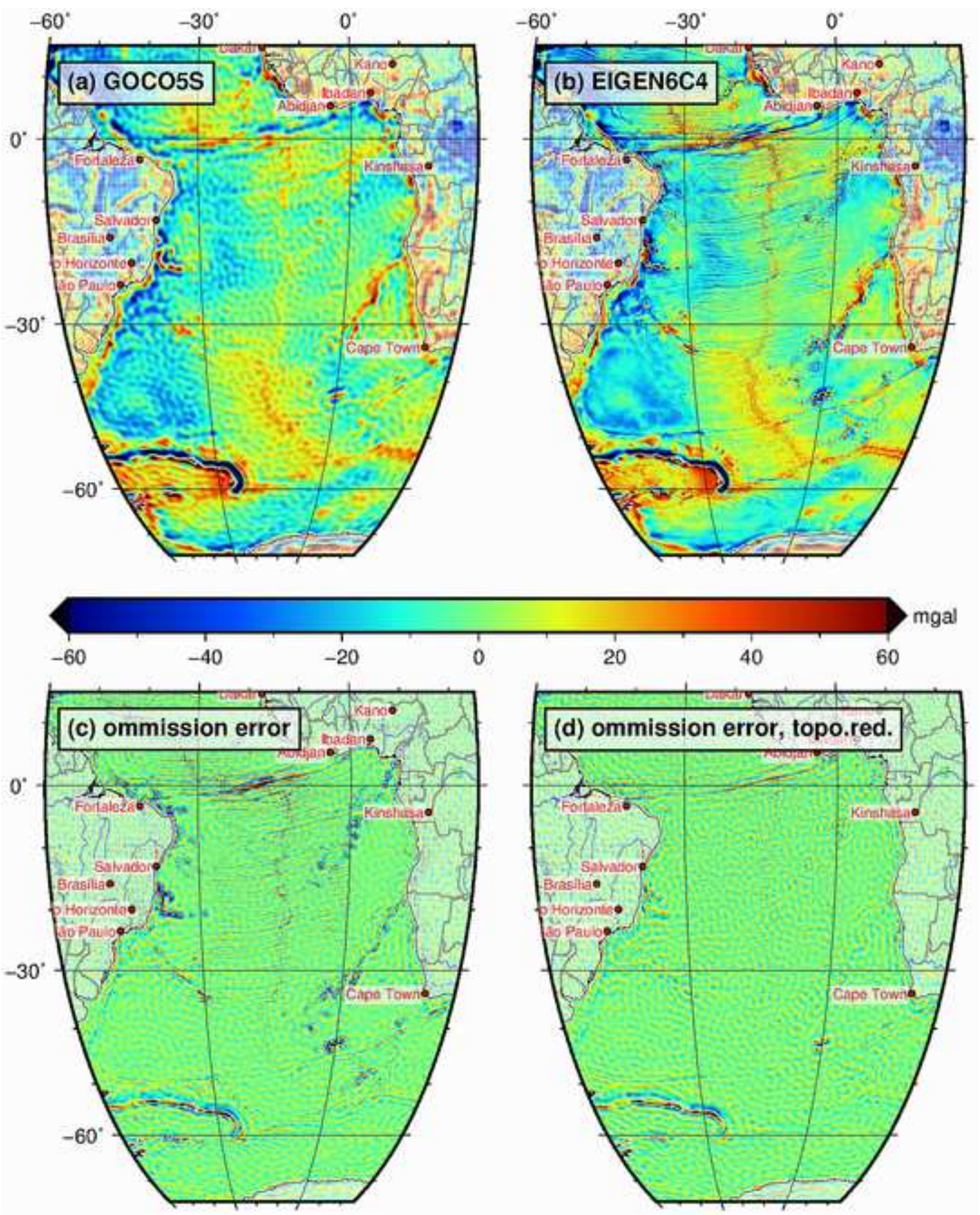
Click here to download high resolution image

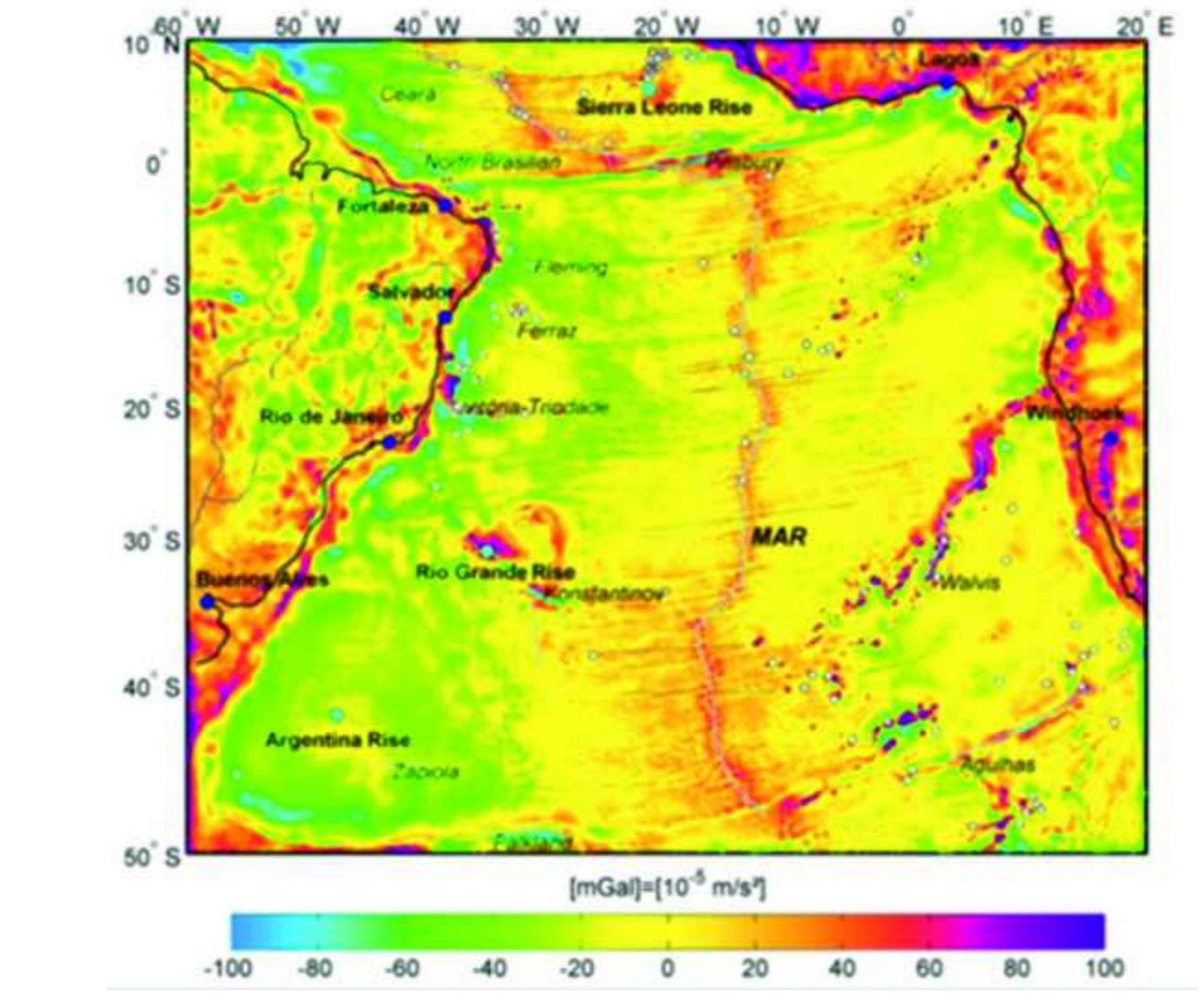




\section{Figure}

Click here to download high resolution image
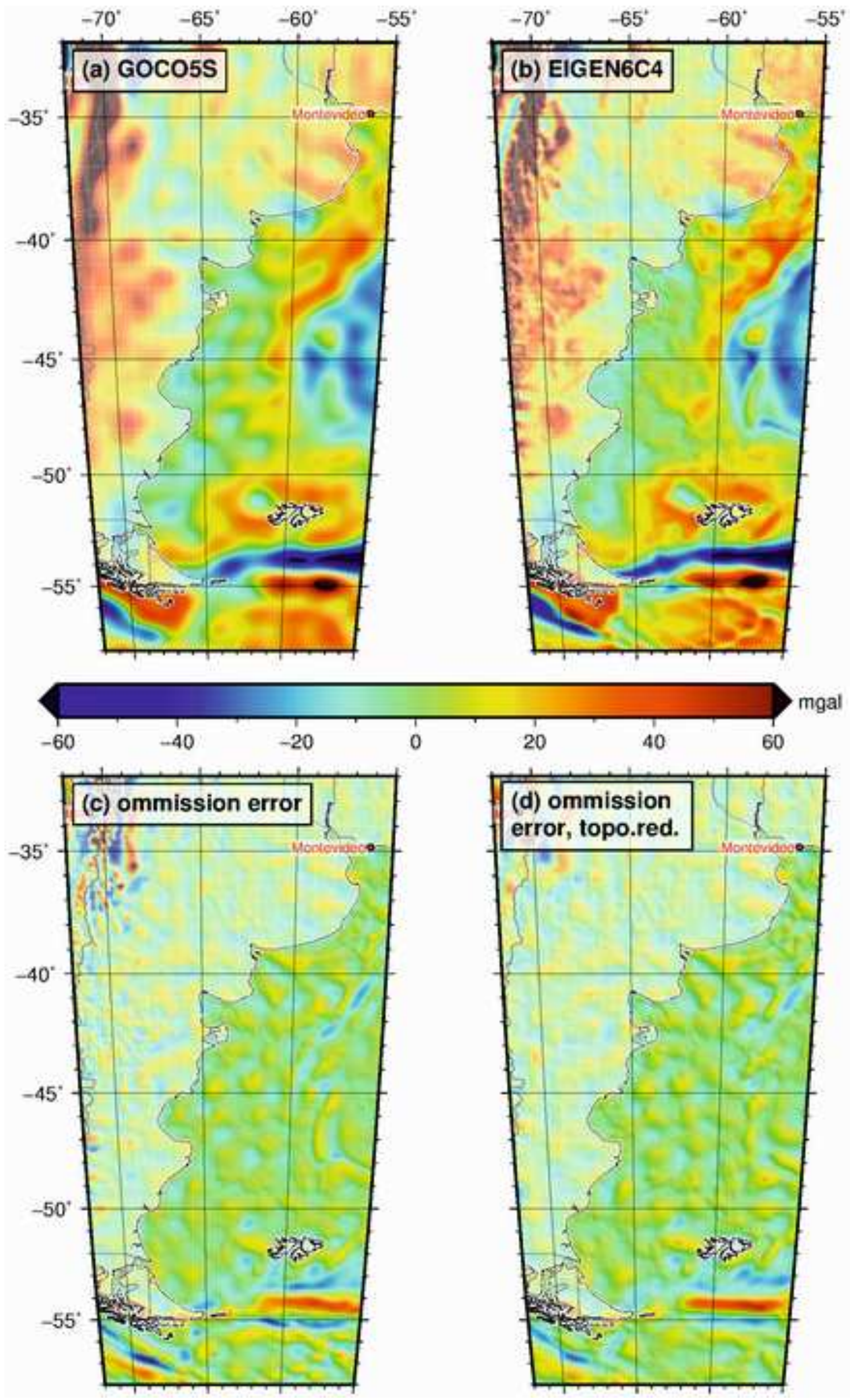


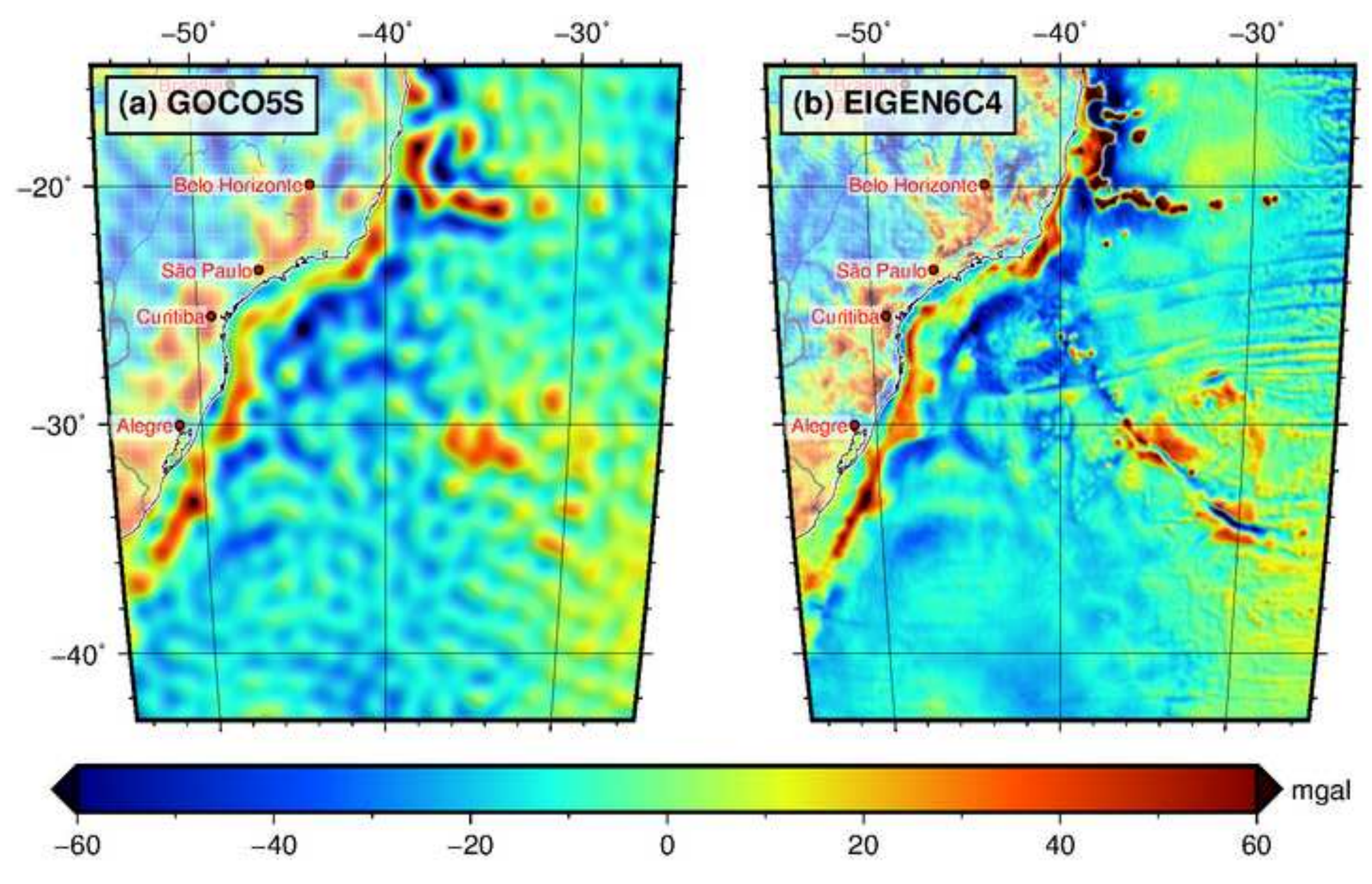




\section{Figure}

Click here to download high resolution image
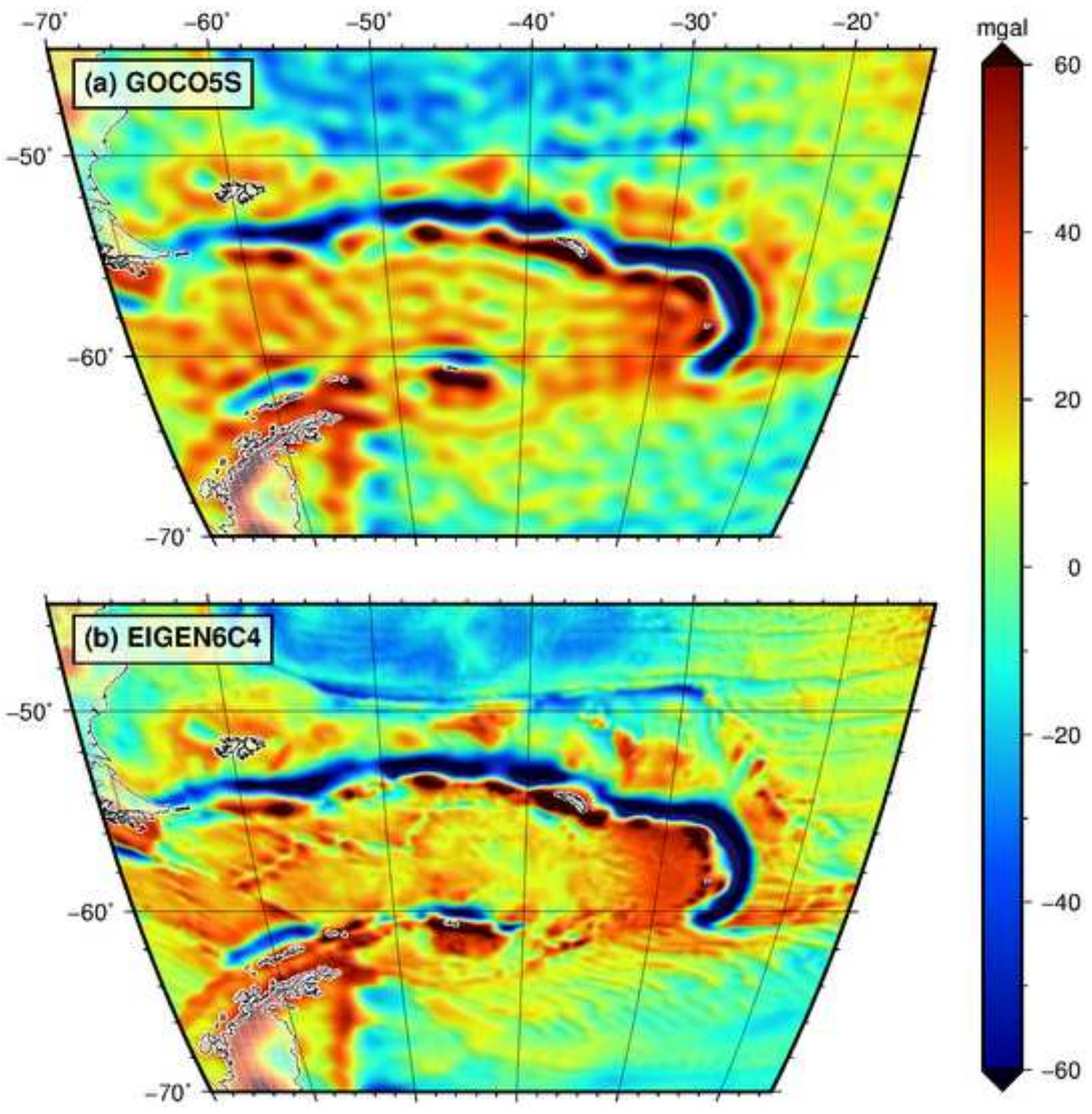

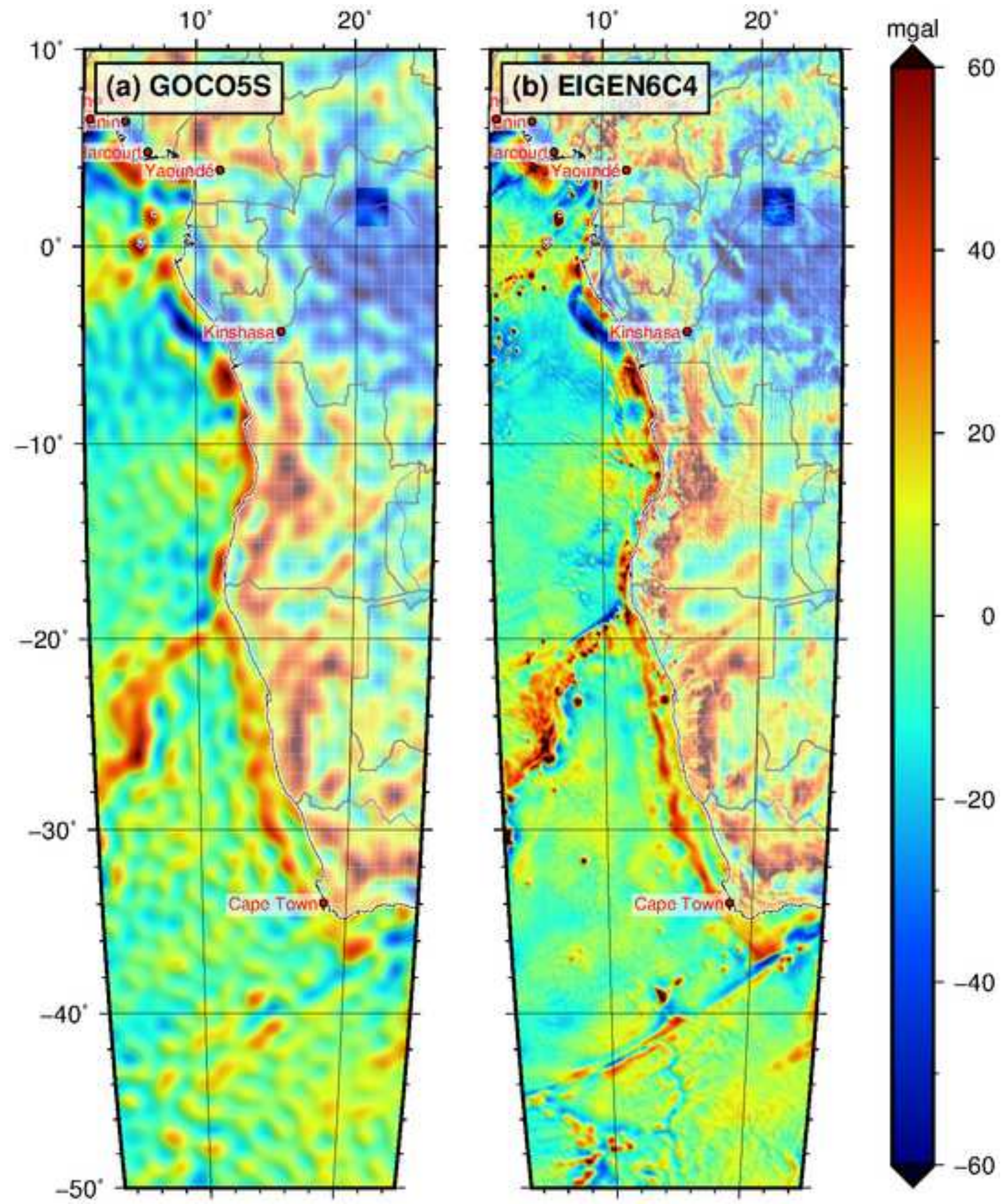
Click here to download high resolution image
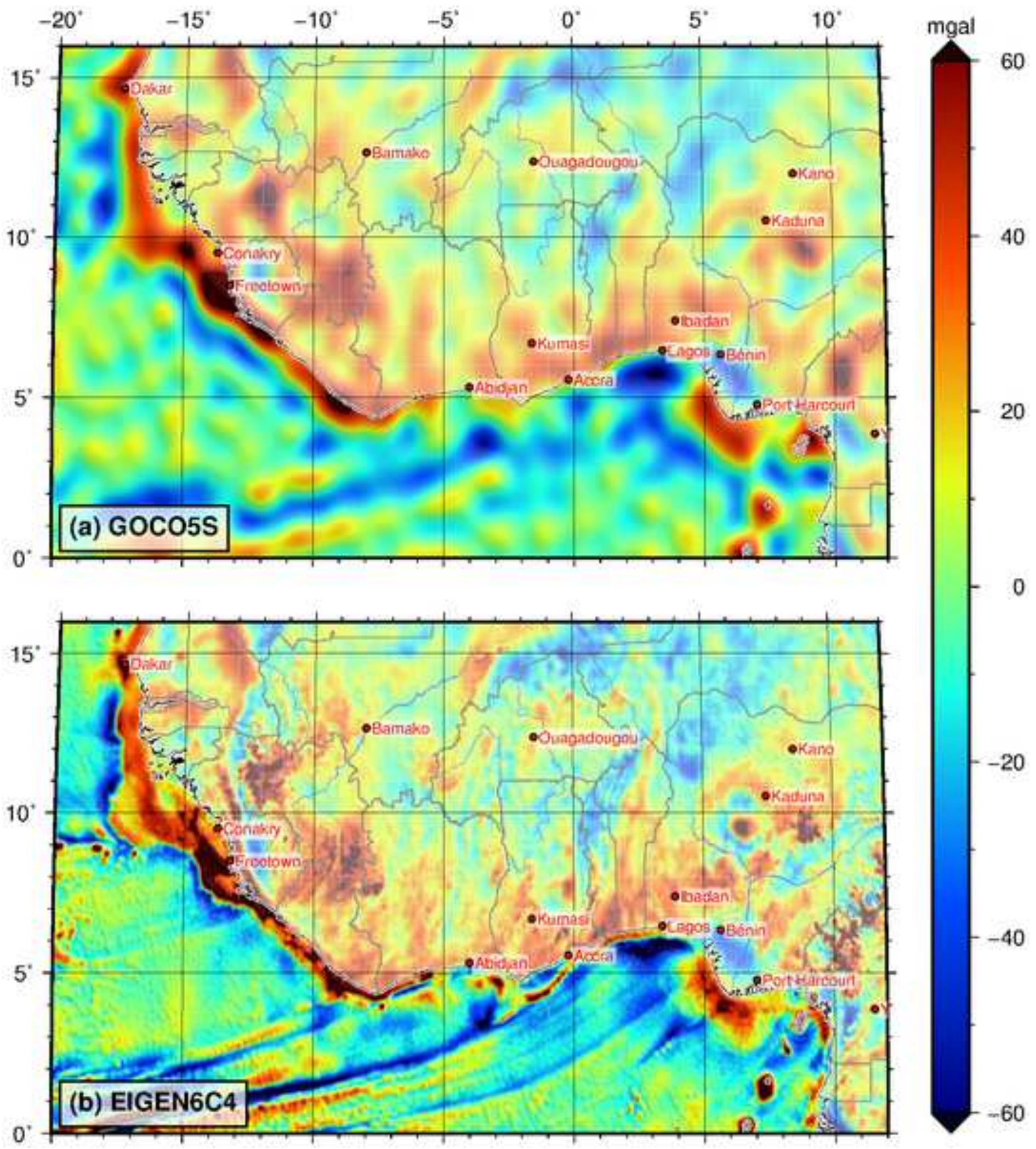


\section{Figure}

Click here to download high resolution image
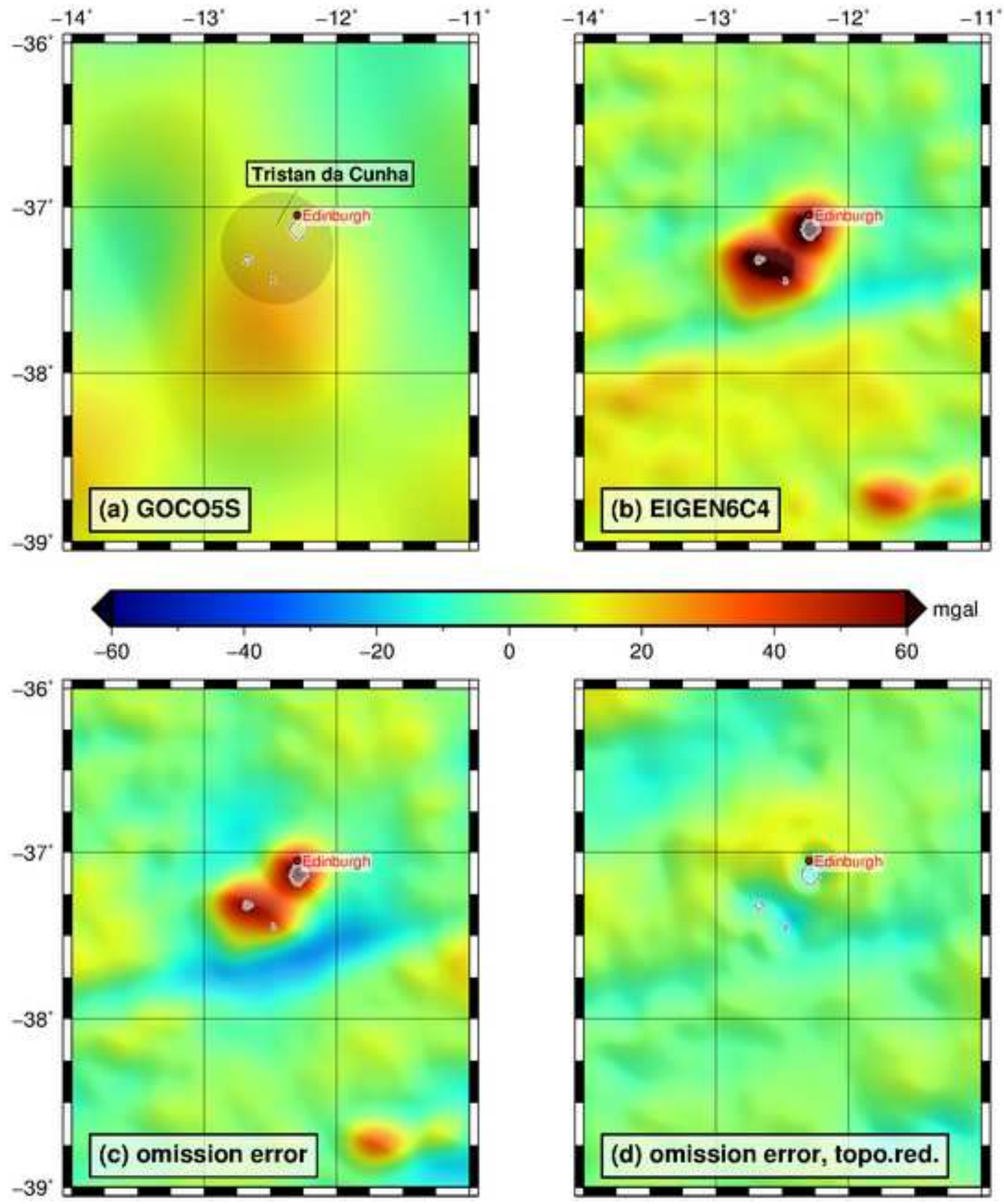
Click here to download high resolution image
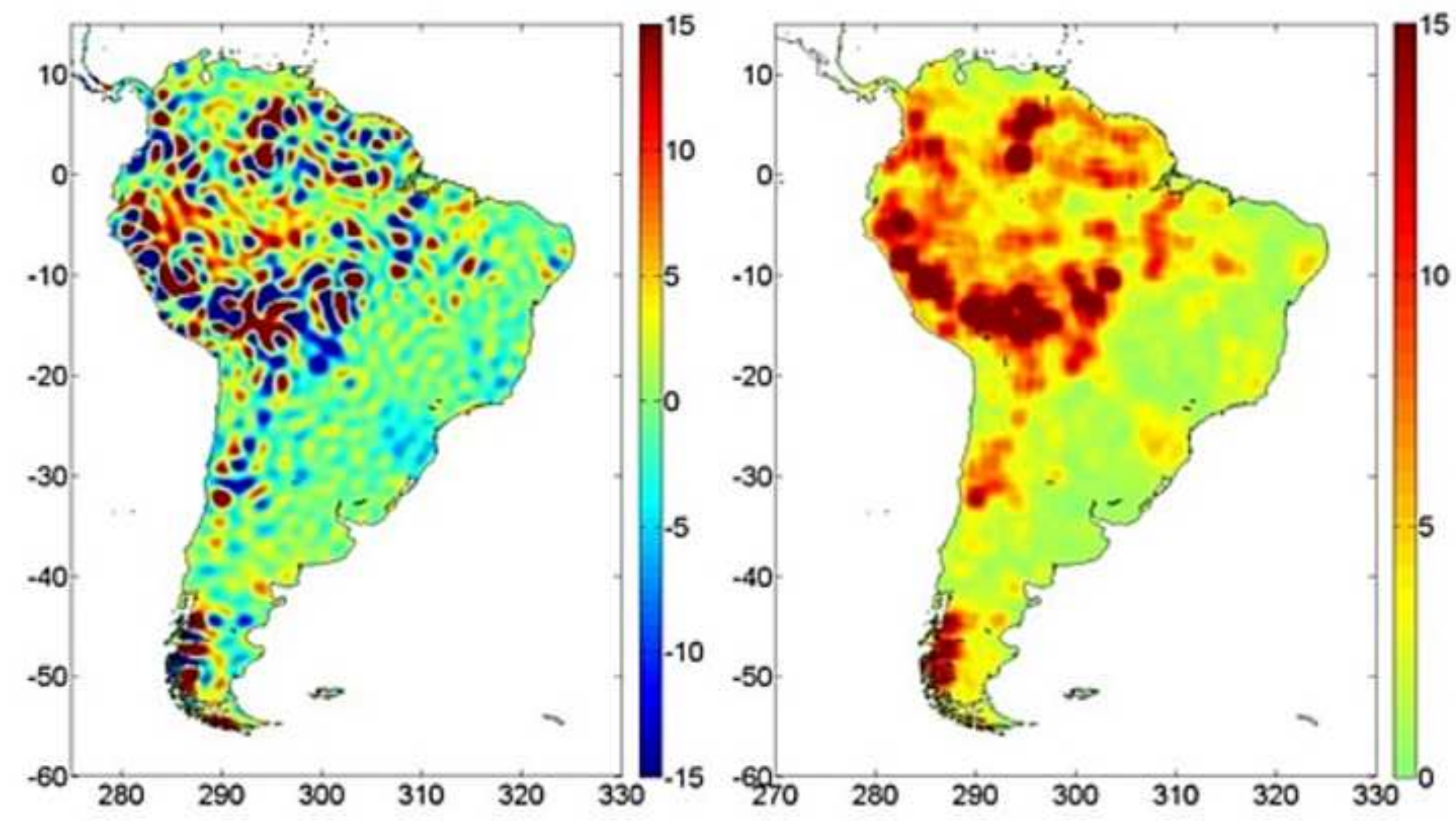

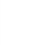


Figure

Click here to download high resolution image

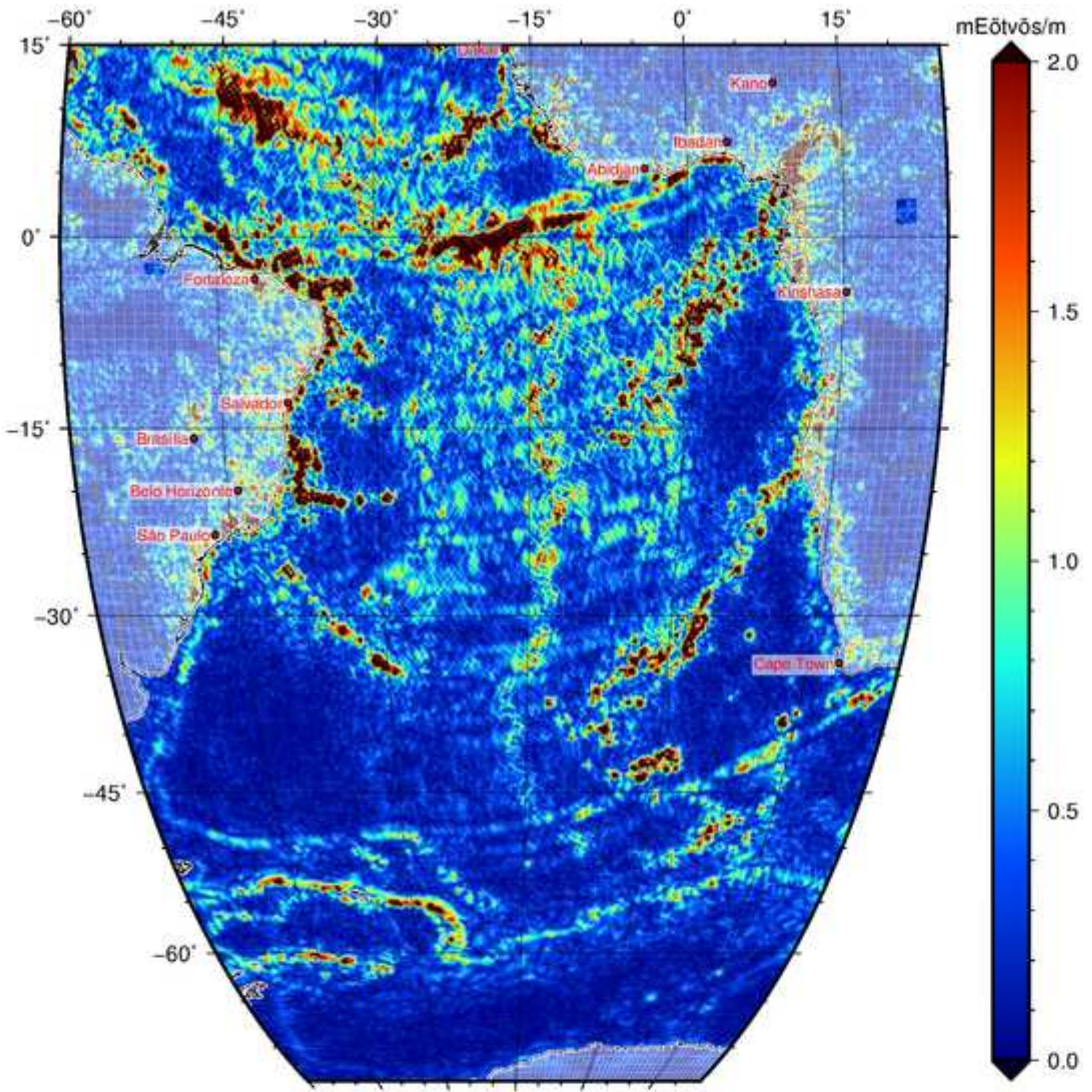




\section{Response to Reviewers/Editors}

We corrected Line 324: „weak“ instaed of „week“.

We replaced in line 186 "Bocher et al." and cited "Colli et al., 2016"

H.-J. Götze and R. Pail 
1 Insights from recent gravity satellite missions in the density structure of

2 continental margins - with focus on the passive margins of the South

3 Atlantic

\section{Abstract \\ 6 We focus on new gravity and gravity gradient data sets from modern satellite \\ 7 missions GOCE, GRACE and CHAMP, and their geophysical interpretation at \\ 8 passive continental margins of the South Atlantic. Both sides, South Africa \\ 9 and South America, have been targets of hydrocarbon exploration and \\ 10 academic research of the German Priority Program SAMPLE (South Atlantic}

11 Margin Processes and Links with onshore Evolution). The achievable spatial

12 resolution, driven by GOCE, is $70-80 \mathrm{~km}$. Therefore, most of the geological

13 structures, which cause a significant gravity effect (by both size and density

14 contrast), can be resolved. However, one of the most important aspects is the

15 evaluation of the omission error, which is not always in the focus of

16 interpreters. It results from high-frequency signals of very rough topographic

17 and bathymetric structures, which cannot be resolved by satellite gravimetry

18 due to the exponential signal attenuation with altitude. The omission error is

19 estimated from the difference of the combined gravity model EIGEN-6C4 and

20 the satellite-only model GOCO05S. It can be significantly reduced by

21 topographic reductions. Simple 2D density models and their related

22 mathematical formulas provide insights in the magnitude of the gravity effect

23 of masses that form a passive continental margin. They are contrasted with

24 results from satellite-only and combined gravity models. Example geophysical

25 interpretations are given for the western and eastern margin of the South

26 Atlantic Ocean, where standard deviations vary from 25 - $16 \mathrm{mGal}$ and 21 -

$2711 \mathrm{mGal}$, respectively. It could be demonstrated, that modern satellite gravity 
28 data provide significant added value in the geophysical gravity data

29 processing domain and in the validation of heterogeneous terrestrial data

30 bases. Combined models derived from high-resolution terrestrial gravity and

31 homogeneous satellite data will lead to more detailed and better constrained

32 lithospheric density models, and hence will improve our knowledge about

33 structure, evolution and state of stress in the lithosphere.

34

\section{Motivation and the concept of Plate Tectonics}

36

Geosciences are striving for an interdisciplinary perception to combine

38 their basic findings in a world embracing synthesis to understand global

39 processes in the Earth interior and at its surface. Most of these processes are

40 generally geothermally driven, and it is easy to accept that their origin lies

41 below the lithosphere, in the Earth's mantle (among others Stadler et al.,

42 2010). Today, the theory of plate tectonics enables us to draw a coherent

43 picture of the Earth's lithosphere. Interactions between the plates at their plate

44 boundaries are responsible for most of the earthquakes that occur here

45 (among many other publications and websites:

46 http://earthquake.usgs.gov/earthquakes/?source=sitenav,

47 http://www.isc.ac.uk/about/ or http://geofon.gfz-potsdam.de/).

48 This paper will review the status of satellite gravity missions and terrestrial

49 data, as well as global gravity models, fields and gradients derived from them.

50 It will focus on their accuracy, resolution and the omission error - which is out

51 of focus of many earth scientists. It is structured as follows: Section 1 defines

52 continent-ocean transitions and recalls some basics in the context of Plate

53 Tectonics concept and passive margins in particular. For those readers who 
54 are not familiar with the interpretation of gravity anomalies at a continental

55 margin in Section 2 the basic concepts are illustrated; this section can be

56 skipped by experts. Further on the focus is set on the question how (satellite)

57 gravity interpretations can help to explore these passive margins (Section

58 2.3). In the course of this paper we will notice later to what extent the new

59 fields and gradients from recent satellite gravity missions can support

60 research at the passive margins of the South Atlantic (Section 2.4). our view on the density structures of the lithosphere particularly at passive

63 margins of the South Atlantic. At last we describe the benefits for combined

64 interpretations in Section 4, and merge information from both terrestrial and

65 satellite gravity fields.

66

1.1 Short introduction to history of plate margins tectonics

68

Considering the history of the Plate Tectonic concepts in the early

70 1960s, Wegener's view on the „the continental drift” (Wegener, 1920) began

71 to be accepted after it was refined and confirmed by geophysical observations

72 namely by early seismological studies on deep earthquakes (Wadati, 1929;

73 Benioff, 1954), later by Isacks et al. (1968), Oliver and Isacks (1967) and

74 paleo-magnetic shipborne observations (Hess, 1962; Vine and Matthews 1963

75 among others). Together with the techniques of radiometric dating (age

76 determination) published first by Boltwood (1907) geophysicists were able to 
77 date the magnetic mid oceanic reversals by precise physical measurements.

78 They helped to get the modern concept of "plate tectonics" fully accepted.

It provides the framework for the interpretation of structures, the history

80 and composition of continental margins. Plate movements and the differences

81 in density of oceanic and continental crust types led to the structural pattern of

82 continental margins and result in a tectonic classification of coastlines as

83 active or passive margins (among others Wefer et al., 2003). Active margins

84 are typical units of the "Circum-Pacific Ring of Fire" in the Pacific where plates

85 are converging and coincide with plate boundaries in a subduction zone.

86 These margins are called active (e.g. Oncken et al., 2006; Lallemand, 2014)

87 due to the big variety of tectonic, magmatic and metamorphic processes that

88 occur here. If continental margins mark only the boundary to the oceanic

89 portion of the same tectonic plate, they are called passive margins. Passive

90 margins are typical of the Atlantic Ocean between Scandinavia and Greenland

91 (Scheck-Wenderoth and Maystrenko 2008), Iberic peninsula and the East

92 American coast or between Africa and South America (Blaich et al., 2011 and

93 many papers within).

94

95

1.2 Passive Margins

96

97

Although we assume that most of the readers are familiar with the

98 concept of plate tectonics we will recall briefly some basics. In particular

99 passive continental margins are characterized by a transition of continental

100 into oceanic crust within the same plate. It emerges from the splitting up of

101 continents and the following divergent plate drift that forms new oceanic

102 lithosphere by seafloor spreading at the divergent plate boundary. At the 
103

104

105

106

107

108

edges of the Atlantic geophysical investigations identify a laterally $10-15 \mathrm{~km}$ thick crustal transition between the thick crust of the continents and the thin oceanic crust. It is interpreted as relicts of thinned, mafic magmas which intruded into continental crust. In addition, passive continental margins are often stretched by intensive fault tectonics. They have a tectonically thinned continental crust, which is characterized by listric faults and tilted fault blocks. Tectonic crustal expansion starts at the time of installation of the continental drift rift system and refines the passive continental margin further (Blaich et al., 2011). These margins are marked by smooth relief due to tectonic inactivity and major sediment accumulation. This phenomenon is due to thermal cooling and sediment loading that led to conditions of subsidence and sediment accumulation, because the margins move away from the spreading center. Irregular subsidence and different sediment load often cause the accumulation of salt diapirs in the sediments of passive continental margins. The tectonic-sedimentary conditions are also favorable for the formation of hydrocarbon deposits and large salt deposits (Mohriak, 2014).

\section{Modern passive margins (Fig. 1) border the oceans formed by the} spreading caused by the break-up of the Gondwana supercontinent (e.g. Bond et al., 1984). From Figure 1 one can see that the margins of the South Atlantic Ocean (Cappelletti et al., 2011; Blaich et al., 2011; Mohriak, 2014), the western Indian Ocean, the Arctic and Norwegian seas (Scheck-Wenderoth and Maystrenko, 2008; Ebbing et al, 2006; Skogseid et al., 2000), the magma poor rifted margins of the North and Central Atlantic Ocean (Reston, 2009; Mohriak, 2014) and the margins of Antarctica are part of this system (Kalberg, 2016). A rising convection cell or a plume in the rifting area caused initial 
129 rifting and a regional uplift as well as volcanic activities above or below

130 oceanic sea level after an initial period of crustal thinning and erosion. Basile

131 (2015) describe another type of margin: "transform continental margins" by

132 simple kinematic models of transform faulting which cause among two other

133 types "passive transform margins". The satellite gravity picture of the

134 Equatorial Atlantic Ocean will be shown in Section 4.2, Fig. 20.

135

136 Figure 1: full page width

137

138 Fig. 1. Continental margins on Earth. Blue lines mark passive continental

139 margins mainly surrounding the Atlantic Ocean, the Antarctic Seas, and Indian

140 Ocean; red lines indicate active margins (subduction zones). Continental

141 margins were taken from from Frisch und Meschede (2005).The underlying

142 gravity field is the map of "gravity disturbance" calculated on base of the

143 EIGEN-6C4 model (Förste et al., 2014). Gravity was calculated on a grid of

$1440.5^{\circ} \times 0.5^{\circ}$

145

146

\subsection{Volcanic passive margins}

147

148 These margins present distinctive genetic and structural features, e.g.,

149 high-rate extension of the lithosphere is associated with catastrophic mantle

150 melting responsible for the accretion of a thick igneous crust (Geoffroy, 2005).

151 Typical rifted "magma-dominated" margins are characterized by large volumes

152 of flood basalts which flow across the continental hinterlands during 
153 continental breakup (among others refer to: Hopper et al., 2004; Eldholm et

154 al., 2000; Gernigon et al., 2006; White and Smith, 2009; O'Connor et al.,

155 2012). Underlying the extrusive lavas at the continent-ocean transition zone,

156 these margins exhibit high seismic velocities in the lower crust of some The

157 deeper crust is characterized by two areas of high seismic velocity (7.2 to 7.4

$158 \mathrm{~km} / \mathrm{s}$; Franke et al., 2010)., which are associated with voluminous igneous

In recent time the question arose in the context of fixing international boundaries offshore of the continents due to economic interests because e.g. hydrocarbon exploration moved further offshore e.g. to explore deep water resources. Toward the definition of this "continent-ocean-boundary, COB" at passive margins one of the crucial questions is how to define these boundaries. Torsvik et al. (2009) described how COB for the South Atlantic margins at both sides can be defined: by the interpretation of seismic, gravimetric, magnetic, bathymetric and geological information. Any identification of the $\mathrm{COB}$ is also important for the definition of plate boundaries at the time of break-up which allows the reconstruction of geometry and earlier position of former continents - e.g. in the reconstruction of Pangaea. It is not the aim of this paper to recalculate COBs. However we trust that the processing of gravity field and its second derivatives for recalculation of $\mathrm{COB}$

73 (Torsvik et al., 2009) will benefit from the increase of high resolution satellite 


\section{Geophysical characteristics of margins}

To investigate both active and passive continental margins almost all geophysical methods can help to discover their lithospheric structures:

Seismic, potential, electro-magnetic and electrical fields. Recent studies (e.g. Torsvik et al. 2009) show that processes in the lithosphere are linked to the dynamic mantle and dynamic processes have an important influence on the evolution of lithospheric plates, which is manifested in the formation of dynamic topography (e.g. Flament et al., 2013; Bocher et al., 2016 $\underline{\text { Colli et al., }}$ 2016). A key example for this interaction is the opening history of the Atlantic, where asthenospheric material reaches the surface at the mid-ocean spreading center. The uplift of hot material of the asthenosphere leads to seafloor spreading which manifests itself in the spreading anomalies in the magnetic field. The spreading axes are expressed either by topographic (heights above sea level, e.g. Iceland) or bathymetric heights (below sea level e.g. Atlantic ocean ridge). The worldwide offshore stripe pattern of magnetic anomalies which are located parallel to mid-ocean ridges allow a temporal classification of developed oceanic crust. The EMAG2 total magnetic field model has a reasonable resolution of two arc-minutes (Maus et al. 2009). The model was compiled from ship-, air-borne and satellite data (CHAMP). For the purpose of interpolation of magnetic field anomalies the oceanic crust ages of Müller et al. (2008) were employed (Maus et al. 2009). Hydro-carboniferous exploration targeted most of the passive margins of the world with both refraction and/or reflection seismic. 

aim to investigate the transition zone between the oceans and continents, e.g.

204 SE Atlantic and the African continent (Franke et al., 2006; 2010; Bauer et al., 2000; Hirsch et al., 2009; Schnabel et al., 2008). These studies reveal the

\subsection{The role of gravity field interpretations and prerequisites}

Remark:

The units used for gravity field values and its gradients are given in mGal (Milligals) and E (Eötvös) - as it is still common use in Geophysics and Geodesy. Converting these units into SI-units, there are: $1 \mathrm{mGal}=10^{-5} \mathrm{~m} / \mathrm{s}^{2}$ and $\mathrm{E}=10^{-9} \mathrm{~s}^{-2}$.

Rock densities are always given in $\mathrm{kg} / \mathrm{m}^{3}$.

First, the situation will be analyzed which was typical before the era of satellite missions which started in the year 2000 with the launch of the CHAMP satellite (refer to Chapter 4). Modelling and interpretation of the Earth's gravity field and its derivatives often had to deal with a merge of data sets with rather different resolution, different age and quality, coverage and 
227 wavelength content. This has been documented in a long list of papers

228 (among many others: Schaller et al., 2015; Bouman et al., 2014; Hosse et al.,

229 2014; Gutknecht et al., 2014; Köther et al., 2012; Tašárová, 2007). These

230 papers have shown that lithospheric models of study regions suffer mainly

231 from two facts:

232 (1) Nearly all information for constrained gravity field modelling of the lithospheric is based on irregularly distributed profiles and access and infrastructure.

237 The global gravity model EGM2008 (Pavlis et al. 2012) inherited - and still 238 inherits - these problems related with available terrestrial databases. Pavlis et 239 al. (2008) described the compilation of the EGM2008 gravity which consists of 240 different sources: up to a spatial resolution of approximately $140 \mathrm{~km}$ GRACE

241 (Gravity Recovery and Climate Experiment) data have been used, data from

$242140 \mathrm{~km}$ to approx. $10 \mathrm{~km}$ spatial resolution are derived from terrestrial and 243 satellite altimetry and so called "fill-in" data (Section 4.2). Today we know that

244 the relative weighting of GRACE with respect to the other datasets was too

245 low, leading to a dominance of terrestrial data errors in spectral regions where

246 better GRACE data would already have been available.

248 Figure 2: Full page width

250 Fig. 2. This figure portrays the terrestrial data inconsistency which is rather 251 typical for gravity surveys in remote areas (here across the South American 252 continent at a swath between $36^{\circ} \mathrm{S}-42^{\circ} \mathrm{S}$ from the passive margin in the East 
253 to the active margin in the West). As an example the different sources of

254 gravity data of the Southern Central American continent are shown together

255 with the visualization of big data gaps (Tašárová, 2007). The green and red

256 points in Chile $(\mathrm{CH})$ and Argentina $(\mathrm{AR})$ are stations in the ARANEDA I and II

257 (University of Chile) datasets; black points in southern Chile and the Arauco

258 Peninsula are ENAP data (Chilean oil industry); the gray dense network in

259 Argentina (AR) show the YPF data (Argentine oil company); yellow points:

260 stations of the MIGRA 2000 dataset, and the MIGRA 2002 data (both

261 measured by the gravity group at the University Kiel) are shown in blue. The

262 brown lines offshore denote the ship-borne gravity data profiles from the

263 German research vessel "Sonne".

Fig. 2 shows the situation some 20 years ago at the central South

265 American subcontinent. For a continental gravity field study the field had to be

266 compiled from very different data sources often without any meta data

267 information - e.g. for gravity data which were measured on behalf of oil

268 companies (grey area in Fig. 2). In other areas, e.g., in the eastern part of

269 Argentina (yellow dots in Fig. 2) data are missing due to difficult or impossible 270 access.

At the end of this Section we will pose the question how large

272 lithospheric structures and how big density differences to their surrounding

273 have to be in order to cause a detectable signal at orbit height of a satellite.

274 This consideration describes the situation at active and passive margins in an 275 analogues manner. In Fig. 3 the effects of gravity and gradients are shown for 276 a simple model. For density contrasts between the values $\Delta \rho=10^{1}-10^{3}$

$277 \mathrm{~kg} / \mathrm{m}^{3}$ Gutknecht et al. (2011) calculated gravity and gradients at the GOCE 278 satellite orbit height of $255 \mathrm{~km}$ resulting from a sphere with minimum 
279 diameters between $d=20-200 \mathrm{~km}(b=10-100 \mathrm{~km}$, refer to Fig. 3$)$ to be

280 tangent to the Earth surface). Within the range of the assumed parameters the

281 minimum diameter required to produce signal differences of $1 \times 10^{-5} \mathrm{~ms}^{-2}$ and

$28212 \times 10^{-12} \mathrm{~s}^{-2}$ at orbit height. This is rather close to the expected accuracies of

283 the gravity and vertical gravity gradient of the GOCE mission (recent values

284 are: $0.45 \mathrm{mE}$ for GOCE-only, $0.2 \mathrm{mE}$ for GOCE+GRACE models, cf. also Fig.

285 13). Fig. 3 conveys that a structure with a diameter of some $45 \mathrm{~km}$ and a

286 density contrast of $240 \mathrm{~kg} \mathrm{~m}^{-3}$ could be detected in satellite gravity at orbit

287 height. If the diameter of the model sphere increases to $90 \mathrm{~km}$, its density

288 contrast should not be less than $33 \mathrm{~kg} \mathrm{~m}^{-3}$.

289 The simple model described above fits rather well the dimension of the

290 Jurassic arc batholiths at the Northern Chilean continental margin with

291 diameters of roughly $60-120 \mathrm{~km}$ (Sobiesiak et al., 2007). This supports the

292 idea that batholithic structures e.g. intrusions at continental margins, can be

293 detected using data of the modern satellite missions- both gravity and

294 gradients.

295

296 Figure 3: one and a half page width

298 Fig. 3. Gravity and gradient signal caused by a minimum diameter of a sphere

299 with given density contrast in the orbit height of $255 \mathrm{~km}$ (Gutknecht et al.,

300 2011). The thick solid and dotted lines represent gravity signals of 1 and 10

$301 \mathrm{mGal}$ at orbit height. The thin dashed and dash-dotted lines represent

302 gradients of 12 and $1000 \mathrm{mE}$, respectively. The grey shaded area shows

303 results which are based on a possible combination of geometry and density

304 parameters of the causing mass anomaly. 
A first look at Fig. 4 provides already helpful information on the gravity

309 gradients of the Earth at the continental margins. The figure bases on the

310 evaluation of gravity field maps from the recent gravity missions. A complete

311 Bouguer anomaly (corrected by the effect of elevation, spherical slab,

312 topography both on- and offshore) was used to calculate the first derivative of

313 the field - the dip curvature of gravity.

315 Figure 4: Full page width

317 Fig 4. Global horizontal gravity gradients. Deep blueish colors mark regions

318 on Earth where the dip curvature (horizontal gradient) of the worldwide

319 Bouguer gravity field (EIGEN-6C4) is small or even zero. The more reddish

320 the colors are the steeper the gradients. The strongest gradients are observed

321 at the active continental margin of Central South America. On the contrary at

322 most of the passive continental margins (Fig. 1) the gradients are rather small.

324 Dark blueish colors indicate rather weeak dip curvature which means that

325 horizontal gravity gradients are small, on the contrary reddish tones point to

326 strong dip curvature and therefore strong gradients. The active continental

327 margins in the area of the Circum-Pacific are generally marked by reddish 
328

329

330 Mostly low gradients - light blueish colors - are typical for passive continental

331 margins. In order to understand this relationship two questions arise:

332 (1) How was the gravity anomaly calculated and how big is its magnitude of 333 the anomaly caused by the mass distribution (both topography/bathymetry

334 and densities) at continental margins and

335 (2) How was the field observed and what is known about accuracy and

336 homogeneity of gravity field observations?

337 With regard to the first question one has to consider that gravity

338 observations at the Earth's surface and the Earth near space vary from the

339 theoretical "normal" field value. Their magnitude is caused not only by the

340 latitude effect but by elevation of observational points, the density of cap

341 beneath the station in the underground and the topographic masses in the

342 neighborhood. After correction of earth tidal effects and air pressure

343 variations the remaining time invariable parts of the measured signal are:
Normal gravity

345

346

347

348

349
Yo

$\delta g_{\text {Tор }}$

$\delta g_{B P L}$

$\delta g_{\text {NIV }}$

$\delta g_{R}$

$\delta g_{G E O L}$ 

depend on what has been calculated as stated in the table above and added as corrections to the measured gravity field values. From all measured gravity

Common representations of gravity measurements in maps and profiles values the normal gravity (in the height and position of the observable) is subtracted, and therefore the term "gravity anomaly" is defined. This is simply the difference between the observable values to "normal" gravity. In Geophysics we distinguish mainly between three anomalies Free air- (FA), Bouguer- (BA) and isostatic anomaly (ISA) which define gravity in the height of the observation (e.g. Li and Götze, 2001; Hackney and Featherstone, 2003; Naudy et al., 1965; LaFehr, 1991 and many others).

With $\delta g_{R}$ we describe the effect of a mountain root and define Free Air, Bouguer and isostatic anomalies such as:

$$
\begin{aligned}
& F A=\Delta g_{0}^{\prime}=g_{o b s}+\delta g_{N I V}\left[+\delta g_{T O P}\right]-\gamma_{0} \\
& B A=\Delta g^{\prime \prime}{ }_{0}=g_{o b s}+\delta g_{N I V}+\delta g_{T O P}+\delta g_{B P L}-\gamma_{0} \\
& I S A=\Delta g_{I S A}=g_{o b s}+\delta g_{N I V}+\delta g_{T O P}+\delta g_{B P L}+\delta g_{R}-\gamma_{0}
\end{aligned}
$$

67 Calculations of the individual correction terms depend on the objective of the survey and are variously complicated to handle. $g_{o b s}$ denotes the measured gravity field value. The calculation of the topographical reduction ( $\left.\delta g_{\text {Top }}\right)$ requires precise knowledge of the terrain and surface near densities and today it is most likely calculated by the aid of digital elevation models (DEM), among others refer to (Holzrichter, 2013 and Szwillus and Götze, 2016); it requires the use of a computer and digital elevation data. The effect of

74 topographic masses is normally calculated in a surrounding circular area of 50 km up to 167 km (e.g. La Fehr, 1991; Hinze et al., 2006). However, Mikuška et 
376 al. (2006), Szwillus and Götze (2016), Szwillus et al., (2016) point to "long

377 distant relief effects" and propose the calculation of all topographic masses on

378 Earth. The gravity effect of a Bouguer slab with a thickness which is defined

379 by the difference between the physical station height and the reference level

380 (normally the geoid) should always be calculated by a spherical cap (e.g.

381 Baeschlin, 1948). For smaller areas (with a reduction radius $\mathrm{R}<20 \mathrm{~km}$ ) and

382 moderate terrain roughness the Bouguer slab can easily be calculated by:

383

$\delta g_{B P L}=-2 \pi G \rho\left(H_{S}-H_{B}\right)$

384

with:

385

386

387

$\mathrm{G}=$ Gravitational constant $\left(6.672 \cdot 10^{-11} \mathrm{~m}^{3} \mathrm{~s}^{-2} \mathrm{~kg}^{-1}\right)$,

$\rho=$ crustal density $\left(2670 \mathrm{~kg} / \mathrm{m}^{3}\right)$; offshore: rock-equivalent 390

In the last step the free air effect $\delta g_{\text {NIV }}$ is calculated by use of the

"normal gradient" (0.3085 mGal/m):

$$
\delta g_{N I V}=0.3085 \cdot\left(H_{S}-H_{B}\right) m G a l / m
$$

394 It has to emphasized that the above used constant gravity gradient for large 395 scale investigations has to be replaced by equivalent values of derivation of 396 closed mathematical expression of the normal gravity which is always latitude 397 and height dependent. It was also recommended to calculate an "atmospheric 398 correction" (Wenzel, 1985) in order to eliminate long wavelengths errors from 399 the observed gravity field. 
420 Figure 5: Full page width

This results in:

\section{Figure 5: Full page width}

Note: the terms of "flat" Bouguer slab in $\delta g_{B P L}$ and the "constant vertical gradient" in $\delta g_{\text {NIV are }}$ in the above formulas are used here for simplification only. Modern satellite gravity field processing at large spatial scales requires a spherical cap calculation and the consideration of latitude and height dependent calculation of the vertical gradient.

Special emphasis has to be put on the situation in oceanic regions. If we assume that station heights are equal to geoidal heights $(h=0 \mathrm{~m})$ Bouguer and Free Air anomaly is equal due to:

$B A=F A+\delta g_{B P L}=F A+\left[-2 \pi G \rho\left(H_{S}-H_{B}\right)\right]$ with: $\mathrm{H}_{\mathrm{s}}-\mathrm{H}_{\mathrm{B}}=0 \mathrm{~m}$;

it follows that $\mathrm{BA}=\mathrm{FA}$, in case the $\mathrm{FA}$ is already corrected by $\delta \mathrm{g}_{\mathrm{TOP}}$ which contains gravity effect of masses at the ocean floor.

In oceanic areas the slab density in the Bouguer slab correction term must be modified due to the known water depth " $\mathrm{D}$ " and the difference in water- and rock density (Fig. 5). If we assume a crustal rock density of 2670 $\mathrm{kg} / \mathrm{m}^{3}$ and a water density of $1030 \mathrm{~kg} / \mathrm{m}^{3}$ the resulting density for calculations of offshore Bouguer anomalies is $\rho^{*}=-1640 \mathrm{~kg} / \mathrm{m}^{3}$.

$B A=F A+\delta g_{B P L}=F A+2 \pi G \rho^{*}\left(H_{S}-H_{D}\right)$

Fig. 5. Illustration for describing the calculation of Bouguer anomalies on continents $(A)$, at the ocean $(B)$ and from satellite $(C)$. $(A)$ : On land the reduction density $\rho$ is commonly taken as $2670 \mathrm{~kg} \mathrm{~m}^{-3}$. The effect of 
425 topography is already removed. The thickness of Bouguer slab equals the

426 station height $\left(H_{s}\right)$. (B): In contrast the reduction density at sea is $-1640 \mathrm{~kg}$

$427 \mathrm{~m}^{-3}$. It is the difference between the sea water density of $1030 \mathrm{~kg} \mathrm{~m}^{-3}$ and the

428 rock density of $2670 \mathrm{~kg} \mathrm{~m}^{-3}$; thickness of the slab now is equal to the different

429 water depths (D). (C): Calculating a Bouguer anomaly in case of satellite

430 gravity a "mass correction" is calculated: $\delta g_{\text {Mass }}=\delta g_{T o p}+\delta g_{B P L}$

431

$432 \quad 2.3$ Gravity at passive continental margins

433

434 In Fig. 6 a very simple Airy-Isostasy model of a passive continental margin is

435 shown. The continental crust is much thicker than the oceanic crust and above

436 the oceanic crust there is the water cover of a few 1000 meters. The specific

437 geometry of the „crust - mantle - water cover“ constellation plays an

438 important role on the trend of the gravity field here. Because of the fact that in

439 the example of Fig. 6 there is no topography, the continental margin remains

440 in an isostatic equilibrium, and one can assume that no Free Air anomaly

441 exists.

443 Figure 6: One and half page width

445 Fig. 6. Airy isostatic model at a continent - ocean transition. Notice the thick

446 continental crust and the thin oceanic crust at a passive continental margin.

447 Crust and mantle densities are simplified. Reasonable contrasts which cause

448 large gravity anomalies are related to the water - continent density contrast 
449 and crust - mantle density at the continent of approx. $430 \mathrm{~kg} \mathrm{~m}^{-3}$. Refer to text

450 for more information.

451

452

453 density model (Fig. 7C) which was shown in Fig. 6. The Fig. 7(A) shows the

454 modelled anomaly only for water effect of gravity: related to a model of a "half-

455 indefinite" plate the resulting anomaly is negative and is caused by a strong

456 gradient. Fig. 7 (B) on the other side contains model results which have been

457 done only for the oceanic mantle: now the anomaly is positive and it has a

458 gentle increase because its position is far deeper. Finally Fig. 7(C)

459 demonstrates how the total Free Air anomaly results from the superposition of

460 both effects: the Free Air anomaly is zero in the continental area and over the

461 ocean as well. However, exactly above the margin the gravity field is

462 characterized by a maximum and a minimum that follows. This distribution is

463 a so called "edge" or boundary effect of the Free Air anomaly and is effected

464 by the difference of the steep gradients in the model.

466 Figure 7: one and a half page width

467

468 Fig. 7. The principal effects on the gravity field at continental margins have

469 equal gravity magnitudes but different gradients. In (A) the water effect causes

470 a steep gradient and in (B) the density surplus of the oceanic mantle is a

471 deeper seated effect which causes only a gentle gradient. In (C) it is explained

472 that a Free Air anomaly at a continental margin is caused by both a negative 
473 and positive "edge effect" due to the superposition of contributions that have

474 equal magnitudes but different gradients.

The trends of a Free air and Bouguer anomalies are shown in Fig. 8.

477 Here modelling again gets use of a "half indefinite" thin plate for the offshore

478 area (water). It is "zero" over the continent zero and over the oceanic area

479 "positive" $\left(\rho_{w}=1030 \mathrm{~kg} / \mathrm{m}^{3}\right)$. The half of the whole Free Air anomaly maximum

480 is accomplished exactly over the edge of the continent.

482 Figure 8a-b: Full page width

483 Figure 8c: One and a half page width

485 Fig. 8. Free Air anomaly and Bouguer anomaly at continental margins which

486 is also in an isostatic balance. (A) The absolute value of the excess mass

$487 \quad|+\Delta m|$ is equal to the absolute value of the deficient mass $|-\Delta m|$. Therefore

488 the integral of gravity change with respect to the $\mathrm{x}$-coordinate is zero: $\int \Delta \mathrm{g} \mathrm{dx}=$

489 0. (B) The Bouguer correction at the ocean (see Fig. 3) applied to the Free Air

490 anomaly in (A) yields the general form of the Bouguer anomaly at passive

491 continental margins. (C) The "geological" mass inhomogeneities at the

492 continental margins (seaward dipping reflectors, magmatic remnants, salt

493 structures etc.) cause rather local gravity anomalies which superimpose the

494 regional gravity wavelengths - which are effected by the "simple" structures in 495 (A) and (B). 

density structure at the "modelled margin" in Fig. 6. In the real world these margins show a rather complicated picture of gravity distribution due to mass inhomogeneities in the Earth's crust and lithosphere (and even in the mantle) which are the results of the long-lasting history of the breakup of the Gondwana supercontinent. This becomes quite clear if looking at the processed gravity fields which are shown in the series of figures (Fig. 14 through 21) in Section 4. Their interpretation in terms of regional tectonic and distribution of rock densities will help to provide a rather detailed insight into the causing structure (geometry) and density distribution of the passive margins in the South Atlantic region.

Most aspects of the calculated anomalies, both Free Air and Bouguer, which were discussed before, are typical for nearly all of the continental passive and active margins on Earth. In the next Section the focus will be set on the situation in the Southern Atlantic between Africa and South America the research area of the German Priority Program 1375 "SAMPLE" of the German Science Foundation - DFG (https://www.sample-spp.de/). The acronym stands for "South Atlantic Margin Processes and Links with onshore Evolution". In this interdisciplinary project the primary research areas are the mantle dynamics and magmatic processes, the lithospheric structure, deformation processes and rifted margin formation, the post-rift topographic evolution and many more. In the following Section we will concentrate on this part of the world because a big variety of data and information is available to responds to one of the key questions - how modern satellite missions can contribute to the interpretations and to the understanding of the transition from continental to oceanic lithosphere.

The gravity fields in Figs. 7 and 8 are caused by the over simplified 
523

524

525

526

527 continents 3D structural models have been designed and evaluated by

528 SAMPLE scientists and their international partners: They constructed detailed

529 density models at both sides of the Southern Atlantic Ocean and a rather

530 preliminary density model for the oceanic part in course of a master thesis

531 (Klinge, 2016). These models are constrained by information and data from

532 boreholes, refraction and reflection seismic, seismological tomography and

533 potential field data - mainly gravity field data. Geophysical fields and

534 observations map geometry and distribution of physical properties of the

535 transitional structures of both crust and lithospheric mantle. Model results (Fig.

536 9) show (Maystrenko et al., 2013; Autin et al., 2016) that basin centers at the

537 western (Argentinean) side are oriented west-east and therefore oblique to the

538 mid ocean rift axis while at the other (African) side basin centers extend

539 parallel to the ocean rift in north-south direction.

540

541 Figure 9: One and a half page width 
543 Fig. 9. For illustration this figure portrays a 3D density model of the SW

544 African continental margin (left, modified after Maystrenko et al., 2013), and

545 the density structure at the Argentinean side (right, Autin et al., 2016).

Apart from these structural differences both sides of the Southern

548 Atlantic reveal similar distributions in temperature and density. Small

549 thicknesses and density modifications in the lithospheric mantle point to small

550 lateral variations of heat transfer into the overlaying crust. However, more

551 relevant for the crustal heat field are lateral thickness changes of the

552 crystalline crust which produce the bigger part of radiogenic heat. This

553 contrasts observations and modelling results at passive continental margins in

554 the area of the Northern Atlantic (Scheck-Wenderoth and Maystrenko, 2008).

555 They found that the oceanic part of lithospheric mantle is much thinner and

556 characterized by smaller densities which cause higher temperatures in the

557 upper crust of the ocean.

To contrasting large scale paleostress fields on the correlating margins

559 of the South Atlantic Salomon et al. (2014) point to in their studies of the

560 South Atlantic. They asked themselves "how passive" continental margins

561 across the globe currently are. Following the results of several other studies

562 these margins experience a variety of stress states and undergo significant

563 vertical movements, as they were deduced from studies of paleo-stresses at

564 both sides of the Southern Atlantic. Here, the bounding continents consist of

565 very different recent geological histories: Africa experiencing continental rifting

566 whereas South America is influenced by subduction on the Pacific side. It is

567 not clear to what extent the Atlantic continental margins are subject to the 
568 same stresses and vertical motions as the main continents. Their results show

569 that the tectonic evolution of the continental margins of the South Atlantic is

570 not only passive and that both margins vary significantly in structural style and

571 stress fields, indicating that variable plate boundary forces play a major role in

572 margin evolution. In Fig. 10 we show the situation at the S-American and S-

573 African margin with reference of the paleo-stress field, as it was published by

574 Salomon et al. (2014). Their findings demand careful modelling of both

575 continental margins and a geophysical database which is able to resolve even

576 very small modifications of physical parameters and their structures; refer also

577 to Fig 9 (a) and (b) and the 3D density modelling of lithospheric by

578 Maystrenko et al. (2013) and Autin et al. (2016).

580 Figure 10: Faull page width

582 Fig. 10. The sketch (Salomon et al., 2014) portrays an E-W cross-Section

583 between South Africa and South America which summarize the situation of

584 their obtained paleo stresses. It shows that the African margin is controlled by

585 extension while compression characterizes the situation at the South

586 American side. Salomon et al. (2014) explained the extensional state in the

587 east by the existing "African superplume" and the compression in the west by

588 the Andean subduction zone.

Novel satellite gravity missions aim at a breakthrough in recovering the

591 Earth's gravity and magnetic fields, their gradients as well as their temporal 
592 variation. Static anomalies in potential fields (refer to Figs. 14 through 21) are

\section{Modern satellite gravity missions} caused by irregular mass distribution on and within the Earth, temporal variations of the gravity field are associated with mass transport processes in the Earth system, such as dynamic processes on the Earth's surface, in lithosphere and upper mantle.

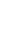


619 Figure 11: Faull page width

621 Fig. 11. Satellite gravity missions CHAMP (left), GRACE (center) und GOCE (right).

(Sources: CHAMP: GFZ Potsdam, GRACE: NASA, GOCE: ESA Medialab)

In these missions, three measurement concepts are implemented:

1. Observation of orbit perturbations of low-flying satellites due to the varying gravitational attraction, by Global Positioning System (GPS), with an accuracy of 2-3 cm. Non-gravitational forces acting on the satellite, such as drag of the residual atmosphere or solar radiation pressure, are measured by an accelerometer and corrected for in the frame of the gravity field modelling. This satellite tracking technique between a low Earth orbiter (LEO) and highflying GPS satellites is called satellite-to-satellite tracking in high-low mode (SST-hl), and is implemented in all three missions CHAMP, GRACE and GOCE. It is the primary measurement technique of CHAMP.

2. Observation of orbit differences (ranges) and their temporal change (range rates) between two LEO satellites. This satellite-to-satellite tracking in low-low mode (SST-II) concept is realized by the GRACE mission. It consists of two identical satellites following each other on the same orbit with an average distance of $200 \mathrm{~km}$. The inter-satellite ranging is performed by means of a Kband microwave system with micrometer accuracy, and shall be done by laser interferometry in future gravity missions in order to further increase the ranging accuracy.

\section{Observation of acceleration differences on very short baselines (satellite} gravity gradiometry, SGG), representing second order derivatives of the gravitational potential $V$ in all three spatial directions. This concept was 


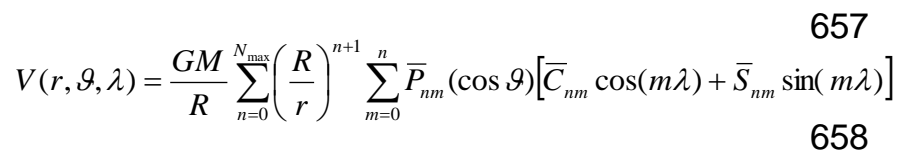

where $G$ is the gravitational constant, $M$ the mass of the Earth, $R$ the mean Earth

661 radius, $\bar{P}_{n m}$ the fully normalized Legendre polynomials of degree $n$ and order $m$, and

$662\left\{\bar{C}_{n m}, \bar{S}_{n m}\right\}$ the corresponding (Stokes) coefficients (e.g Torge, 2001). Therefore, the

663 degree error median describes the achievable gravity field accuracy at a certain

664 spatial (half) wavelength $\lambda$. The wavelength $\lambda$ is linked to the harmonic degree $n$ by

668 As an example, a harmonic degree of $n=200$, which was the minimum target

669 resolution for the GOCE mission, corresponds to a spatial wavelength of $\lambda=$

$67020000 \mathrm{~km} / n=100 \mathrm{~km}$.

As a reference, the stippled black curve in Fig. 12 shows the gravity field

672 signal itself. Correspondingly, the cross-over point of a mission performance curve 
673 with the black stippled curve indicates at which harmonic degree the signal-to-noise

674 ratio is ' 1 '.

676 Figure 12: One and a half page width

678 Fig. 12. Absolute gravity signal and error estimates of different observation concepts

679 as a function of the harmonic degree $n$ (bottom axis) and spatial wavelength $\lambda$ (top

680 axis).

681

682 From the orbit information (SST-hl) only the long-wavelength features of the gravity

683 field can be extracted. Although this observation type is not a direct gravity field

684 functional, it can be interpreted as disturbing acceleration acting on the orbit, and

685 thus the first order spatial derivative of the gravitational potential $\partial V / \partial x_{i}$. As a

686 representative of this measurement concept, the grey dot-and-dashed line curve

687 shows the performance of the CHAMP-only model AIUB-CHAMP 03S (Prange,

688 2011), which is based on 8 years of CHAMP kinematic orbit data.

The grey curve shows the performance of the recent GRACE-only model

690 ITSG-Grace2014 (Mayer-Gürr et al., 2014), which is based on almost 11 years of K-

691 band inter-satellite ranging data following the SST-II concept (and supported by SST-

$692 \mathrm{hl}$ in the very low degrees). Compared to CHAMP, the superior measurement

693 principle of SST-II results in a significantly better accuracy in the low to medium

694 degree range as well as a higher spatial resolution. This can be explained by the fact

695 that the SST-II concept can be interpreted as a measurement of acceleration

696 differences on long baselines of about $200 \mathrm{~km}$. The excellent performance of GRACE

697 in this spectral range makes this mission sensitive to the tiny temporal variations of

698 the Earth's gravity field, which are 4 - 5 magnitudes smaller than the static signal.

699 The black solid curve shows the performance of GOCE, represented by the

700 GOCE-only model GOCE-TIM-R5 (Brockmann et al., 2014). It is mainly based on the 
measurement technique of SGG and again SST-hl in the low degrees, because SGG alone (green curve) is weak in this spectral range due to the specific noise characteristics of the gravity gradiometer instrument. Measuring acceleration differences on very short baselines of about half a meter, which approximate second order derivatives of the gravitational potential $\partial^{2} V /\left(\partial x_{i} \partial x_{j}\right)$, enables a further increase of sensitivity for high-frequency signals. GOCE starts to become superior over GRACE approximately at degree $n=115$.

\subsection{Global Gravity Field Models}

Gravity field models including GOCE data from the complete mission period are meanwhile available. While the model GOCE-TIM-R5, which is based on the time-wise approach (Pail et al., 2011), is based purely on GOCE data, GOCE-DIRR5, which is based on the direct method (Bruinsma et al., 2014), contains also GRACE and satellite laser ranging (SLR) data. Further satellite-only models are, e.g., EIGEN-6S2 (Rudenko et al., 2014), or the S-models of the GOCO series (Pail et al., 2010). The maximum degree of expansion of these models is driven by the resolution of GOCE, and varies from $\mathrm{n}=280$ to 300 , corresponding to about $70 \mathrm{~km}$ spatial wavelength. This makes clear that all medium scaled geological structures at continental margins and elsewhere in the world which cause a significant gravity effect can be detected (resolved) in the GOCE gravity field. Combination models (notice the "C" in the field identifier) including also terrestrial, air- and shipborne as well as altimetric gravity are, e.g., the already mentioned pre-GOCE model EGM2008 (Pavlis et al. 2012), EIGEN-6C4 (Förste et al., 2014), and GOCO05C (Fecher et al., 2013, 2016). These models extend the spatial resolution beyond degree 2000 (which corresponds to $10 \mathrm{~km}$ wavelength). However, it should be noticed that there are many regions with sparse and/or lowquality terrestrial data, where it has to be questioned if such a high resolution is 
729 justified. This holds for many areas worldwide, e.g., the Central Andes in South

730 America and also for the passive continental margins of the South Atlantic.

731

732

733

\subsection{Products for use in Earth sciences interpretation}

Specifically regarding GOCE-related data, modelers and other users have the choice among basically three representations of gravity field products:

\subsubsection{Spherical harmonic coefficients}

The most commonly used representation of the global gravitational potential $V$ is its series expansion into spherical harmonics (Section 3). There corresponding fully normalized spherical harmonic (Stokes) coefficients $\left\{\bar{C}_{n m}, \bar{S}_{n m}\right\}$ represent the model parameters, and are usually the target quantity when deriving the model from the original gravity field data. The advantage of using this representation is that it can be considered as a weighted average of the original measurement data, so that the original noise level is significantly reduced due to this averaging. Based on the set of spherical harmonic coefficients any arbitrary gravity anomaly can be derived at the Earth's surface or at any height in outer space. All the global gravity models discussed above are given in this parametrization.

\subsubsection{Original gravity gradients along the satellite's orbit}

In principle, also the gravity gradient time series for all six tensor components measured along GOCE's satellite orbit can be used for geophysical modelling (refer e.g. to Fig. 3). They represent the most original measurements. However, it has to be considered that they are measured in a rotating reference frame, the so-called "gradiometer reference frame" (GRF), which means that tensor rotations of the base 
757 functions have to be applied to exploit them to the best possible extent. Additionally,

758 they are affected by the colored noise characteristics of the GOCE gradiometer (Pail

759 et al., 2011), so that a single point-wise gravity gradient observation is affected by

760 large instrument noise, and therefore by itself has a low signal-to-noise ratio. All

761 these drawbacks make it difficult to use this data type directly for geophysical 762 modelling.

\subsubsection{Gravity gradient grids}

A reasonable compromise between the use of spherical harmonics and original gravity gradients (see above) results in the use of gravity gradient grids, which are usually defined in a well-oriented radial (North-East-up) frame at a constant altitude. They are computed from the original gravity gradients defined in the GRF by means of regional gravity processing methods. In fact, they are the spatial equivalent 771 of the spherical harmonic representation, but much easier to use and interpret. Pure 772 GOCE gravity gradient grids result from the space-wise method (Gatti and 773 Reguzzoni, 2015). In the frame of the ESA project GEOExplore global grids of all six 774 components of the gravity gradient tensor, based on a combination of GOCE and 775 GRACE data, and defined in a radial Earth-fixed reference frame at two altitudes of $776225 \mathrm{~km}$ and $255 \mathrm{~km}$, have been derived (Bouman et al., 2015). Since these grid 777 values are products of "averaging" original gradient data, the error level should be 778 similar as that of gradients synthesized from global spherical harmonic models.

779 There is an ongoing discussion whether the gradient data contain more (high780 frequency) signal than global gravity models that have been derived from them. The 781 answer to this question lies in the constraints applied to these models. Constraints 782 applied to global gravity models are usually designed to optimize the signal-to-noise 783 ratio on a global scale. This means that in regions of very rough topography and 784 therefore high-frequency gravity signals there is the tendency to constrain the system 
785 too strongly. Regional gravity solutions techniques, which are usually applied to generate gridded gravity gradient products, allow for regionally optimized constraints,

787 but on the cost of global homogeneity. In Pail et al. (2015b) it could be shown, that 788 compared to global models the gravity gradient grids are affected by a higher noise 789 level.

790 The achievable accuracy and sensitivity of current gravity field models or 791 corresponding gravity (gradient) grids can be expressed by cumulative quantities, 792 which describe the estimated cumulative error at a certain harmonic degree (or the 793 corresponding spatial wavelength). Fig. 13 shows cumulative gravity anomaly errors

794 (a), as well as cumulative vertical gravity gradient errors at GOCE satellite altitude of $795250 \mathrm{~km}$ (b), and ground level (c), for the GRACE models ITSG-GRACE2014s, the 796 pure GOCE model GOCE-TIM-R5, the combined satellite-only model GOCO05S and 797 the combined models EGM2008 (pre-GOCE) and GOCO05C (including GOCE data). 798 From Fig. 13 we can learn which geological structure at passive continental 799 margins (or elsewhere) can be resolved by the different gravity model types. 800 Assuming that the geological structure/mass anomaly generates a gravity anomaly 801 with a certain spatial wavelength on the Earth's surface, Fig. 13a then provides the 802 accuracy in mGal with which this anomaly can been captured. (The connection from 803 the size of a disturbing body to the resulting gravity signal is made in Fig. 3.). As an 804 example, a gravity signal with $100 \mathrm{~km}$ spatial wavelength at the Earth's surface could 805 be measured by satellites with an accuracy of about $0.5 \mathrm{mGal}$ (black dashed and 806 solid grey curves). It can clearly be seen that the accuracy for shorter wavelength 807 signals dramatically decreases, and is already larger than $2 \mathrm{mGal}$ for gravity signals 808 with approx. $80 \mathrm{~km}$ spatial wavelength. Beyond this resolution, satellites cannot 809 significantly contribute anymore, and high-accuracy terrestrial information, as it was 810 included, e.g., in 
813

814 Figure 13: Full page width

815

816 Fig. 13. Cumulative gravity anomaly errors in (mGal) (a); vertical gravity gradient

817 errors in (mE) at $250 \mathrm{~km}(\mathrm{~b})$, and ground level (c). This figure shows the generally

818 dramatic increase of the gravity gradient errors at ground level as a result of

819 downward continuation. geological structures. This becomes immediately clear if looking at the series of Figs.

824 smaller than $80 \mathrm{~km}$. On the other hand we state that the regional gravity field caused

825 at the ocean-continent transition can satisfyingly be resolved by satellite only models

826 (S models). Fig. 13a also shows the major step forward due to satellite missions 827 compared to pre-GOCE models such as EGM2008 (black dot-and-dashed line) 828 especially in the long to medium wavelengths for gross interpretations at a 829 continental scale.

Fig. $13 \mathrm{~b}$ shows a similar representation when using gravity gradients at satellite altitude as basis information for geophysical modelling of geological 834 provide gravity gradients at satellite altitude with standard deviations of $0.45 \mathrm{mE}$ for 835 gravity signals with a spatial resolution of $100 \mathrm{~km}$. These values can be decreased 836 further to $0.25 \mathrm{mE}$ by combination with GRACE information, as it was done, e.g., in 837 the GOCO05S model (solid grey curve). Evidently, GRACE alone (dashed grey 838 curve) results in very high error amplitudes in the higher degrees, demonstrating the 839 dominant impact of GOCE at shorter wavelengths. Modern combined gravity models 840 such as GOCO05C (solid black curve) further increase the performance in the short- 
841 wavelength range by complementing the satellite data by ground data over the 842 continents and satellite altimetry over the oceans. Also here the improvement

843 compared to pre-GOCE combined models such as EGM2008 (black dot-and-dashed

844 line curve) is significant. Recently gradients of the satellite gravity field came into the

845 focus for modelling purposes which can support interdisciplinary interpretations

846 (Ebbing et al., 2013; Schaller et al., 2015; Götze, 2015).

847 In Fig. 13b a very interesting feature is the flat curve of the combined gravity 848 model GOCO05C beyond degree 250. This results from the fact that beyond this 849 degree the signal amplitude of gravity gradients is already below the mE level, i.e., 850 due to signal attenuation with altitude there is no significant gradient signal left in orbit 851 altitude beyond this degree, because most parts have been "filtered out" due to 852 upward continuation. Inversely, this also means that GOCE has captured $97 \%$ of the amplitude of the gradient signal that exists in orbit altitude.

The picture changes completely (Fig. 13c) when continuing the gradient

855 information down to ground level. Here the GOCE model (black dashed curve) and

856 the GOCE+GRACE combination (solid grey curve) perform practically identical, again

857 showing the dominance of GOCE compared to GRACE at shorter scales. However,

858 also here for gravity signals with spatial scales below $80-100 \mathrm{~km}$ a combination with

859 terrestrial/airborne gravity information is necessary to achieve acceptable accuracies

860 (solid black curve), so that the gravity field information can be used for local

861 geophysical modelling of short-scale density structures.

862

863

\subsection{Not always in focus: the omission error}

In order to perform a complete evaluation of the impact of modern satellite 866 missions for deriving density structure of continental margins, one of the most 867 important aspects is the evaluation of the omission error. It results from high868 frequency signals, which cannot be resolved by satellite gravimetry due to the 
869 exponential signal attenuation with altitude. These missing signals of satellite-only

870 models are an important issue for the determination of near-surface density

871 variations, but also shallow lithospheric structures.

872 Fig. 14 shows gravity anomaly fields for the South Atlantic region. Fig. 14 a is

873 based on the GOCO05S model resolved up to its maximum resolution of degree $n=$

874280 ( $70 \mathrm{~km}$ ), while Fig. $14 \mathrm{~b}$ displays the free-air gravity anomalies based on

875 EIGEN-6C4 with its maximum resolution of degree $n=2160$ (10 km). Comparing

876 these two figures, the current limits of satellite-only models regarding their spatial

877 resolution becomes evident, and can only be coped with by combination with

878 complementary data sources from terrestrial/airborne/shipborne gravimetry, and

879 satellite altimetry over the oceans, as it was done in EIGEN-6C4. An estimate of the

880 omission error (Fig. $14 \mathrm{c}$ ) for satellite gravity models is given by the difference of

881 EIGEN-6C4 and GOCO05S, being equivalent to the difference of the Figs. 14 a and

882 b. Evidently, very rough topographic and bathymetric structures, generating high-

883 frequency gravity field anomalies and steep slopes, cannot be resolved by the

884 satellite data. However, usually these topographic features are not the main focus of 885 geophysical modelling and interpretation, but rather sub-surface lithospheric

886 structures. Therefore, a topographic reduction was applied, using the 887 RWI_TOPO_2015 topographic potential model (Grombein et al., 2015) and thus 888 taking away the effect of topographic masses up to zero level: $\delta g_{\mathrm{TOP}}+\delta g_{\mathrm{BPL}}$. The so 889 called "mass reduction effect" was already introduced in Fig. 6. The result is a 890 significantly reduced omission error (Fig. 14 d).

891 This difference field in Figs. $14 \mathrm{c}$ and $\mathrm{d}$ can be considered as errors made 892 when computing Bouguer anomalies from pure satellite models, which are then 893 further used for lithospheric modelling. Table 1 gives an overview of the main 894 statistical parameters of the gravity anomaly fields shown in Fig. 14. 
898 Fig. 14. Free-air gravity anomalies (mGal) of the South Atlantic region based on satellite-only model GOCO05S (a) resolved up to degree 280 , combined gravity model EIGEN-6C4 (b) resolved up to degree 2160, omission error of a satellite-only

901 model (c) and omission error after reduction of topographic signals (d).

Table 1: Main statistical parameters of gravity fields of the South Atlantic region. 904

\begin{tabular}{|l|c|c|c|c|}
\hline Gravity field & Figure & $\begin{array}{c}\min \\
(\mathrm{mGal})\end{array}$ & $\max$ (mGal) & $\begin{array}{c}\text { std.dev. } \\
(\mathrm{mGal})\end{array}$ \\
\hline GOCO05S (d/o 280) & $14 \mathrm{a}$ & -199.8 & 116.1 & 18.8 \\
\hline EIGEN-6C4 (d/o 2160) & $14 \mathrm{~b}$ & -227.7 & 453.8 & 21.3 \\
\hline GOCO05S omission error & $14 \mathrm{c}$ & -166.7 & 415.1 & 10.8 \\
\hline $\begin{array}{l}\text { GOCO05S omission error, } \\
\text { topo-reduced }\end{array}$ & $14 \mathrm{~d}$ & -143.1 & 112.8 & 7.1 \\
\hline
\end{tabular}

906

\section{Benefits for combined interpretations}

However, in relation with the two key questions asked in Section 2.3

910 (processing, quality and secondly availability for interpretations at continental

911 margins) we have to respond to them in the light of interpretations of solid Earth

912 structures. For example a precise geoid can be used to identify global and deep

913 anomalies related to mantle lithosphere and deeper structures. Gravity anomalies,

914 being first order radial derivatives of the gravitational potential, are sensitive to gravity

915 effects of the entire lithosphere, and in particular to the crustal and upper crustal

916 structures and density variations e.g. at active and passive continental margins. As it

917 has been shown above (Fig. 14), each combination of satellite gravity data with 
918 terrestrial gravity data can be used for all interdisciplinary interpretations techniques,

919 e.g., "back stripping" in basin modelling at the African continental margin (Dressel et

920 al. 2015) which also includes thermal subsidence in the reconstruction of the passive

921 margins through time or 3D modelling of Moho undulations. The new database was

922 also used to reconstruct the Gondwana continent (Braitenberg, 2015). Fig. 15 refers

923 to the isostatic residual anomaly in the Southern Atlantic. It was calculated by Klinge

924 (2016) on base of the corresponding formula for "ISA" in Section 2.3 and the EIGEN-

$9256 \mathrm{C} 4$ model also portrayed in Fig. 14 (b).

Both anomaly maps are rather similar and caused by the main tectonic

927 features of the South Atlantic: the "highs" which are caused by the Mid Atlantic ridge,

928 the extended "lows" of the four basins in front of South America (Argentinean and

929 Brazilian basins) and South Africa (Cape and Angola basins). The hotspot trail (e.g.

930 Torsvik et al., 2009 among others) is visible in the structure of the SW-NE trending

931 Walvis Ridge offshore South Africa and the corresponding trace of the Rio Grande

932 Rise at the western side. To the North of the Romanche Fracture Zone between

933 Fortaleza in the west and Lagos in the East the Sierra Leone Rise is located. Even

934 the regions of salt deposits offshore Brazil and West Africa (blueish colors indicating

935 low gravity values) and the magmatic margins at both sides of the margins (reddish

936 colors and high gravity values) can be distinguished in the satellite derived fields. The

937 very short wavelengths in the gravity field correspond to masses that are located in

938 the crust and lithosphere - they were already mentioned in the sketch of Fig. 8 and

939 mark places of different density contrast at the margins. Other examples were given

940 in Bouman et al. (2014), Gutknecht et al. (2014), and Hosse et al. (2014).

942 Figure 15: one and a half page width

943

944 Fig. 15. The isostatic residual field was calculated by Klinge (2016) in the framework 945 of his MSc thesis. Reference depth $\mathrm{T}_{0}=30 \mathrm{~km}$ and $\mathrm{T}_{\mathrm{e}}=20 \mathrm{~km}$ (elastic thickness 
946 which was kept constant over the entire area). The figure shows the residual gravity

947 field in the Southern Atlantic Ocean of the combined EIGEN-6C4 model (Förste et al.,

948 2014). It correlates well with bathymetric/topographic structures e.g. the Mid Atlantic

949 Rift (MAR) and portrays also the effect of geological bodies: the positive anomalies in

950 the area of Windhoek and Buenos Aires. Along the Mid-ocean rift axes positive

951 anomalies of up to $40 \mathrm{mGal}$ exist. MAR = Mid Atlantic rift.

\subsection{The continental margins of the South Atlantic}

New light can be shed on the gravity structures of South Atlantic oceanic

956 margins at regional (Figs. 16, 17, 19 and 20) and more local scales (Figs. 18 and 21).

By the help of these new compiled maps we will show that modern satellite gravity

fields described in Section 4 can support (1) interpretations of the lithospheric structures in the South Atlantic and its passive margins and (2) provide much more details in the gravity field than it was showed along the oversimplified profiles of Figs.

962 With reference to the Fig. 14, the following sequence of Figs. (16 - 21) contains

963 always the same information for comparative reasons: the two gravity fields based on

964 the "satellite only" model GOCO05S (a) and the "combined model" EIGEN-6C4 (b),

965 and additionally Figs. 18 and 19 include the omission errors without (c) and with (d)

966 calculated topographic reductions.

Table 2 provides a summary of the standard deviations of the gravity fields

968 shown in these figures. $\mathbf{d} / \mathbf{o}$ refer to the spherical harmonic analysis: to degree and

969 order of the expansion.

970

971 Table 2: Standard deviations (mGal) of the gravity fields shown in Figures 16 to 21.

\begin{tabular}{|l|l|l|l|l|l|}
\hline Region & Figure & GOCO05S & EIGEN-6C4 & GOCO05S & GOCO05S \\
\hline
\end{tabular}




\begin{tabular}{|c|c|c|c|c|c|}
\hline & & $(\mathrm{d} / \mathrm{o} 280)$ & $(\mathrm{d} / \mathrm{o} 2160)$ & $\begin{array}{c}\text { omission } \\
\text { error }\end{array}$ & $\begin{array}{l}\text { omission } \\
\text { error, topo- } \\
\text { reduced }\end{array}$ \\
\hline $\begin{array}{l}\text { Argentinean } \\
\text { coast }\end{array}$ & 16 & 22.4 & 24.6 & 9.8 & 7.1 \\
\hline Brazilian coast & 17 & 15.9 & 18.8 & 10.8 & 6.3 \\
\hline Falkland Bank & 18 & 24.4 & 25.3 & 7.3 & 5.9 \\
\hline African coast & 19 & 19.3 & 21.5 & 10.6 & 7.3 \\
\hline $\begin{array}{l}\text { Equatorial } \\
\text { African margin }\end{array}$ & 20 & 19.3 & 23.9 & 14.3 & 9.8 \\
\hline $\begin{array}{l}\text { Tristan da Cunha } \\
\text { isle }\end{array}$ & 21 & 6.9 & 12.3 & 10.3 & 4.8 \\
\hline
\end{tabular}

Continental gravity edge effects indicate a fast change from positive to

976 In Fig. 16 the positive anomalies indicate in the offshore area the seaward dipping

977 reflectors (SDR) which are of magmatic origin (e.g. Blaich, 2011; Franke et al. 2006;

978 Section 2). The negative anomalies (greenish and blueish colors) offshore are

979 caused by the sedimentary infill of the margin basins e.g. Colorado and Salado (e.g.

980 Autin et al., 2013; 2016). Onshore positive anomalies follow W-E trending

981 topographic features (Salado and Colorado Basin) and in the western continental part of the maps the topography of the Southern Central Andes.

983

984 Figure 16: Full page width

985

986 Fig. 16. Detailed picture of the free-air gravity field along the Argentinean coast

987 compiled by the GOCO05S (a) and the EIGEN-6C4 (b) models. The lower two 
988 figures indicate the omission errors without (c) and with topographic correction (d).

989 For more information refer to manuscript. The continental areas are marked by

990 transparent overlays.

991

In general the series of the following figures will portray similar gravity

993 anomalies (both magnitude and trend of anomalies). It is no wonder that all EIGEN-

9946 C4 compilations consist of more structural details than the GOCO05S models which

995 base on data in the orbit height of some $250 \mathrm{~km}$ where small local gravity anomalies

996 are not detectable.

997 Figs. 17 (a) and (b) shows that the "central Atlantic segment" is dominated by

998 high density rocks which cause positive anomalies. The positive gravity offshore

999 between $40^{\circ}-30^{\circ}$ longitude is caused by the "Rio Grande High" which marks the

1000 most western edge of the hot spot trace which starts at the position of the Tristan da

1001 Cunha hotspot area. The negative gravity anomalies close to the Brazilian coast are

1002 caused by negative densities of salt accumulation here (Mohriak, 2014). The SDRs

1003 with their high rock densities (Section 2.2) of the southern segment are not

1004 documented here with high resolution; they are too small to be resolved in detail as

1005 we show already in Fig. 3. However, at a larger scale the belt of positive gravity

1006 marks the area of SRDs quite well.

1007

1008 Figure 17: Full page width

1009

1010 Fig. 17. The gravity fields (a) GOCO5S and (b) EIGEN6C4 along the Brazilian coast

1011 and offshore regions of the "central segment" of the southern Atlantic. Figures

1012 content is equal to Figs. 14 and 16. However the omission errors are not portrayed 1013 here.

1014 
1015 The resolution of gravity anomaly in the off-shore area of the Falkland Bank

1016 and the Scotia Plate with the Eastern Sandwich trench allows the separation of

1017 subduction related trench lithosphere, the eastern border of the Sandwich Plate, and

1018 the southern rim with the Antarctic Plate (low gravity corresponding to blueish colors

1019 in Fig. 18) from high density rocks of the Scotia Plate and Sandwich Isles (yellow and

1020 reddish colors in Fig. 18 ( $a$ and b). Exactly here in a region with rather complex

1021 interplay of different plates the resolution of gravity fields before the era of the

1022 modern satellite missions was extremely low and often hindered a tectonic

1023 interpretation of lithosphere at medium scale. The Scotia Plate in the center (reddish

1024 colors in Fig. 18) is clearly separated from the other plates of the region (South

1025 American plate to the North, Antarctic plate to the South, Scotia plate to center.

1026

1027 Figure 18: One and a half page width

1029 Fig. 18. The gravity field of the Falkland bank and the Scotia plate with the eastern

1030 South Sandwich trench after the processing of new satellite gravity (GOCO5S: (a)

1031 and EIGEN6C4: (b). Figures content is equal to Fig. 14.

1032

1033

Due to the symmetry of evolution of the South American and South African

1034 margins also the gravity field of the western African margin shows the same general

1035 features as it was exemplified for the South American margin: in the southern

1036 segment the magma dominated structures cause small positive gravity anomalies

1037 and North of the Walvis Ridge the area of salt layers is characterized by negative

1038 anomalies (blueish colors) in Fig. 19. The SW - NE trending Walvis Ridge separates

1039 the domains of magmatic material from salt layers. Positive gravity anomalies of the

1040 ridge clearly indicate the Tristan da Cunha hotspot trace - as it was already

1041 explained for the western part of the Southern Atlantic. More to the South at the

1042 South African tip of the Cape a second ridge (Agulhas Ridge) can be identified. 
1043 Onshore at the African continent close to the equator the extended gravity low (-50

1044 mGal) of the Congo Basin with its thick sediments dominates the gravity picture.

1046 Figure 19: full page width

1048 Fig. 19. The gravity field of the African margin in the central and southern segment

1049 (Fig.15) after the GOCE gravity (a) and the EIGEN-6C4 data (b) processing. The

1050 series of maps correspond to the displayed formats of figures before; transparent

1051 overlay mark continental area.

1052 One of the most spectacular fracture zones in the Equatorial and Northern

1053 South Atlantic connecting Africa and South America is illustrated in Fig. 20 (a and b).

1054 Fairhead and Wilson (2005) explain the formation of the fracture system with

1055 processes which were related with the opening of the Central and South Atlantic.

1056 They state that a differential motion between plate segments was absorbed in the

1057 Caribbean and West and Central African rift systems. The fracture system developed

1058 due to the temporal different opening phases of the northern and southern Atlantic.

1059 Then the two independent spreading centers joined a major shear zone developed

1060 between West Africa and the northern margin of Brazil. The maps of satellite gravity

1061 image impressively this major shear zone. The gravity map of the EIGEN6C4 model

1062 provides a clear and sharp picture of the fractures zones.

1064 Figure 20: One a a half page width

1065

1066 Fig. 20. The two gravity fields (GOCO5S (a) and EIGEN (b)) of the Equatorial Atlantic

1067 Ocean map major transform structures offshore the African margin. Sequence of

1068 maps corresponds with displayed formats of figures before; transparent overlay mark

1069 continental area. 
The limits of resolution of modern satellite only gravity fields (S models) can

1072 nicely be demonstrated by the gravity field of the Tristan da Cunha Isle, whose gravity field signal is at the edge of the spatial resolution of current satellite gravity missions. Fig. 21 shows that although GOCE is able to detect the gravity field signal of this island, it is significantly damped. It should be emphasized, that a constraint

1077 procedure in order to improve the signal-to-noise ratio at higher degrees, i.e. noise is

1078 filtered out at the cost of damping also the signal. As already discussed in

1079 Section 3.2, the strength of constraining the solution was optimized on a global scale.

1080 Therefore, it is not tailored to small regions with strong gravity field signal, where a

1081 weaker constraint would be preferable due to a larger signal-to-noise ratio in this

1082 region compared to the global average. If the satellite gravity solution were optimized

1083 for this specific region, it can be expected that in such a regionally tailored solution

1084 slightly more signal could be retained. The series of Figs. 21 (a) -21 (d) shows that

1085 the satellite gravity fields of both GOCE and EIGEN-6c4 are mainly caused by the

1086 topography of the island. Perfectly seen is the "ring" of negative anomalies in Fig. 21

1087 (b) which can be explained by the flexure of oceanic lithosphere due to isostatic

1088 response of the loaded isle masses. After calculating a topographic correction (Fig.

108921 (d)) an anomaly of some 20 mGal appears. One may speculate if this negative

1090 anomaly is caused by a mass deficit which is related to the hot spot or to crustal 1091 thickening..

1092 The statistics in Table 2 shows that for such rather small-scale structures the

1093 amplitude of the omission error can be larger than the signal captured by GOCE.

1094 However, Fig. 21d shows that significant parts of this high-frequency gravity signal

1095 result from topography.

1096

1097 Figure 21: one a half page width 
1099 Fig. 21. The Free Air gravity field of the Tristan de Cunha area after the GOCE (a)

1100 gravity and EIGEN-6C4 (b) data processing. Sequence of the four maps corresponds

1101 with displayed formats of figures before; omission error without (c) and (d) with

1102 topographic correction. The limits of resolution of satellite observations can nicely be

1103 demonstrated by these gravity fields.

1104

1105 Figure 21a: Small column size

1107 Fig. 21a. In addition to what we interpret in Fig. 21 this sketch can explain the typical

1108 negative ring around the positive anomaly in the last figure: the central mass causes

1109 the positive anomaly while the sediments around the central mass cause a

1110 symmetrical gravity low. The extent of deformed crust below the mass crust depends

1111 on the rigidity of the surrounding crust: the left situation (rigidity R1) demonstrates a

1112 case with extreme high rigidity, on the right a lower crustal rigidity R2 was assumed.

11144.2 Validation of terrestrial gravity by GOCE data

1115

The GOCE mission provided not only new geoid and gravity fields, but also

1117 gravity gradient data. Representing the second derivatives of the gravitational

1118 potential, they are more sensitive to the density structures of the upper crust than

1119 gravity data normally are. Additionally, gravity gradients provide a better resolution of 1120 flanks of geological structures, faults, lineaments or even large intrusions at 1121 continental margins. Gradient data from satellite missions have the potential to 1122 identify the extent of different structures with varying densities even in the lower crust 1123 (e.g. Ebbing et al., 2013). Panet et al. (2014) even identify correlations of certain 1124 components of the gravity gradient tensor with lower mantle structures.

1125 For gravity interpretations at larger wavelengths the new satellite gravity 1126 database will help to identify a density zonation and segmentation in horizontal and 
1127 vertical directions in the lithosphere. As shown in Section 3.2, GOCE satellite-only 1128 gradient data provide a spatial (horizontal) resolution in the range of less than 100 $1129 \mathrm{~km}$. However, for many structures - in particular for offshore studies of Applied

1130 Geophysics - this spatial resolution is not yet sufficient, because smaller crustal 1131 structures cause anomalies with smaller spatial wavelengths. Therefore, terrestrial 1132 and airborne gravity measurements have not become obsolete even in the modern 1133 satellite era, but on the contrary they complement satellite observations on the short-

1134 wavelength scale where satellite data lack sensitivity.

1135 In addition to their very high accuracy in the long to medium wavelength 1136 range, modern satellite gravity data definitely provide significant added value in the 1137 geophysical gravity fields processing domain, especially for:

1138 a) Validation of heterogeneous terrestrial gravity data bases and identification 1139 of outliers;

1140 b) Fill-in of regions with sparse terrestrial data coverage or even data gaps.

1141 As an example of the first task (a), Fig. 22 a shows the difference between a 1142 terrestrial gravity data base of South America and GOCO05S, resolved up to 1143 degree 200. To bring them to the same spatial resolution, the terrestrial data have 1144 been expanded as part of a global $0.25^{\circ} \times 0.25^{\circ}$ terrestrial gravity anomaly grid into a 1145 spherical harmonic series to degree 720 , and then have been cut at degree 200. Fig. 114622 a clearly indicates systematic differences, which can be attributed to errors of the 1147 terrestrial data, because of the globally homogeneous accuracy of less than $1 \mathrm{mGal}$ 1148 for the satellite model. Based on this result, the terrestrial database can be further 1149 screened for outliers and suspicious observations (either of the gravity value itself or 1150 the attached height information, Hosse et al., 2014 ). This information can then be 1151 used to derive empirical error estimates of the terrestrial dataset, which can be further 1152 used for a spatially depending weighting scheme in the frame of a combined solution 1153 with satellite data (Fecher et al., 2013, 2016). The implicit assumption is that the data 1154 quality of a terrestrial observation is already reflected in its long-wavelength 
1155 component. By means of this procedure, satellite data get a higher weight in regions

1156 where a lower accuracy of terrestrial data is suspected.

1157

1158 Figure 22: Full page width

1159

1160 Fig 22. (a) Gravity anomaly differences (mGal) between a South American terrestrial

1161 database (kindly provided by the US National Geospatial-Intelligence Agency) and

1162 GOCO05S, consistently resolved up to degree 200; b) empirical error estimates

1163 (mGal) derived from the difference field (after: Fecher et al. (2015), modified).

1164

It should be emphasized, that this validation procedure can be applied in any region on Earth. Thereby, a globally uniform satellite gravity model provides the chance to estimate a-posteriori the accuracy and reliability even of historical gravity data bases (terrestrial, ship- and air-borne), for which only incomplete or even no meta-information about the measurement process and conditions is available.

Also Bomfim et al. (2013) describe how gradients of the GOCE mission can help to estimate systematic errors in terrestrial gravity data in the cratonal basins (e.g. Amazon and Parnaiba Basins) in Brazil. Here they calculate an average value of terrestrial gravity anomaly and compare its long- and medium-wavelength content of the terrestrial gravity with the GOCE gravity field. The analysis shows that where terrestrial data are sparse and therefore require an improvement in data coverage, satellite data can be substituted in order to represent the gravity field correctly. The method they proposed can be used directly to control other gravity databases and constitutes as a tool for the quality assessment of terrestrial gravity observations, both on- and offshore.

The second task (b) also addressed the heterogeneity of terrestrial gravity data. There are many regions worldwide where terrestrial data are of very bad quality 
1182 or not available/accessible at all (refer to Fig. 2). In these regions, data from satellite gravity missions are the only available data source.

These examples demonstrate, that although satellite missions provide (only) long to medium wavelength gravity field data, they are able to provide new gravity field information especially in regions where up to now the gravity field has been practically unknown. This regional model can then been used as constraint for an improved lithospheric density model and the derivation of the state of stress of the subduction zone (Gutknecht et al., 2014), clearly demonstrating the added value of GOCE especially in these data-critical onshore regions.

\section{Conclusions and outlook}

The resolution of "satellite only data" up to now does not fall below a resolution of $80-100 \mathrm{~km}$. This is still the borderline for studies presented in the above mentioned Sections. In summary we have to say that rather small complex structures related e.g. to the "seaward dipping reflectors at passive continental margins (SDR)" with small size and density contrast cannot be resolved as separated anomalies in the orbit heights of recent satellite missions (e.g. Schaller et al. 2015). For this purpose terrestrial gravity data have to be combined with satellite data in gravity models e.g. GOCO5C. The interpretations of Section 4.1. showed that gravity and its gradients from the modern satellite missions support interpretations at a medium scale - at passive continental margins and elsewhere.

Modelers of lithospheric structures at continental margins hope that medium scale gravity data from the recent and future satellite missions (GRACE and/or GOCE; GRACE follow on) can support combined interpretation together with seismological and gravity studies. For rather local models (wavelengths of gravity anomalies are smaller than $20 \mathrm{~km}$ ) both resolution and quality of satellite only gravity data have to be seen still reluctant until today. However, there is no doubt that combinations with 
1210 terrestrial gravity data bases and satellite gravity with a spatial resolution of $10-20$

$1211 \mathrm{~km}$ can provide detailed insight in the structural behavior of continental margins.

1212 For modelling at continental scales Fig. 2 demonstrated that terrestrial databases

1213 often are of inhomogeneous distribution (e.g. in South America), just if gravity data

1214 are sampled over long time-consuming field campaigns with big human efforts: there

1215 remain big gaps in the data base. They are mainly caused by limited access to the

1216 terrain in remote areas of the world - high mountains, deserts, swamps and jungle.

1217 Even more field procedures and technical instrumentation varied over time and

1218 together with missing other metadata a homogeneous data base can be established

1219 only with big effort and high costs. Here the new data bases already helped in a

1220 spectacular way: Hosse et al. (2014) and Gutknecht et al. (2014) replaced the

1221 incomplete terrestrial gravity data base by homogeneously measured satellite gravity

1222 and gravity gradient data for lithospheric modelling. New data were applied to the

1223 calculation of GPE (gravity potential energy), stress distributions and combined

1224 interpretation of complex geologic structures. Satellite gravity information was also

1225 used for validation and cleaning of inhomogeneous gravity databases taking the

1226 benefit of very homogeneous error characteristics and accuracy of global satellite

1227 gravity data (Hosse et. al, 2014; Bomfim et al., 2013). The high spatial resolution of

1228 terrestrial gravity combined with the homogeneous lower-orbit satellite data leads to

1229 more detailed and better-constrained lithospheric density models, and hence

1230 improves our knowledge about structure, evolution and state of stress in the

1231 lithosphere basing on the consistency in the long-to-medium wavelengths, down to

$123210-50 \mathrm{~km}$.

1233

1234 At the beginning (Section 1.1) we mentioned the calculation/recalculation of the

$1235 \mathrm{COB}$ from an integrated interpretation of gravity, magnetic, seismic, electrical

1236 methods and geology (Torsvik et al., 2009). We did not deal with the calculation of

$1237 \mathrm{COB}$, however, we think that the combined satellite fields can successfully replace 
1238 the terrestrial gravity data which have to be used in former times. Because we

1239

1240

1241

1242

1243 1244

1245

1246

1247

1248 1249 analyzed Free Air gravity from the GOCE mission, in Fig. 23 topographic features onand offshore are enhanced. These enhancements indicate clearly the slopes of the continental shelf regions of the Southern Atlantic.

Figure 23: Full page width

Fig. 23. The third derivations of the gravitational potential and the resulting total gradient of the vertical gravity gradient were calculated from the GOCO5C model (expansion to degree 720). It provides already good insight into local gravity field structures particularly at the margins by the derivations of the vertical gradient $\left(V_{z z}\right)$.

In the near future complementary information from seismic and magnetics could be included in a joint inversion for lithospheric modelling also at passive continental margins. ESA's magnetic field mission Swarm was successfully launched in November 2013 and provides valuable information of the long to medium wavelength Earth's magnetic field and its temporal variations with an accuracy on the nT- (nano tesla) level (http://esamultimedia.esa.int/multimedia/publications/BR-302/). The value of the mission for the determination of the crustal remanent magnetic field will increase in the future, because the three satellites will continuously lower their orbit altitudes during mission lifetime, thus also increasing their sensitivity for detail magnetic field structures. However, a joint interpretation of remanent magnetic and gravity field is only possible in the case of common sources, i.e. similar contrasts in density and magnetization. In this case Poisson's equation can be applied, which links the magnetic and gravity potential fields. Swarm is already now a very valuable tool to determine the electric conductivity of the Earth's mantle and thus provides very important information on the thermochemical and compositional structure of the Earth. 
Several concepts for future satellite mission constellations to explore the

1267

Earth's potential fields are under development and investigation. A strong need by

1268

the user communities was expressed in terms of a joint IUGG resolution adopted at

1269 the IUGG General Assembly 2015 (IUGG, 2015). The science requirements and user

1270 needs for a future gravity field mission constellation were consolidated (Pail et al.,

1271 2015a) also under active participation of the geophysical user community. In addition

1272 to an improved temporal resolution for the detection of co- and post-seismic

1273 deformation, an increased spatial resolution together with an improved accuracy will

1274 shift the capabilities to use satellite-based gravity observations for geophysical

1275 interpretation in passive continental margins, and elsewhere, to even more small-

1276 scale structures.

1277

\section{Acknowledgements}

1280

128

1282 financed by the Deutsche Forschungsgemeinschaft (DFG), Bonn which is thankfully

1283 acknowledged. HJG thanks M. Scheck-Wenderoth and members of her research

1284 team at GeoForschungsZentrum Potsdam for their continuous interest and many

1285 fruitful discussions over the last years. The satellite part of the paper was elaborated

1286 in a second DFG Priority Program "Mass Transport and Mass Distribution". HJG and

1287 RP are deeply grateful to their research teams at the Christian Albrechts Universität

1288 Kiel, Technische Universität München and Friedrich-Schiller-Universität, Jena. We

1289 thank Reiner Rummel and Jörg Ebbing for their intensive "test reading" and fruitful

1290 suggestions. Carla Braitenberg, Bruno Meurers and an anonymous reviewer

1291 improved an earlier version of the paper by their careful reviews. 
1293

1294

1295

1296

1297

1298

1299

1300

1301

1302

1303

1304

1305

1306

1307

1308

1309

1310

1311

1312

1313

1314

1315

1316

1317

1318

1319

1320

1321

1322

1323

1324

1325

1326

1327

1328

1329

1330

\section{References}

Autin, J., Scheck-Wenderoth, M., Loegering, M.J., Anka, Z., Vallejo, E., Rodriguez, J.F.,Dominguez, F., Marchal, D., Reichert, C., di Primio, R., Götze, H.-J., 2013. Colorado Basin 3D structure and evolution, Argentine passive margin.

Tectonophysics 604, 264-279, doi:10.1016/j.tecto.2013.05.019

Autin, J., Scheck-Wenderoth, M., Götze, H.-J., Reichert, Ch., Marchal, D., 2016. Deep structure of the Argentine margin inferred from 3D gravity and temperature modelling, Colorado Basin. Tectonophysics 676, pp. 198-210, doi.org/10.1016/j.tecto.2015.11.023.

Baeschlin, C. F., 1948. Lehrbuch der Geodäsie. Verlag Orell Füssli, Zürich.

Bauer, K., Neben, S., Schreckenberger, B., Emmermann, R., Hinz, K., Fechner, N., Gohl, K., Schulze, A., Trumbull, R.B., Weber, K., 2000. Deep structure of the Namibia continental margin as derived from integrated geophysical studies. Journal of Geophysical Research 105, pp. 25829 - 25,853.

Basile, C., 2015. Transform continental margins - Part 1: Concepts and models. Tectonophysics, Elsevier, no. 661, pp.1-10. 10.1016/j.tecto.2015.08.034

Benioff, H., 1954. Orogenesis and deep crustal structure - additional evidence from seismology, Bulletin of the Seismological Society of America, 66, 385-400.

Blaich, O. A., Faleide, J. I., Tsikalas, F., 2011. Crustal breakup and continent-ocean transition at South Atlantic conjugate margins, Journal of Geophysical Research. 116, B01402, doi:10.1029/2010JB007686.

Bocher, M., Coltice, N., Fournier, A. and Tackley, J.P., 2016. A sequential data assimilation approach for the joint reconstruction of mantle convection and surface tectonics. Geophysical Journal International, 204, pp. 200-214.

Boltwood, B., 1907. The Ultimate Disintegration Products of the Radio-active Elements. Part II. The disintegration products of uranium. American Journal of Science series, 4, 23, 77-88. doi:10.2475/ajs.s4-23.134.78.

Bomfim, E.P., Braitenberg, C. and Molina, E.C., 2013. Mutual evaluation of global gravity models (EGM2008 and GOCE) and terrestrial data in Amazon Basin, Brazil. Geophysical Journal International, 14 pages, doi: 10.1093/gji/ggt283.

Bond, G.C., Nickelson, P.A., Kominz, M. A., 1984. Breakup of supercontinent between $625 \mathrm{Ma}$ and $55 \mathrm{Ma}$, New evidence and implicationes for continental histories. Earth and Planetary Science Letters, 70, 325-345.

Bouman J., Ebbing J., Meekes S., Fattah R.A., Fuchs M., Gradmann S., Haagmans R., Lieb V., Schmidt M., Dettmering D., Bosch W., 2015. GOCE gravity gradient data for lithospheric modeling. International Journal of Applied Earth Observation and Geoinformation 35(A): 16-30, Elsevier, 10.1016/j.jag.2013.11.001. 
1331

Bouman, J., Fuchs, M., Lieb, V., Schmidt, M., Ebbing, J., Holzrichter, N., Gradmann, S., Abdul Fattah, R., Meekes, S., Novak, P., Sebera, J., 2014. GOCE+ GeoExolore Final Report ESA, RP-GOCE+-DNT-11, 2.1, 1 - 443.

Braitenberg, C., 2015. Exploration of tectonic structures with GOCE in Africa and across continents. International Journal of Applied Earth Observation and Geoinformation, 35, pp. 88-95.

Brockmann, J.M., Zehentner, N., Höck, E., Pail, R., Loth, I., Mayer-Gürr, T., Schuh, W.-D., 2014. EGM_TIM_RL05: An independent Geoid with Centimeter Accuracy purely based on the GOCE Mission. Geophysical Research Letters, Wiley, doi: 10.1002/2014GL061904.

Bruinsma, S.L., C. Foerste, O. Abrikosov, J.M. Lemoine, J.C. Marty, S. Mulet, M.H. Rio und S. Bonvalot. 2014. ESA's satellite-only gravity field model via the direct approach based on all GOCE data. Geophysical Research Letters, 41(21), 75087514, DOI: 10.1002/2014GL062045.

Cappelletti, A., Salvi, F., Meda, M., Cavozzi, C., Chowdhury, B.R., Nestola, Y., Argnani, A., Tsikalas, F., Magistroni, M., Dalla, S., Roveri, M., Bevilacqua, N., 2011. Tectono-Stratigraphic Evolution of South Atlantic Extensional Rifted Margins: Constraints from Sandbox Analogue Modeling. Search and Discovery Article, no. 30204.

Colli, L., Ghelichkhan, S. and, Bunge, H. -P., 2016. Geophysical Research Letters, Volume 43 Issue 6, pp. 2510-2516.

Dressel, I., Scheck-Wenderoth, M., Cacace, M., Lewerenz, B., Götze, H.-J., Reichert, Ch., 2015. Reconstruction of the southwestern African continental margin by backward modeling. Marine and Petroleum Geology, 67, DOI: 10.1016/j.marpetgeo.2015.06.006.

Drinkwater, M.R., Floberghagen, R., Haagmans, R., Muzi, D., Popescu, A., 2003. GOCE: ESA's first Earth Explorer Core mission. In Beutler, G., Drinkwater, M.R., Rummel, R., von Steiger, R. (eds.), Earth Gravity Field from Space - From Sensors toEarth Sciences, Space Sciences Series of ISSI, vol. 17. Kluwer Academic Publishers,Dordrecht, The Netherlands, S. 419-432, ISBN: 1-4020-1408-2.

Ebbing J., Bouman J., Fuchs M., Lieb V., Haagmans R., Meekes J.A.C., Fattah R.A., 2013. Advancements in satellite gravity gradient data for crustal studies. Leading Edge, 32 (8), pp. 900-906.

Ebbing, J., Lundin, E., Olesen, O., Hansen, E.K., 2006. The mid-Norwegian margin: A discussion of crustal lineaments, mafic intrusions, and remnants of the Caledonian root by $3 \mathrm{D}$ density modelling and structural interpretation. Journal of the Geological Society, 163, 47-60.

Eldholm, O., Gladczenko, T.P, Skogseid, J., Planke, S., 2000. Atlantic volcanic margins: a comparative study. In: Nøttvedt, A., Larsen, B.T., Olaussen, S., Tørudbakken, B., Skogseid, J., Gabrielsen, R.H., Brekke, H.,Ø. Birkeland (eds.), Dynamics of the Norwegian Margin. Geological Society of London, Special Publication 167, 411-428. 
1373 Fairhead, J.D. and Wilson, M. 2005. Plate tectonic processes in the South Atlantic

1374

1375

1376

1377

1378

1379

1380

1381

1382

1383

1384

1385

1386

1387

1388

1389

1390

1391

1392

1393

1394

1395

1396

1397

1398

1399

1400

1401

1402

1403

1404

1405

1406

1407

1408

1409

1410

1411

1412
Ocean: do we need deep mantle plumes? In: G.R. Foulger, J.H. Natland, D.C.

Presnall, D.L. Anderson (Eds.), Plates, Plumes, and Paradigms, Geological Society of America Special Paper, 388, pp. 537-553.

Fecher T., Pail R., Gruber T., 2013. Global gravity field modeling based on GOCE and complementary gravity data. International Journal of Applied Earth Observation and Geoinformation, doi: 10.1016/j.jag.2013.10.005.

Fecher T., Pail R., Gruber T. 2016. GOCO05c - A new combined gravity field model based on full normal equations and regionally varying weighting. Surveys in Geophysics, in review.

Fecher T., Pail R., Gruber Th., Holmes S., 2015. Validation of South American Terrestrial Gravity Anomalies by GOCE. Geophysical Research Abstracts, 17, EGU2015-4859-1 European Geosciences Union General Assembly 2015, Vienna, 14.04.2015.

Flament, N., Gurnis, M. and Müller, R.D., 2013. A review of observations and models of dynamic topography, Lithosphere, vol. 5, no. 2, pp. 189-210. doi: 10.1130/L245.1

Förste, C., Bruinsma, S. L., Abrikosov, O., Lemoine, J.-M., Marty, J. C., Flechtner, F., Balmino, G., Barthelmes, F., Biancale, R., 2014. EIGEN-6C4 The latest combined global gravity field model including GOCE data up to degree and order 2190 of GFZ Potsdam and GRGS Toulouse. GFZ Data Services.

http://dx.doi.org/10.5880/icgem.2015.1

Franke, D., Neben, S., Schreckenberger, B., Schulze, A., Stiller, M., and Krawczyk, C.M., 2006. Crustal structure across the Colorado Basin, offshore Argentina.

Geophys. J.Int., 165, 850 - 864.

Franke, D., Ladage, S., Schnabel, M., Schreckenberger, B., Reichert, C., Hinz, K.,Paterlini, M., de Abelleyra, J., Siciliano, M., 2010. Birth of a volcanic margin off Argentina, South Atlantic. Geochemistry, Geophysics, Geosystems 11,Q0AB04.

Frisch, W. und Meschede, M., 2005. Plattentektonik. Kontinentverschiebung und Gebirgsbildung. Primus Verlag GmbH, 208 Seiten. ISBN-10: 3896785257.

Gatti, A., Reguzzoni, M., 2015. Comparison of the space-wise grids with other GOCE solutions. Geophysical Research Abstracts, Vol. 17, EGU2015-11112, EGU General Assembly 2015.

Geoffroy, L.C.R., 2005. Volcanic passive margins. Geoscience 337, 1395 -1408. doi:10.1016/j.crte.2005.10.006.

Gernigon, L., Lucazeau, F., Brigaud, F., Ringenbach, J.-C., Planke, S., Le Gall, B., 2006. A moderate melting model for the Vøring margin (Norway) based on structural observations and a thermo-kinematical modelling: Implication for the meaning of the lower crustal bodies. Tectonophysics 412 (3-4), 255-278.

Götze, H.-J., 2015. Potential Methods and Geoinformation Systems. In: Freeden, W., Nashed, M.Z., Sonar, T. (Eds.): Handbook of Geo-Mathematics. Berlin, Heidelberg, 
1413 Springer Verlag, S. 1-21. - ISBN 978-3-642-27793-1, (doi>10.1007/978-3-642-27793-

1414 1_52-2)

1415 Grombein, T.; Seitz, K.; Heck, B. 2015. RWI_TOPO_2015: An update of the Rock-

1416 Water-Ice topographic gravity field model of the Earth, available from

1417 http://www.gik.kit.edu/rwi_model.php

1418 Gutknecht, B.D., Götze, H.-J., Jahr, T., Jentzsch, G., Mahatsente, R., Zeumann, S., 1419 2014. Surveys of Geophysics, 35, 1417-1440. DOI 10.1007/s10712-014-9296-9.

1420 Gutknecht, B.D., Köther, N., Mahatsente, R., Götze, H.J., 2011. Utilisation of Gravity 1421 Gradients and Invariants for 3D Density Modelling. Proc. General Assembly of the 1422 International Union of Geodesy and Geophysics (IUGG), Melbourne, Australia.

1423 Hackney, R. I. and Featherstone, W. E., 2003. Geodetic versus geophysical 1424 perspectives of the 'gravity anomaly'. Geophysical Journal International 154 (1), 351425 43. doi: 10.1046/j.1365-246X.2003.01941.x

1426 Heit, B., Sodoudi, f., Yuan, X., Bianchi, M., Kind, R., 2007. An S- Receiver Function 1427 Analysis of the Lithospheric Structure in South America, Geophyical. Resarch Letters, 1428 34, L14307, doi:10.1029/2007GL030317.

1429 Hess, H. H., 1962. History of Ocean Basins. In A. E. J. Engel, Harold L. James, and 1430 B. F. Leonard. Petrologic studies: a volume in honor of A. F. Buddington. Boulder, 1431 CO: Geological Society of America. pp. 599-620.

1432 Hinz, K., Neben, S., Schreckenberger, B., Roeser, H.A., Block, M., Goncalves de 1433 Souza, K., Meyer, H., 1999. The Argentine continental margin north of $48^{\circ} \mathrm{S}$ :

1434 sedimentary successions, volcanic activity during break-up. Mar. \& Petrol. Geol.,16, 1 $1435-25$.

1436 Hinze, W.J., Aiken, C., Brozena, J., Coakley, B., Dater, D., Flanagan, G., Forsberg,

1437

1438

1439

1440

1441

1442

1443

1444

1445

1446

1447

1448

1449

1450

1451

1452
R., Hildenbrand, T., Keller, G.R., Kellogg, J., Kucks, R., Li, X., Mainville, A., Morin, R., Pilkington, M., Plouff, D., Ravat, D., Roman, D., Urrutia-Fucugauchi, J., Véronneau, M., Webring, M., Winester, D., 2006. New standards for reducing gravity observations: The Revised North American Gravity Database: http://paces.geo.utep.edu/research/gravmag/PDF/Final\%20NAGDB\%20Report\%200 91403.pdf

Hirsch, K.K., Bauer, K., Scheck-Wenderoth, M., 2009. Deep structure of the western South African passive margin e results of a combined approach of seismic, gravity and isostatic investigations. Tectonophysics 470, 57 - 70.

http://dx.doi.org/10.1016/j.tecto.2008.04.028.

Holzrichter, N., 2013. Processing and interpretation of satellite and ground based gravity data at different lithospheric scales. Dissertation, 126 pages. ChristianAlbrechts-Universität zu Kiel. Fakultät für Mathematik und Naturwissenschaften.

Hopper, J.R., Funck, T., Tucholke, B.E., Larsen, H.C., Holbrook, W.S., Louden, K.E., Shillington, D., Lau, H., 2004. Geological Society of America. Geology, 32, (1), 93 96. DOI 10.1130/G19694.1. 
1453 Hosse, M., Pail, R., Horwath, M., Holzrichter, N., Gutknecht, B.D., 2014. Combined 1454 Regional Gravity Model of the Andean Convergent Subduction Zone and Its 1455 Application to Crustal Density Modelling in Active Plate Margins. Surveys in 1456 Geophysics, 35, (6), 1393-1415.

1457 Isacks, B., Oliver, J.,Sykes, L. R., 1968. Seismology and the New Global Tectonics. 1458 Journal of Geophysical Research, 73, (18), 5855.

1459 IUGG, 2015. Resolutions adpoted by the IUGG Council at the XXVI General

1460 Assembly, Prague, Czech Republic, 22 June - 2 July 2015;

1461 http://www.iugg.org/resolutions/IUGGResolutions2015.pdf

1462 Kalberg, T., 2016. Interpretation tektonomagmatischer Prozesse basierend auf 3D

1463 Potentialfeldmodellierungsergebnissen. Dissertation 185 pages. Fachbereich für

1464 Geowissenschaften, Universität Bremen.

1465 Klinge, L., 2016. Gravitational potential energy (GPE) und Stress im südlichen

1466 Atlantik (in German). Master Arbeit, 89 pages. Institut für Geowissenschaften,

1467 Mathematisch-naturwissenschaftliche Fakultät der Christian-Albrechts-Universität

1468 Kiel.

1469 Köther, N., Götze, H.-J., Gutknecht, B.G., Jahr, T., Jentzsch, G., Lücke, O.H.,

1470 Mahatsentea, R., Sharma, R., Zeumann, S., 2012. The seismically active Andean

1471 and Central American margins: Can satellite gravity map lithospheric structures?

1472 Journal of Geodynamics, 59-60, 207-218.

1473 LaFehr, T.R., 1991. An exact solution for the gravity curvature (Bullard B) correction:

1474 Geophysics, 56, (8), 1179-1184, doi: 10.1190/1.1443138.

1475 Lallemand S., 2014. Active continental margin. In Encyclopedia of Marine

1476 Geosciences, Springer Science, Eds.: Harff, J., Meschede, M., Petersen, S. and

1477 Thiede, J., 7 pages, DOI 10.1007/978-94-007-6644-0_102-2.

1478 Li, X. and Götze, H.-J., 2001. Ellipsoid, Geoid, Gravity, Geodesy, and Geophysics - A 1479 Tutorial. Geophysics, vol. 66, no. 6, 1660-1668.

1480 Maus, S., Barckhausen, U., Berkenbosch, H., Bournas, N., Brozena, J., Childers, V., 1481 Dostaler, F., Fairhead, J.D., Finn, C., von Frese, R. R. B., Gaina, C., Golynsky, S., 1482 Kucks, R., Lühr, H., Milligan, P., Mogren, S., Müller, R.D., Olesen, O., Pilkington, M., 1483 Saltus, R., Schreckenberger, B., Thébault, E. and Caratori Tontini, F., 2009. EMAG2: 1484 A 2-arc min resolution Earth Magnetic Anomaly Grid compiled from satellite, airborne, 1485 and marine magnetic measurements. Geochemistry, Geophysics, Geosystems, vol. 1486 10, no. 8. doi: 10.1029/2009GC002471.

1487 Mayer-Gürr, T., Zehentner, N., Klinger, B., Kvas, A., 2014. ITSG-Grace2014: a new 1488 GRACE gravity field release computed in Graz. Presented at GRACE Science Team 1489 Meeting (GSTM), Potsdam, 29.09.2014.

1490 Maystrenko, Y.P., Scheck-Wenderoth, M., Hartwig, A., Anka, Z., Watts, A.B., Hirsch, 1491 K.K, Fishwick, S. 2013. Salt as a 3D element in structural modeling - Example from 1492 the Central European Basin System. Tectonophysics,

1493 doi:10.1016/j.tecto.2012.06.030 
1494 Mikuška, J., Pašteka, R., Marušiak, I., 2006. Estimation of distant relief effect in

1495 gravimetry. GEOPHYSICS, 71, (6), J59-J69, doi: 10.1190/1.2338333.

1496 Mohriak, W., 2014. Birth and development of continental margin basins: analogies

1497 from the South Atlantic, North Atlantic and the Red Sea. Search and Discovery article, http://www.searchanddiscovery.com/pdfz/documents /2014/41502mohriak/ndx mohriak.pdf.html

1500 Müller, R. D., Sdrolias, M., Gaina, C. and Roest, W.R., 2008. Age, spreading rates, and spreading asymmetry of the world's ocean crust. Geochemistry, Geophysics, Geosystems, vol. 9, no. 4., 19 pages, doi: 10.1029/2007GC001743.

1503 Naudy, H. and Neumann R., 1965. Sur la définition de l'anomalie de Bouguer et ses

1504

1505

1506

1507

1508

1509

1510

1511

1512

1513

1514

1515

1516

1517

1518

1519

1520

1521

1522

1523

1524

1525

1526

1527

1528

1529

1530

1531

1532

1533

conséquences pratiques, Geophys. Prosp., vol 13, 1-110'Connor, J.M., Jokat, W., le Roex, A.P., Class,C., Wijbrans,J.R., Keßling, S., Kuiper, K.F. and Nebel, O., 2012. Hotspot trails in the South Atlantic controlled by plume and plate tectonic processes. Nature Geoscience 5, pp. 735-738, doi:10.1038/ngeo1583.

Oliver, J., Isacks, B., 1967. Deep earthquake zones, anomalous structures in the upper mantle, and the lithosphere. Journal of Geophysical Research, 72 (16), pp. 4259-4275.

Oncken, O., Chong, G., Franz, G., Giese, P., Götze, H.-J., Ramos, V., Strecker, M. and Wigger, P., (Eds), 2006: The Andes - Active Subduction Orogeny., Frontiers in Earth Sciences, 1, Springer Verlag, pp. 570.

Pail R., Fecher T., Rexer M. 2015b. Validation of GOCE gravity gradient grids for geophysical applications. Geophysical Research Abstracts, Vol. 17, EGU2015-1652, Poster presented at EGU General Assembly 2015, Vienna.

Pail, R., Bingham, R., Braitenberg, C., Dobslaw, H., Eicker, A., Güntner, A., Horwath, M., Ivins, E., Longuevergne, L., Panet, I., Wouters, B. 2015a. Science and User Needs for Observing Global Mass Transport to Understand Global Change and to Benefit Society. Surveys in Geophysics, 36(6): 743-772, Springer Netherlands, doi: 10.1007/s10712-015-9348-9.

Pail, R., Goiginger, H., Schuh, W.-D., Höck, E., Brockmann, J. M., Fecher, T., Gruber, T., Mayer-Gürr, T., Kusche, J., Jäggi, A., Rieser, D. 2010. Combined satellite gravity field model GOCO01S derived from GOCE and GRACE. Geophysical Research Letters, Vol. 37, L20314, doi:10.1029/2010GL044906.

Pail, R., S. Bruinsma, F. Migliaccio, C. Förste, H. Goiginger, W.-D. Schuh, E. Höck, M. Reguzzoni, J. M. Brockmann, O. Abrikosov, M. Veicherts, T. Fecher, R.

Mayrhofer, I. Krasbutter, F. Sansò, and C. C. Tscherning 2011. First GOCE gravity field models derived by three different approaches, Journal of Geodesy, 85(11), 819843, doi: 10.1007/s00190-011-0467-x.

Panet I., G. Pajot-Métivier, M. Greff-Lefftz, L. Métivier, M. Diament \& M. Mandea 2014. Mapping the mass distribution of Earth's mantle using satellite-derived gravity gradients, Nature Geoscience 7, 131-135, doi:10.1038/ngeo2063. 
1534 Pavlis, N.K., Holmes, S.A., Kenyon, S.C., Factor, J.K., 2008. An Earth Gravitational

1535

1536

1537

1538

1539

1540

1541

1542

1543

1544

1545

1546

1547

1548

1549

1550

1551

1552

1553

1554

1555

1556

1557

1558

1559

1560

1561

1562

1563

1564

1565

1566

1567

1568

1569

1570

1571

1572
Model to Degree 2160: EGM2008. In: Proceedings of the European Geosciences Union General Assembly, April 13-18, Vienna, Austria.

Pavlis, N.K., Holmes, S.A., Kenyon, S.C., Factor, J.K., 2012. The development and evaluation of the Earth Gravitational Model 2008 (EGM2008). Journal of Geophysical Research, 117, (B4), 2156 - 2202, doi: 10.1029/2011JB008916.

Prange, L., 2011. Global Gravity Field Determination Using the GPS Measurements Made Onboard the Low Earth Orbiting Satellite CHAMP. PhD Thesis, Geodätischgeophysikalische Arbeiten in der Schweiz, vol. 81. http://www.sgc.ethz.ch/sgcvolumes/sgk-81.pdf

Reigber, C., Balmino, G., Schwintzer, P., Biancale, R., Bode, A., Lemoine, J.-M., Koenig, R., Loyer, S., Neumayer, H., Marty, J.C., Barthelmes, F., Perossanz, F., 2002. A high quality global gravity field model from CHAMP GPS tracking data and accelerometry (EIGEN-1S). Geophysical Research Letters, 29, 14, dx.doi.org/10.1029/2002GL015064

Reston, T.J., 2009. The structure, evolution and symmetry of the magma-poor rifted margins of the North and Central Atlantic: A synthesis. Tectonophysics 468, 6-27. doi:10.1016/j.tecto.2008.09.002.

Rudenko S., Dettmering D., Esselborn S., Schoene T., Foerste C., Lemoine J-M, Ablain M, Alexandre D, Neumayer K.-H., 2014. Influence of time variable geopotential models on precise orbits of altimetry satellites, global and regional mean sea level trends. Advances in Space Research, doi: 10.1016/j.asr.2014.03.010.

Salomon, A., Koehn, D., Passchier, C., Hackspacher, P.C. and Glasmacher, U.A., 2014. Contrasting stress fields on correlating margins of the South Atlantic,

Gondwana Research, doi.org/10.1016/j.gr.2014.09.006.

Schaller. T., Andersen, J., Götze, H.-J., Koproch, N., Schmidt, S., Sobiesiak, M., Splettstößer,S., 2015. Segmentation of the Andean margin by isostatic models and gradients. Journal of South American Earth Sciences, 59, 69-85.

Scheck-Wenderoth, M., Maystrenko, Y., 2008. How warm are passive continental margins? A 3D lithosphere-scale study from the Norwegian margin. Geology, 36, (5), 419-422, DOI: 10.1130/G24545A.1.

Skogseid, J., Planke, S., Faleide, J.I., Pedersen, T., Eldholm, O., Neverdal, F., 2000. NE Atlantic continental rifting and volcanic margin formation, in Nottvedt, A.e.a., Ed., Dynamics of the Norwegian Margin, 167: London, Geological Society of London, Special Publications, p. 55-82.

Sobiesiak, M., Meyer U., Schmidt S., Götze H.-J., Krawczyk C.M., 2007. Asperity generating upper crustal sources revealed by $b$ value and isostatic residual anomaly grids in the area of Antofagasta, Chile. Journal of Geophysical Research, v. 112, B12308, doi: 10.1029/2006JB004796. 
1573 Stadler, G., Gurnis,M., Burstedde, C., Wilcox, L.C., Alisic, L., Ghattas, O., 2010. The 1574 Dynamics of Plate Tectonics and Mantle Flow: From Local to Global Scales. Science, 1575 Vol. 329, Issue 5995, pp. 1033-1038, DOI: 10.1126/science.1191223.

1576 Szwillus, W., Ebbing, J. and Holzrichter, N., 2016. Importance of far-field topographic and isostatic corrections for regional density modelling. Geo- physical Journal International, 207 (1), pp. 274-287, doi:10.1093/gji/ggw270

Szwillus, W., Götze, H.-J., 2016. Efficient mass correction using an adaptive method. In: R, Pasteka et al., Proceedings of the workshop on Bouguer Anomaly, Bratislava (Slowak Republic). Accepted.

Tapley, B.D., Bettadpur, S., Watkins, M., Reigber, C., 2004. The gravity recovery and climate experiment: mission overview and early results. Geophysical Research Letters, 31(9), L09607, AmericanGeophysical Union, http://dx.doi.org/10.1029/2004GL019920.

Tašárová, Z., 2007. Towards understanding the lithospheric structure of the southern Chilean subduction zone $\left(36^{\circ} \mathrm{S}-42^{\circ} \mathrm{S}\right)$ and its role in the gravity field. Geophysical Journal International, 170, (3), 995-1014. doi:10.1111/j.1365-246X.2007.03466.x

Torge W., 2001. Geodesy, 3rd edition, 416 pages. De Gruyter Berlin, ISBN 3-11017072-8.

Torsvik, T. H., Rousse, S., Labails, C. and Smethurst, M.A., 2009. A new scheme for the opening of the South Atlantic Ocean and the dissection of an Aptian salt basin. Geophysical Journal International, 177, 3, pp. 1315-1333. doi: 10.1111/j.1365246X.2009.04137.x.

Vine, F. J.; Matthews, D. H., 1963. Magnetic Anomalies Over Oceanic Ridges. Nature 199 (4897), 947-949.

Wadati, K., 1929. Shallow and deep earthquakes (2nd paper): Geophysical Magazine, 2, 1-36.

Wefer,G., Billet, D., Hebbeln, D., Barker Jorgensen, B., Schlüter, M., van Weering, T.C.E., 2003. Eds. Ocean Margin Systems. Springer, pp. 495. Doi.10.007/978/-3662-05127-6

Wegener, A., 1920. Die Entstehung der Kontinente und Ozeane. In: E. Wiedemann (Herausgeber), Die Wissenschaft, Friedrich Vieweg und Sohn, Braunschweig, 2. Auflage, 66, 1-135.

Wenzel H., 1985: Hochauflösende Kugelfunktionsmodelle für das Gravitationspotential der Erde: Wissenschaftliche Arbeiten der Fachrichtung Vermessungswesen der Universität Hannover, 137, 1-155.White, R. S., Smith,L.K., 2009. Crustal structure of the Hatton and the conjugate east Greenland rifted volcanic continental margins, NE Atlantic. Journal of Geophysical Research, 114. B02305.

1610 DOI 10.1029/2008JB005856 
1 Insights from recent gravity satellite missions in the density structure of 2 continental margins - with focus on the passive margins of the South

3 Atlantic

\section{Abstract}

6 We focus on new gravity and gravity gradient data sets from modern satellite

7 missions GOCE, GRACE and CHAMP, and their geophysical interpretation at

8 passive continental margins of the South Atlantic. Both sides, South Africa

9 and South America, have been targets of hydrocarbon exploration and

10 academic research of the German Priority Program SAMPLE (South Atlantic

11 Margin Processes and Links with onshore Evolution). The achievable spatial

12 resolution, driven by GOCE, is $70-80 \mathrm{~km}$. Therefore, most of the geological

13 structures, which cause a significant gravity effect (by both size and density

14 contrast), can be resolved. However, one of the most important aspects is the

15 evaluation of the omission error, which is not always in the focus of

16 interpreters. It results from high-frequency signals of very rough topographic

17 and bathymetric structures, which cannot be resolved by satellite gravimetry

18 due to the exponential signal attenuation with altitude. The omission error is

19 estimated from the difference of the combined gravity model EIGEN-6C4 and

20 the satellite-only model GOCO05S. It can be significantly reduced by

21 topographic reductions. Simple 2D density models and their related

22 mathematical formulas provide insights in the magnitude of the gravity effect

23 of masses that form a passive continental margin. They are contrasted with

24 results from satellite-only and combined gravity models. Example geophysical

25 interpretations are given for the western and eastern margin of the South

26 Atlantic Ocean, where standard deviations vary from 25 - 16 mGal and 21 -

$2711 \mathrm{mGal}$, respectively. It could be demonstrated, that modern satellite gravity 
28 data provide significant added value in the geophysical gravity data

29 processing domain and in the validation of heterogeneous terrestrial data

30 bases. Combined models derived from high-resolution terrestrial gravity and

31 homogeneous satellite data will lead to more detailed and better constrained

32 lithospheric density models, and hence will improve our knowledge about

33 structure, evolution and state of stress in the lithosphere.

35 1. Motivation and the concept of Plate Tectonics

Geosciences are striving for an interdisciplinary perception to combine

38 their basic findings in a world embracing synthesis to understand global

39 processes in the Earth interior and at its surface. Most of these processes are

40 generally geothermally driven, and it is easy to accept that their origin lies

41 below the lithosphere, in the Earth's mantle (among others Stadler et al.,

42 2010). Today, the theory of plate tectonics enables us to draw a coherent

43 picture of the Earth's lithosphere. Interactions between the plates at their plate

44 boundaries are responsible for most of the earthquakes that occur here

45 (among many other publications and websites:

46 http://earthquake.usgs.gov/earthquakes/?source=sitenav,

47 http://www.isc.ac.uk/about/ or http://geofon.gfz-potsdam.de/).

48 This paper will review the status of satellite gravity missions and terrestrial

49 data, as well as global gravity models, fields and gradients derived from them.

50 It will focus on their accuracy, resolution and the omission error - which is out

51 of focus of many earth scientists. It is structured as follows: Section 1 defines

52 continent-ocean transitions and recalls some basics in the context of Plate

53 Tectonics concept and passive margins in particular. For those readers who 
54 are not familiar with the interpretation of gravity anomalies at a continental

55 margin in Section 2 the basic concepts are illustrated; this section can be

56 skipped by experts. Further on the focus is set on the question how (satellite)

57 gravity interpretations can help to explore these passive margins (Section

58 2.3). In the course of this paper we will notice later to what extent the new

59 fields and gradients from recent satellite gravity missions can support

60 research at the passive margins of the South Atlantic (Section 2.4).

61 In Section 3 we will demonstrate how this new information augmented

62 our view on the density structures of the lithosphere particularly at passive

63 margins of the South Atlantic. At last we describe the benefits for combined

64 interpretations in Section 4, and merge information from both terrestrial and 65 satellite gravity fields.

1.1 Short introduction to history of plate margins tectonics

68

Considering the history of the Plate Tectonic concepts in the early

70 1960s, Wegener's view on the „the continental drift” (Wegener, 1920) began

71 to be accepted after it was refined and confirmed by geophysical observations

72 namely by early seismological studies on deep earthquakes (Wadati, 1929;

73 Benioff, 1954), later by Isacks et al. (1968), Oliver and Isacks (1967) and

74 paleo-magnetic shipborne observations (Hess, 1962; Vine and Matthews 1963

75 among others). Together with the techniques of radiometric dating (age

76 determination) published first by Boltwood (1907) geophysicists were able to 
77 date the magnetic mid oceanic reversals by precise physical measurements.

78 They helped to get the modern concept of "plate tectonics" fully accepted.

79 It provides the framework for the interpretation of structures, the history

80 and composition of continental margins. Plate movements and the differences

81 in density of oceanic and continental crust types led to the structural pattern of

82 continental margins and result in a tectonic classification of coastlines as

83 active or passive margins (among others Wefer et al., 2003). Active margins

84 are typical units of the "Circum-Pacific Ring of Fire" in the Pacific where plates

85 are converging and coincide with plate boundaries in a subduction zone.

86 These margins are called active (e.g. Oncken et al., 2006; Lallemand, 2014)

87 due to the big variety of tectonic, magmatic and metamorphic processes that

88 occur here. If continental margins mark only the boundary to the oceanic

89 portion of the same tectonic plate, they are called passive margins. Passive

90 margins are typical of the Atlantic Ocean between Scandinavia and Greenland

91 (Scheck-Wenderoth and Maystrenko 2008), Iberic peninsula and the East

92 American coast or between Africa and South America (Blaich et al., 2011 and

93 many papers within).

95 1.2 Passive Margins

97 Although we assume that most of the readers are familiar with the

98 concept of plate tectonics we will recall briefly some basics. In particular

99 passive continental margins are characterized by a transition of continental

100 into oceanic crust within the same plate. It emerges from the splitting up of

101 continents and the following divergent plate drift that forms new oceanic

102 lithosphere by seafloor spreading at the divergent plate boundary. At the 
103 edges of the Atlantic geophysical investigations identify a laterally $10-15 \mathrm{~km}$

104 thick crustal transition between the thick crust of the continents and the thin

105 oceanic crust. It is interpreted as relicts of thinned, mafic magmas which

106 intruded into continental crust. In addition, passive continental margins are

107 often stretched by intensive fault tectonics. They have a tectonically thinned

108 continental crust, which is characterized by listric faults and tilted fault blocks.

109 Tectonic crustal expansion starts at the time of installation of the continental

110 drift rift system and refines the passive continental margin further (Blaich et

111 al., 2011). These margins are marked by smooth relief due to tectonic

112 inactivity and major sediment accumulation. This phenomenon is due to

113 thermal cooling and sediment loading that led to conditions of subsidence and

114 sediment accumulation, because the margins move away from the spreading

115 center. Irregular subsidence and different sediment load often cause the

116 accumulation of salt diapirs in the sediments of passive continental margins.

117 The tectonic-sedimentary conditions are also favorable for the formation of

118 hydrocarbon deposits and large salt deposits (Mohriak, 2014).

Modern passive margins (Fig. 1) border the oceans formed by the

121 spreading caused by the break-up of the Gondwana supercontinent (e.g.

122 Bond et al., 1984). From Figure 1 one can see that the margins of the South

123 Atlantic Ocean (Cappelletti et al., 2011; Blaich et al., 2011; Mohriak, 2014),

124 the western Indian Ocean, the Arctic and Norwegian seas (Scheck-Wenderoth

125 and Maystrenko, 2008; Ebbing et al, 2006; Skogseid et al., 2000), the magma

126 poor rifted margins of the North and Central Atlantic Ocean (Reston, 2009;

127 Mohriak, 2014) and the margins of Antarctica are part of this system (Kalberg,

128 2016). A rising convection cell or a plume in the rifting area caused initial 
129 rifting and a regional uplift as well as volcanic activities above or below

130 oceanic sea level after an initial period of crustal thinning and erosion. Basile

131 (2015) describe another type of margin: "transform continental margins" by

132 simple kinematic models of transform faulting which cause among two other

133 types "passive transform margins". The satellite gravity picture of the

134 Equatorial Atlantic Ocean will be shown in Section 4.2, Fig. 20.

135

136 Figure 1: double column

138 Fig. 1. Continental margins on Earth. Blue lines mark passive continental

139 margins mainly surrounding the Atlantic Ocean, the Antarctic Seas, and Indian

140 Ocean; red lines indicate active margins (subduction zones). Continental

141 margins were taken from from Frisch und Meschede (2005).The underlying

142 gravity field is the map of "gravity disturbance" calculated on base of the

143 EIGEN-6C4 model (Förste et al., 2014). Gravity was calculated on a grid of $1440.5^{\circ} \times 0.5^{\circ}$.

\subsection{Volcanic passive margins}

148 These margins present distinctive genetic and structural features, e.g.,

149 high-rate extension of the lithosphere is associated with catastrophic mantle

150 melting responsible for the accretion of a thick igneous crust (Geoffroy, 2005).

151 Typical rifted "magma-dominated" margins are characterized by large volumes

152 of flood basalts which flow across the continental hinterlands during 
153 continental breakup (among others refer to: Hopper et al., 2004; Eldholm et

154 al., 2000; Gernigon et al., 2006; White and Smith, 2009; O'Connor et al.,

155 2012). Underlying the extrusive lavas at the continent-ocean transition zone,

156 these margins exhibit high seismic velocities in the lower crust of some The

157 deeper crust is characterized by two areas of high seismic velocity (7.2 to 7.4

$158 \mathrm{~km} / \mathrm{s}$; Franke et al., 2010)., which are associated with voluminous igneous

159 rocks intruded into the lower crust.

In recent time the question arose in the context of fixing international

161 boundaries offshore of the continents due to economic interests because e.g.

162 hydrocarbon exploration moved further offshore e.g. to explore deep water

163 resources. Toward the definition of this "continent-ocean-boundary, COB" at

164 passive margins one of the crucial questions is how to define these

165 boundaries. Torsvik et al. (2009) described how COB for the South Atlantic

166 margins at both sides can be defined: by the interpretation of seismic,

167 gravimetric, magnetic, bathymetric and geological information. Any

168 identification of the $\mathrm{COB}$ is also important for the definition of plate boundaries

169 at the time of break-up which allows the reconstruction of geometry and earlier

170 position of former continents - e.g. in the reconstruction of Pangaea. It is not

171 the aim of this paper to recalculate COBs. However we trust that the

172 processing of gravity field and its second derivatives for recalculation of COB

173 (Torsvik et al., 2009) will benefit from the increase of high resolution satellite

174 derived gravity fields. Later we will return to this point in the conclusion

175 (Section 5) suggesting calculating the $2^{\text {nd }}$ derivative of satellite gravity

176 (derivative of the gravity gradient). 


\section{2. Geophysical characteristics of margins}

To investigate both active and passive continental margins almost all

181 geophysical methods can help to discover their lithospheric structures:

182 Seismic, potential, electro-magnetic and electrical fields. Recent studies (e.g.

183 Torsvik et al. 2009) show that processes in the lithosphere are linked to the

184 dynamic mantle and dynamic processes have an important influence on the

185 evolution of lithospheric plates, which is manifested in the formation of

186 dynamic topography (e.g. Flament et al., 2013; Colli et al., 2016). A key

187 example for this interaction is the opening history of the Atlantic, where

188 asthenospheric material reaches the surface at the mid-ocean spreading

189 center. The uplift of hot material of the asthenosphere leads to seafloor

190 spreading which manifests itself in the spreading anomalies in the magnetic

191 field. The spreading axes are expressed either by topographic (heights above

192 sea level, e.g. Iceland) or bathymetric heights (below sea level e.g. Atlantic

193 ocean ridge). The worldwide offshore stripe pattern of magnetic anomalies

194 which are located parallel to mid-ocean ridges allow a temporal classification

195 of developed oceanic crust. The EMAG2 total magnetic field model has a

196 reasonable resolution of two arc-minutes (Maus et al. 2009). The model was

197 compiled from ship-, air-borne and satellite data (CHAMP). For the purpose of

198 interpolation of magnetic field anomalies the oceanic crust ages of Müller et al.

199 (2008) were employed (Maus et al. 2009). Hydro-carboniferous exploration

200 targeted most of the passive margins of the world with both refraction and/or

201 reflection seismic. 
202 Seismic onshore-offshore investigations of a passive continental margin

203 aim to investigate the transition zone between the oceans and continents, e.g.

204 SE Atlantic and the African continent (Franke et al., 2006; 2010; Bauer et al.,

205 2000; Hirsch et al., 2009; Schnabel et al., 2008). These studies reveal the

206 history and mechanisms of the break-up and its relation to the driving

207 magmatic processes (plume - crust interactions) in the underlying mantle and

208 lithosphere. The South American side of the southern Atlantic was target of

209 multiple seismic investigations since many years (Mohriak, 2014; Blaich et al.,

210 2011; Franke et al. 2006; Heit et al. 2007; Hinz et al., 1999 and many more) to

211 investigate the shelf areas offshore, the continent-ocean transition and the

212 seaward dipping reflectors (SDR) which are characterized by high seismic

213 velocities and related high densities.

214

2152.1 The role of gravity field interpretations and prerequisites

216 Remark:

217 The units used for gravity field values and its gradients are given in

$218 \mathrm{mGal}$ (Milligals) and E (Eötvös) - as it is still common use in

219 Geophysics and Geodesy. Converting these units into SI-units, there

220 are: $1 \mathrm{mGal}=10^{-5} \mathrm{~m} / \mathrm{s}^{2}$ and $\mathrm{E}=10^{-9} \mathrm{~s}^{-2}$.

$221 \quad$ Rock densities are always given in $\mathrm{kg} / \mathrm{m}^{3}$.

222 First, the situation will be analyzed which was typical before the era of

223 satellite missions which started in the year 2000 with the launch of the

224 CHAMP satellite (refer to Chapter 4). Modelling and interpretation of the

225 Earth's gravity field and its derivatives often had to deal with a merge of data

226 sets with rather different resolution, different age and quality, coverage and 
227 wavelength content. This has been documented in a long list of papers

228 (among many others: Schaller et al., 2015; Bouman et al., 2014; Hosse et al.,

229 2014; Gutknecht et al., 2014; Köther et al., 2012; Tašárová, 2007). These

230 papers have shown that lithospheric models of study regions suffer mainly

231 from two facts:

232 (1) Nearly all information for constrained gravity field modelling of the 233 lithospheric is based on irregularly distributed profiles and

(2) large data gaps and partly low data quality due to very limited access and infrastructure.

237 The global gravity model EGM2008 (Pavlis et al. 2012) inherited - and still 238 inherits - these problems related with available terrestrial databases. Pavlis et 239 al. (2008) described the compilation of the EGM2008 gravity which consists of

240 different sources: up to a spatial resolution of approximately $140 \mathrm{~km}$ GRACE

241 (Gravity Recovery and Climate Experiment) data have been used, data from

$242140 \mathrm{~km}$ to approx. $10 \mathrm{~km}$ spatial resolution are derived from terrestrial and

243 satellite altimetry and so called "fill-in" data (Section 4.2). Today we know that

244 the relative weighting of GRACE with respect to the other datasets was too

245 low, leading to a dominance of terrestrial data errors in spectral regions where

246 better GRACE data would already have been available.

248 Figure 2: double column

250 Fig. 2. This figure portrays the terrestrial data inconsistency which is rather

251 typical for gravity surveys in remote areas (here across the South American

252 continent at a swath between $36^{\circ} \mathrm{S}-42^{\circ} \mathrm{S}$ from the passive margin in the East 
253 to the active margin in the West). As an example the different sources of

254 gravity data of the Southern Central American continent are shown together

255 with the visualization of big data gaps (Tašárová, 2007). The green and red

256 points in Chile $(\mathrm{CH})$ and Argentina (AR) are stations in the ARANEDA I and II

257 (University of Chile) datasets; black points in southern Chile and the Arauco

258 Peninsula are ENAP data (Chilean oil industry); the gray dense network in

259 Argentina (AR) show the YPF data (Argentine oil company); yellow points:

260 stations of the MIGRA 2000 dataset, and the MIGRA 2002 data (both

261 measured by the gravity group at the University Kiel) are shown in blue. The

262 brown lines offshore denote the ship-borne gravity data profiles from the

263 German research vessel "Sonne".

264 Fig. 2 shows the situation some 20 years ago at the central South

265 American subcontinent. For a continental gravity field study the field had to be

266 compiled from very different data sources often without any meta data

267 information - e.g. for gravity data which were measured on behalf of oil

268 companies (grey area in Fig. 2). In other areas, e.g., in the eastern part of

269 Argentina (yellow dots in Fig. 2) data are missing due to difficult or impossible 270 access.

271 At the end of this Section we will pose the question how large

272 lithospheric structures and how big density differences to their surrounding

273 have to be in order to cause a detectable signal at orbit height of a satellite.

274 This consideration describes the situation at active and passive margins in an

275 analogues manner. In Fig. 3 the effects of gravity and gradients are shown for

276 a simple model. For density contrasts between the values $\Delta \rho=10^{1}-10^{3}$

$277 \mathrm{~kg} / \mathrm{m}^{3}$ Gutknecht et al. (2011) calculated gravity and gradients at the GOCE

278 satellite orbit height of $255 \mathrm{~km}$ resulting from a sphere with minimum 
279 diameters between $d=20-200 \mathrm{~km}(b=10-100 \mathrm{~km}$, refer to Fig. 3$)$ to be

280 tangent to the Earth surface). Within the range of the assumed parameters the

281 minimum diameter required to produce signal differences of $1 \times 10^{-5} \mathrm{~ms}^{-2}$ and

$28212 \times 10^{-12} \mathrm{~s}^{-2}$ at orbit height. This is rather close to the expected accuracies of

283 the gravity and vertical gravity gradient of the GOCE mission (recent values

284 are: $0.45 \mathrm{mE}$ for GOCE-only, $0.2 \mathrm{mE}$ for GOCE+GRACE models, cf. also Fig.

285 13). Fig. 3 conveys that a structure with a diameter of some $45 \mathrm{~km}$ and a

286 density contrast of $240 \mathrm{~kg} \mathrm{~m}^{-3}$ could be detected in satellite gravity at orbit

287 height. If the diameter of the model sphere increases to $90 \mathrm{~km}$, its density

288 contrast should not be less than $33 \mathrm{~kg} \mathrm{~m}^{-3}$.

289 The simple model described above fits rather well the dimension of the

290 Jurassic arc batholiths at the Northern Chilean continental margin with

291 diameters of roughly $60-120 \mathrm{~km}$ (Sobiesiak et al., 2007). This supports the

292 idea that batholithic structures e.g. intrusions at continental margins, can be

293 detected using data of the modern satellite missions- both gravity and

294 gradients.

295

296 Figure 3: one and a half page width

298 Fig. 3. Gravity and gradient signal caused by a minimum diameter of a sphere

299 with given density contrast in the orbit height of $255 \mathrm{~km}$ (Gutknecht et al.,

300 2011). The thick solid and dotted lines represent gravity signals of 1 and 10

$301 \mathrm{mGal}$ at orbit height. The thin dashed and dash-dotted lines represent

302 gradients of 12 and $1000 \mathrm{mE}$, respectively. The grey shaded area shows

303 results which are based on a possible combination of geometry and density

304 parameters of the causing mass anomaly. 
308 A first look at Fig. 4 provides already helpful information on the gravity

309 gradients of the Earth at the continental margins. The figure bases on the

310 evaluation of gravity field maps from the recent gravity missions. A complete

311 Bouguer anomaly (corrected by the effect of elevation, spherical slab,

312 topography both on- and offshore) was used to calculate the first derivative of

313 the field - the dip curvature of gravity.

315 Figure 4: Full page width

317 Fig 4. Global horizontal gravity gradients. Deep blueish colors mark regions

318 on Earth where the dip curvature (horizontal gradient) of the worldwide

319 Bouguer gravity field (EIGEN-6C4) is small or even zero. The more reddish

320 the colors are the steeper the gradients. The strongest gradients are observed

321 at the active continental margin of Central South America. On the contrary at

322 most of the passive continental margins (Fig. 1) the gradients are rather small.

324 Dark blueish colors indicate rather weak dip curvature which means that

325 horizontal gravity gradients are small, on the contrary reddish tones point to

326 strong dip curvature and therefore strong gradients. The active continental

327 margins in the area of the Circum-Pacific are generally marked by reddish 
328 colors - strong gradients - which are related with extended density variations

329 in crust and mantle in the transition from oceanic to continental margins.

330 Mostly low gradients - light blueish colors - are typical for passive continental

331 margins. In order to understand this relationship two questions arise:

332 (1) How was the gravity anomaly calculated and how big is its magnitude of

333 the anomaly caused by the mass distribution (both topography/bathymetry

334 and densities) at continental margins and

335 (2) How was the field observed and what is known about accuracy and

336 homogeneity of gravity field observations?

337 With regard to the first question one has to consider that gravity

338 observations at the Earth's surface and the Earth near space vary from the

339 theoretical "normal" field value. Their magnitude is caused not only by the

340 latitude effect but by elevation of observational points, the density of cap

341 beneath the station in the underground and the topographic masses in the

342 neighborhood. After correction of earth tidal effects and air pressure

343 variations the remaining time invariable parts of the measured signal are:

$344 \quad$ Normal gravity $\quad$ Yo

$345 \quad$ Effect of topographic masses $\delta g_{\text {TOP }}$

$346 \quad$ Bouguer slab $\delta g_{B P L}$

$347 \quad$ Elevation effect (free air term) $\quad \delta g_{\text {NIV }}$

$348 \quad$ Effect of the crustal root $\delta g_{R}$

$349 \quad$ Known mass inhomogeneities $\quad \delta g_{\mathrm{GEOL}}$ 
$351 \quad$ Common representations of gravity measurements in maps and profiles

352 depend on what has been calculated as stated in the table above and added

353 as corrections to the measured gravity field values. From all measured gravity

354 values the normal gravity (in the height and position of the observable) is

355 subtracted, and therefore the term "gravity anomaly" is defined. This is simply

356 the difference between the observable values to "normal" gravity. In

357 Geophysics we distinguish mainly between three anomalies Free air- (FA),

358 Bouguer- (BA) and isostatic anomaly (ISA) which define gravity in the height

359 of the observation (e.g. Li and Götze, 2001; Hackney and Featherstone, 2003;

360 Naudy et al., 1965; LaFehr, 1991 and many others).

361 With $\delta g_{R}$ we describe the effect of a mountain root and define Free Air,

362 Bouguer and isostatic anomalies such as:

363

364

365

$$
F A=\Delta g_{0}^{\prime}=g_{o b s}+\delta g_{N I V}\left[+\delta g_{T O P}\right]-\gamma_{0}
$$$$
B A=\Delta g^{\prime \prime}{ }_{0}=g_{o b s}+\delta g_{N I V}+\delta g_{T O P}+\delta g_{B P L}-\gamma_{0}
$$$$
I S A=\Delta g_{I S A}=g_{o b s}+\delta g_{N I V}+\delta g_{T O P}+\delta g_{B P L}+\delta g_{R}-\gamma_{0}
$$

367 Calculations of the individual correction terms depend on the objective of the

368 survey and are variously complicated to handle. $g_{o b s}$ denotes the measured

369 gravity field value. The calculation of the topographical reduction $\left(\delta g_{\text {Top }}\right)$

370 requires precise knowledge of the terrain and surface near densities and

371 today it is most likely calculated by the aid of digital elevation models (DEM),

372 among others refer to (Holzrichter, 2013 and Szwillus and Götze, 2016); it

373 requires the use of a computer and digital elevation data. The effect of

374 topographic masses is normally calculated in a surrounding circular area of 50 $375 \mathrm{~km}$ up to $167 \mathrm{~km}$ (e.g. La Fehr, 1991; Hinze et al., 2006). However, Mikuška et 
376 al. (2006), Szwillus and Götze (2016), Szwillus et al., (2016) point to "long

377 distant relief effects" and propose the calculation of all topographic masses on

378 Earth. The gravity effect of a Bouguer slab with a thickness which is defined

379 by the difference between the physical station height and the reference level

380 (normally the geoid) should always be calculated by a spherical cap (e.g.

381 Baeschlin, 1948). For smaller areas (with a reduction radius $\mathrm{R}<20 \mathrm{~km}$ ) and

382 moderate terrain roughness the Bouguer slab can easily be calculated by:

383

$$
\delta g_{B P L}=-2 \pi G \rho\left(H_{S}-H_{B}\right)
$$

384

with:

385

386

387

388

389

$\mathrm{G}=$ Gravitational constant $\left(6.672 \cdot 10^{-11} \mathrm{~m}^{3} \mathrm{~s}^{-2} \mathrm{~kg}^{-1}\right)$,

$\rho \quad=\quad$ crustal density $\left(2670 \mathrm{~kg} / \mathrm{m}^{3}\right)$; offshore: rock-equivalent density

390

391

In the last step the free air effect $\delta g_{\text {NIV }}$ is calculated by use of the

392 "normal gradient" $(0.3085 \mathrm{mGal} / \mathrm{m})$ :

393

$$
\delta g_{N I V}=0.3085 \cdot\left(H_{S}-H_{B}\right) m G a l / m
$$

394 It has to emphasized that the above used constant gravity gradient for large

395 scale investigations has to be replaced by equivalent values of derivation of

396 closed mathematical expression of the normal gravity which is always latitude

397 and height dependent. It was also recommended to calculate an "atmospheric 398 correction" (Wenzel, 1985) in order to eliminate long wavelengths errors from 399 the observed gravity field. 
$400 \quad$ Note: the terms of "flat" Bouguer slab in $\delta g_{B P L}$ and the "constant vertical

401 gradient" in $\delta g_{\text {NIV }}$ are in the above formulas are used here for simplification

402 only. Modern satellite gravity field processing at large spatial scales requires a

403 spherical cap calculation and the consideration of latitude and height

404 dependent calculation of the vertical gradient.

405 Special emphasis has to be put on the situation in oceanic regions. If

406 we assume that station heights are equal to geoidal heights $(\mathrm{h}=0 \mathrm{~m})$ Bouguer

407 and Free Air anomaly is equal due to:

408

$$
B A=F A+\delta g_{B P L}=F A+\left[-2 \pi G \rho\left(H_{S}-H_{B}\right)\right]
$$

409

with: $H_{s}-H_{B}=0$ m;

410 it follows that $B A=F A$, in case the $F A$ is already corrected by $\delta g_{\text {Tор }}$ which

411 contains gravity effect of masses at the ocean floor.

412 In oceanic areas the slab density in the Bouguer slab correction term

413 must be modified due to the known water depth "D" and the difference in

414 water- and rock density (Fig. 5). If we assume a crustal rock density of 2670

$415 \mathrm{~kg} / \mathrm{m}^{3}$ and a water density of $1030 \mathrm{~kg} / \mathrm{m}^{3}$ the resulting density for calculations

416 of offshore Bouguer anomalies is $\rho^{*}=-1640 \mathrm{~kg} / \mathrm{m}^{3}$.

417 This results in:

418

$$
B A=F A+\delta g_{B P L}=F A+2 \pi G \rho^{*}\left(H_{S}-H_{D}\right)
$$

420 Figure 5: Full page width

421

422 Fig. 5. Illustration for describing the calculation of Bouguer anomalies on

423 continents $(A)$, at the ocean (B) and from satellite (C). (A): On land the

424 reduction density $\rho$ is commonly taken as $2670 \mathrm{~kg} \mathrm{~m}^{-3}$. The effect of 
425 topography is already removed. The thickness of Bouguer slab equals the

426 station height $\left(H_{s}\right)$. (B): In contrast the reduction density at sea is $-1640 \mathrm{~kg}$

$427 \mathrm{~m}^{-3}$. It is the difference between the sea water density of $1030 \mathrm{~kg} \mathrm{~m}^{-3}$ and the

428 rock density of $2670 \mathrm{~kg} \mathrm{~m}^{-3}$; thickness of the slab now is equal to the different

429 water depths (D). (C): Calculating a Bouguer anomaly in case of satellite

430 gravity a "mass correction" is calculated: $\delta g_{\text {Mass }}=\delta g_{\text {Top }}+\delta g_{B P L}$.

431

$432 \quad 2.3$ Gravity at passive continental margins

433

434 In Fig. 6 a very simple Airy-Isostasy model of a passive continental margin is

435 shown. The continental crust is much thicker than the oceanic crust and above

436 the oceanic crust there is the water cover of a few 1000 meters. The specific

437 geometry of the „crust - mantle - water cover" constellation plays an

438 important role on the trend of the gravity field here. Because of the fact that in

439 the example of Fig. 6 there is no topography, the continental margin remains

440 in an isostatic equilibrium, and one can assume that no Free Air anomaly

441 exists.

443 Figure 6: One and half page width

445 Fig. 6. Airy isostatic model at a continent - ocean transition. Notice the thick

446 continental crust and the thin oceanic crust at a passive continental margin.

447 Crust and mantle densities are simplified. Reasonable contrasts which cause

448 large gravity anomalies are related to the water - continent density contrast 

449 and crust - mantle density at the continent of approx. $430 \mathrm{~kg} \mathrm{~m}^{-3}$. Refer to text
450 for more information.

451

452

However, in Fig. 7 (A) strong gravity anomaly results from the same

453 density model (Fig. 7C) which was shown in Fig. 6. The Fig. 7(A) shows the

454 modelled anomaly only for water effect of gravity: related to a model of a "half-

455 indefinite" plate the resulting anomaly is negative and is caused by a strong

456 gradient. Fig. 7 (B) on the other side contains model results which have been

457 done only for the oceanic mantle: now the anomaly is positive and it has a

458 gentle increase because its position is far deeper. Finally Fig. 7(C)

459 demonstrates how the total Free Air anomaly results from the superposition of

460 both effects: the Free Air anomaly is zero in the continental area and over the

461 ocean as well. However, exactly above the margin the gravity field is

462 characterized by a maximum and a minimum that follows. This distribution is

463 a so called "edge" or boundary effect of the Free Air anomaly and is effected

464 by the difference of the steep gradients in the model.

465

466 Figure 7: one and a half page width

468 Fig. 7. The principal effects on the gravity field at continental margins have

469 equal gravity magnitudes but different gradients. In (A) the water effect causes

470 a steep gradient and in (B) the density surplus of the oceanic mantle is a

471 deeper seated effect which causes only a gentle gradient. In (C) it is explained

472 that a Free Air anomaly at a continental margin is caused by both a negative 
473 and positive "edge effect" due to the superposition of contributions that have

474 equal magnitudes but different gradients.

475

476 The trends of a Free air and Bouguer anomalies are shown in Fig. 8.

477 Here modelling again gets use of a "half indefinite" thin plate for the offshore

478 area (water). It is "zero" over the continent zero and over the oceanic area

479 "positive" $\left(\rho_{\mathrm{w}}=1030 \mathrm{~kg} / \mathrm{m}^{3}\right)$. The half of the whole Free Air anomaly maximum

480 is accomplished exactly over the edge of the continent.

481

482 Figure 8a-b: Full page width

483 Figure 8c: One and a half page width

484

485 Fig. 8. Free Air anomaly and Bouguer anomaly at continental margins which

486 is also in an isostatic balance. (A) The absolute value of the excess mass

$487|+\Delta \mathrm{m}|$ is equal to the absolute value of the deficient mass $|-\Delta \mathrm{m}|$. Therefore

488 the integral of gravity change with respect to the $\mathrm{x}$-coordinate is zero: $\int \Delta \mathrm{g} d \mathrm{x}=$

489 0. (B) The Bouguer correction at the ocean (see Fig. 3) applied to the Free Air

490 anomaly in (A) yields the general form of the Bouguer anomaly at passive

491 continental margins. (C) The "geological" mass inhomogeneities at the

492 continental margins (seaward dipping reflectors, magmatic remnants, salt

493 structures etc.) cause rather local gravity anomalies which superimpose the

494 regional gravity wavelengths - which are effected by the "simple" structures in 495 (A) and (B). 
The gravity fields in Figs. 7 and 8 are caused by the over simplified

497 density structure at the "modelled margin" in Fig. 6. In the real world these

498 margins show a rather complicated picture of gravity distribution due to mass

499 inhomogeneities in the Earth's crust and lithosphere (and even in the mantle)

500 which are the results of the long-lasting history of the breakup of the

501 Gondwana supercontinent. This becomes quite clear if looking at the

502 processed gravity fields which are shown in the series of figures (Fig. 14

503 through 21) in Section 4. Their interpretation in terms of regional tectonic and

504 distribution of rock densities will help to provide a rather detailed insight into

505 the causing structure (geometry) and density distribution of the passive

506 margins in the South Atlantic region.

Most aspects of the calculated anomalies, both Free Air and Bouguer,

508 which were discussed before, are typical for nearly all of the continental

509 passive and active margins on Earth. In the next Section the focus will be set

510 on the situation in the Southern Atlantic between Africa and South America -

511 the research area of the German Priority Program 1375 "SAMPLE" of the

512 German Science Foundation - DFG (https://www.sample-spp.de/). The

513 acronym stands for "South Atlantic Margin Processes and Links with onshore

514 Evolution". In this interdisciplinary project the primary research areas are the

515 mantle dynamics and magmatic processes, the lithospheric structure,

516 deformation processes and rifted margin formation, the post-rift topographic

517 evolution and many more. In the following Section we will concentrate on this

518 part of the world because a big variety of data and information is available to

519 responds to one of the key questions - how modern satellite missions can

520 contribute to the interpretations and to the understanding of the transition from

521 continental to oceanic lithosphere. 
5232.4 Focus region: South Atlantic passive margins

524

525 To study deeper structures and the overall evolution of conjugate

526 passive continental margins of the South African and South American

527 continents 3D structural models have been designed and evaluated by

528 SAMPLE scientists and their international partners: They constructed detailed

529 density models at both sides of the Southern Atlantic Ocean and a rather

530 preliminary density model for the oceanic part in course of a master thesis

531 (Klinge, 2016). These models are constrained by information and data from

532 boreholes, refraction and reflection seismic, seismological tomography and

533 potential field data - mainly gravity field data. Geophysical fields and

534 observations map geometry and distribution of physical properties of the

535 transitional structures of both crust and lithospheric mantle. Model results (Fig.

536 9) show (Maystrenko et al., 2013; Autin et al., 2016) that basin centers at the

537 western (Argentinean) side are oriented west-east and therefore oblique to the

538 mid ocean rift axis while at the other (African) side basin centers extend

539 parallel to the ocean rift in north-south direction.

540

541 Figure 9o: One and a half page width

542 Figure 9u: One and a half page width 
544 Fig. 9. For illustration this figure portrays a 3D density model of the SW

545 African continental margin (above, modified after Maystrenko et al., 2013),

546 and the density structure at the Argentinean side (below, Autin et al., 2016).

Apart from these structural differences both sides of the Southern

549 Atlantic reveal similar distributions in temperature and density. Small

550 thicknesses and density modifications in the lithospheric mantle point to small

551 lateral variations of heat transfer into the overlaying crust. However, more

552 relevant for the crustal heat field are lateral thickness changes of the

553 crystalline crust which produce the bigger part of radiogenic heat. This

554 contrasts observations and modelling results at passive continental margins in

555 the area of the Northern Atlantic (Scheck-Wenderoth and Maystrenko, 2008).

556 They found that the oceanic part of lithospheric mantle is much thinner and

557 characterized by smaller densities which cause higher temperatures in the

558 upper crust of the ocean.

$559 \quad$ To contrasting large scale paleostress fields on the correlating margins

560 of the South Atlantic Salomon et al. (2014) point to in their studies of the

561 South Atlantic. They asked themselves "how passive" continental margins

562 across the globe currently are. Following the results of several other studies

563 these margins experience a variety of stress states and undergo significant

564 vertical movements, as they were deduced from studies of paleo-stresses at

565 both sides of the Southern Atlantic. Here, the bounding continents consist of

566 very different recent geological histories: Africa experiencing continental rifting

567 whereas South America is influenced by subduction on the Pacific side. It is

568 not clear to what extent the Atlantic continental margins are subject to the 
569 same stresses and vertical motions as the main continents. Their results show

570 that the tectonic evolution of the continental margins of the South Atlantic is

571 not only passive and that both margins vary significantly in structural style and

572 stress fields, indicating that variable plate boundary forces play a major role in

573 margin evolution. In Fig. 10 we show the situation at the S-American and S-

574 African margin with reference of the paleo-stress field, as it was published by

575 Salomon et al. (2014). Their findings demand careful modelling of both

576 continental margins and a geophysical database which is able to resolve even

577 very small modifications of physical parameters and their structures; refer also

578 to Fig 9 (a) and (b) and the 3D density modelling of lithospheric by

579 Maystrenko et al. (2013) and Autin et al. (2016).

580

581 Figure 10: Faull page width

582

583 Fig. 10. The sketch (Salomon et al., 2014) portrays an E-W cross-Section

584 between South Africa and South America which summarize the situation of

585 their obtained paleo stresses. It shows that the African margin is controlled by

586 extension while compression characterizes the situation at the South

587 American side. Salomon et al. (2014) explained the extensional state in the

588 east by the existing "African superplume" and the compression in the west by

589 the Andean subduction zone.

Novel satellite gravity missions aim at a breakthrough in recovering the

592 Earth's gravity and magnetic fields, their gradients as well as their temporal 
593 variation. Static anomalies in potential fields (refer to Figs. 14 through 21) are

594 caused by irregular mass distribution on and within the Earth, temporal

595 variations of the gravity field are associated with mass transport processes in

596 the Earth system, such as dynamic processes on the Earth's surface, in

597 lithosphere and upper mantle.

598

\section{3. Modern satellite gravity missions}

600

601

The launch of the first generation of satellite gravity missions (Fig. 11) has

602 revolutionized our knowledge of the global Earth's gravity field and its temporal

603 changes. The German CHAMP (Challanging Minisatellite payload; mission period

604 2000-2010; Reigber et al., 2002; http://op.gfz-potsdam.de/champ/) mission, the

605 US/German GRACE (Gravity Recovery and Climate Experiment; mission period

606 2002-ongoing; Tapley et al., 2004; http://www.csr.utexas.edu/grace/) mission, and the

607 European GOCE (Gravity field and steady-state Ocean Circulation Explorer; mission

608 period 2009-2013; Drinkwater et al., 2003;

609 http://www.esa.int/Our_Activities/Observing_the_Earth/The_Living_Planet_Programm

610 e/Earth_Explorers/GOCE/ESA_s_gravity_mission_GOCE) operated by the European

611 Space Agency (ESA), improved significantly the coverage and availability of high

612 resolution and precisely measured data. These gravity missions are the only

613 measurement technique that can directly observe mass changes on a global scale,

614 and thus they provide a unique observation system for monitoring mass transport in

615 the Earth system. For modern magnetic field observation, apart from the CHAMP

616 mission (2000-2010), with ESA's three SWARM satellites that have been successfully

617 launched in November 2013 also gradients observations have become available

618 (http://esamultimedia.esa.int/multimedia/publications/BR-302/). 
620 Figure 11: one and a half page width

621

622 Fig. 11. Satellite gravity missions CHAMP (left), GRACE (center) und GOCE (right).

623 (Sources: CHAMP: GFZ Potsdam, GRACE: NASA, GOCE: ESA Medialab)

624

625 In these missions, three measurement concepts are implemented:

626 1. Observation of orbit perturbations of low-flying satellites due to the varying 627 gravitational attraction, by Global Positioning System (GPS), with an accuracy 628 of $2-3 \mathrm{~cm}$. Non-gravitational forces acting on the satellite, such as drag of the 629 residual atmosphere or solar radiation pressure, are measured by an 630 accelerometer and corrected for in the frame of the gravity field modelling 631 This satellite tracking technique between a low Earth orbiter (LEO) and high632 flying GPS satellites is called satellite-to-satellite tracking in high-low mode 633 (SST-hl), and is implemented in all three missions CHAMP, GRACE and 634 GOCE. It is the primary measurement technique of CHAMP.

6362 2. Observation of orbit differences (ranges) and their temporal change (range 637 rates) between two LEO satellites. This satellite-to-satellite tracking in low-low 638 mode (SST-II) concept is realized by the GRACE mission. It consists of two 639 identical satellites following each other on the same orbit with an average 640 distance of $200 \mathrm{~km}$. The inter-satellite ranging is performed by means of a K641 band microwave system with micrometer accuracy, and shall be done by laser 642 interferometry in future gravity missions in order to further increase the 643 ranging accuracy.

6453 . Observation of acceleration differences on very short baselines (satellite 646 gravity gradiometry, SGG), representing second order derivatives of the 647 gravitational potential $V$ in all three spatial directions. This concept was 
648 applied by the GOCE mission. Its core measurement, the gravity gradiometer, 649 was composed of 6 accelerometers fixed on 3 orthogonal axes symmetrically 650 around the center of mass of the satellite, measuring acceleration differences 651 on very short baselines of only half a meter in all three spatial dimensions.

652 The achievable performance of satellite gravity missions depends mainly on the 653 observation technique and the orbit altitude. Fig. 12 shows the performance of 654 different mission concepts in terms of the degree error median, which describes the 655 average signal or noise amplitude at a certain degree $n$ of the spherical harmonic 656 series expansion of the gravitational potential $V$ in spherical coordinates (with radius $657 r$, co-latitude $\vartheta$, longitude $\lambda$ ):

$$
V(r, \vartheta, \lambda)=\frac{G M}{R} \sum_{n=0}^{N_{\max }}\left(\frac{R}{r}\right)^{n+1} \sum_{m=0}^{n} \bar{P}_{n m}(\cos \vartheta)\left[\bar{C}_{n m} \cos (m \lambda)+\bar{S}_{n m} \sin (m \lambda)\right]
$$

660

661 where $G$ is the gravitational constant, $M$ the mass of the Earth, $R$ the mean Earth

662 radius, $\bar{P}_{n m}$ the fully normalized Legendre polynomials of degree $n$ and order $m$, and

$663\left\{\bar{C}_{n m}, \bar{S}_{n m}\right\}$ the corresponding (Stokes) coefficients (e.g Torge, 2001). Therefore, the

664 degree error median describes the achievable gravity field accuracy at a certain

665 spatial (half) wavelength $\lambda$. The wavelength $\lambda$ is linked to the harmonic degree $n$ by 666

667

$$
\lambda=20000 \mathrm{~km} / n
$$

668

669 As an example, a harmonic degree of $n=200$, which was the minimum target

670 resolution for the GOCE mission, corresponds to a spatial wavelength of $\lambda=$

$67120000 \mathrm{~km} / n=100 \mathrm{~km}$.

672 As a reference, the stippled black curve in Fig. 12 shows the gravity field

673 signal itself. Correspondingly, the cross-over point of a mission performance curve 
674 with the black stippled curve indicates at which harmonic degree the signal-to-noise

675 ratio is ' 1 '.

676

677 Figure 12: One and a half page width

678

679 Fig. 12. Absolute gravity signal and error estimates of different observation concepts

680 as a function of the harmonic degree $n$ (bottom axis) and spatial wavelength $\lambda$ (top

681 axis).

682

683 From the orbit information (SST-hl) only the long-wavelength features of the gravity

684 field can be extracted. Although this observation type is not a direct gravity field

685 functional, it can be interpreted as disturbing acceleration acting on the orbit, and

686 thus the first order spatial derivative of the gravitational potential $\partial V / \partial x_{i}$. As a

687 representative of this measurement concept, the grey dot-and-dashed line curve

688 shows the performance of the CHAMP-only model AIUB-CHAMP 03S (Prange,

689 2011), which is based on 8 years of CHAMP kinematic orbit data.

690 The grey curve shows the performance of the recent GRACE-only model

691 ITSG-Grace2014 (Mayer-Gürr et al., 2014), which is based on almost 11 years of K-

692 band inter-satellite ranging data following the SST-II concept (and supported by SST-

$693 \mathrm{hl}$ in the very low degrees). Compared to CHAMP, the superior measurement

694 principle of SST-II results in a significantly better accuracy in the low to medium

695 degree range as well as a higher spatial resolution. This can be explained by the fact

696 that the SST-II concept can be interpreted as a measurement of acceleration

697 differences on long baselines of about $200 \mathrm{~km}$. The excellent performance of GRACE

698 in this spectral range makes this mission sensitive to the tiny temporal variations of

699 the Earth's gravity field, which are 4 - 5 magnitudes smaller than the static signal.

700 The black solid curve shows the performance of GOCE, represented by the

701 GOCE-only model GOCE-TIM-R5 (Brockmann et al., 2014). It is mainly based on the 
702 measurement technique of SGG and again SST-hl in the low degrees, because SGG

703 alone (green curve) is weak in this spectral range due to the specific noise

704 characteristics of the gravity gradiometer instrument. Measuring acceleration

705 differences on very short baselines of about half a meter, which approximate second

706 order derivatives of the gravitational potential $\partial^{2} V /\left(\partial x_{i} \partial x_{j}\right)$, enables a further increase

707 of sensitivity for high-frequency signals. GOCE starts to become superior over

708 GRACE approximately at degree $n=115$.

709

$710 \quad 3.1$ Global Gravity Field Models

711

712 Gravity field models including GOCE data from the complete mission period

713 are meanwhile available. While the model GOCE-TIM-R5, which is based on the

714 time-wise approach (Pail et al., 2011), is based purely on GOCE data, GOCE-DIR-

715 R5, which is based on the direct method (Bruinsma et al., 2014), contains also

716 GRACE and satellite laser ranging (SLR) data. Further satellite-only models are, e.g.,

717 EIGEN-6S2 (Rudenko et al., 2014), or the S-models of the GOCO series (Pail et al.,

718 2010). The maximum degree of expansion of these models is driven by the resolution

719 of GOCE, and varies from $\mathrm{n}=280$ to 300 , corresponding to about $70 \mathrm{~km}$ spatial

720 wavelength. This makes clear that all medium scaled geological structures at

721 continental margins and elsewhere in the world which cause a significant gravity

722 effect can be detected (resolved) in the GOCE gravity field.

723 Combination models (notice the "C" in the field identifier) including also

724 terrestrial, air- and shipborne as well as altimetric gravity are, e.g., the already

725 mentioned pre-GOCE model EGM2008 (Pavlis et al. 2012), EIGEN-6C4 (Förste et

726 al., 2014), and GOCO05C (Fecher et al., 2013, 2016). These models extend the

727 spatial resolution beyond degree 2000 (which corresponds to $10 \mathrm{~km}$ wavelength).

728 However, it should be noticed that there are many regions with sparse and/or low-

729 quality terrestrial data, where it has to be questioned if such a high resolution is 
730 justified. This holds for many areas worldwide, e.g., the Central Andes in South

731 America and also for the passive continental margins of the South Atlantic.

732

733 3.2 Products for use in Earth sciences interpretation

734

735 Specifically regarding GOCE-related data, modelers and other users have the

736 choice among basically three representations of gravity field products:

737

738 3.2.1 Spherical harmonic coefficients

739

740 The most commonly used representation of the global gravitational potential $V$

741 is its series expansion into spherical harmonics (Section 3 ). There corresponding fully

742 normalized spherical harmonic (Stokes) coefficients $\left\{\bar{C}_{n m}, \bar{S}_{n m}\right\}$ represent the model

743 parameters, and are usually the target quantity when deriving the model from the

744 original gravity field data. The advantage of using this representation is that it can be

745 considered as a weighted average of the original measurement data, so that the

746 original noise level is significantly reduced due to this averaging. Based on the set of

747 spherical harmonic coefficients any arbitrary gravity anomaly can be derived at the

748 Earth's surface or at any height in outer space. All the global gravity models

749 discussed above are given in this parametrization.

750

751 3.2.2 Original gravity gradients along the satellite's orbit

752

753 In principle, also the gravity gradient time series for all six tensor components

754 measured along GOCE's satellite orbit can be used for geophysical modelling (refer

755 e.g. to Fig. 3). They represent the most original measurements. However, it has to be

756 considered that they are measured in a rotating reference frame, the so-called

757 "gradiometer reference frame" (GRF), which means that tensor rotations of the base 
758 functions have to be applied to exploit them to the best possible extent. Additionally,

759 they are affected by the colored noise characteristics of the GOCE gradiometer (Pail

760 et al., 2011), so that a single point-wise gravity gradient observation is affected by

761 large instrument noise, and therefore by itself has a low signal-to-noise ratio. All

762 these drawbacks make it difficult to use this data type directly for geophysical

763 modelling.

764

765 3.2.3 Gravity gradient grids

766

767 A reasonable compromise between the use of spherical harmonics and 768 original gravity gradients (see above) results in the use of gravity gradient grids, 769 which are usually defined in a well-oriented radial (North-East-up) frame at a constant 770 altitude. They are computed from the original gravity gradients defined in the GRF by 771 means of regional gravity processing methods. In fact, they are the spatial equivalent 772 of the spherical harmonic representation, but much easier to use and interpret. Pure 773 GOCE gravity gradient grids result from the space-wise method (Gatti and 774 Reguzzoni, 2015). In the frame of the ESA project GEOExplore global grids of all six 775 components of the gravity gradient tensor, based on a combination of GOCE and

776 GRACE data, and defined in a radial Earth-fixed reference frame at two altitudes of $777225 \mathrm{~km}$ and $255 \mathrm{~km}$, have been derived (Bouman et al., 2015). Since these grid 778 values are products of "averaging" original gradient data, the error level should be 779 similar as that of gradients synthesized from global spherical harmonic models.

780 There is an ongoing discussion whether the gradient data contain more (high781 frequency) signal than global gravity models that have been derived from them. The 782 answer to this question lies in the constraints applied to these models. Constraints 783 applied to global gravity models are usually designed to optimize the signal-to-noise 784 ratio on a global scale. This means that in regions of very rough topography and 785 therefore high-frequency gravity signals there is the tendency to constrain the system 
786 too strongly. Regional gravity solutions techniques, which are usually applied to

787 generate gridded gravity gradient products, allow for regionally optimized constraints,

788 but on the cost of global homogeneity. In Pail et al. (2015b) it could be shown, that

789 compared to global models the gravity gradient grids are affected by a higher noise

790 level.

791 The achievable accuracy and sensitivity of current gravity field models or

792 corresponding gravity (gradient) grids can be expressed by cumulative quantities,

793 which describe the estimated cumulative error at a certain harmonic degree (or the

794 corresponding spatial wavelength). Fig. 13 shows cumulative gravity anomaly errors

795 (a), as well as cumulative vertical gravity gradient errors at GOCE satellite altitude of $796250 \mathrm{~km}$ (b), and ground level (c), for the GRACE models ITSG-GRACE2014s, the

797 pure GOCE model GOCE-TIM-R5, the combined satellite-only model GOCO05S and

798 the combined models EGM2008 (pre-GOCE) and GOCO05C (including GOCE data).

799 From Fig. 13 we can learn which geological structure at passive continental

800 margins (or elsewhere) can be resolved by the different gravity model types.

801 Assuming that the geological structure/mass anomaly generates a gravity anomaly

802 with a certain spatial wavelength on the Earth's surface, Fig. 13a then provides the

803 accuracy in mGal with which this anomaly can been captured. (The connection from

804 the size of a disturbing body to the resulting gravity signal is made in Fig. 3.). As an

805 example, a gravity signal with $100 \mathrm{~km}$ spatial wavelength at the Earth's surface could

806 be measured by satellites with an accuracy of about $0.5 \mathrm{mGal}$ (black dashed and

807 solid grey curves). It can clearly be seen that the accuracy for shorter wavelength

808 signals dramatically decreases, and is already larger than 2 mGal for gravity signals

809 with approx. $80 \mathrm{~km}$ spatial wavelength. Beyond this resolution, satellites cannot

810 significantly contribute anymore, and high-accuracy terrestrial information, as it was

811 included, e.g., in

812

813 
815 Figure 13: Full page width

816

817 Fig. 13. Cumulative gravity anomaly errors in (mGal) (a); vertical gravity gradient

818 errors in (mE) at $250 \mathrm{~km}(\mathrm{~b})$, and ground level (c). This figure shows the generally

819 dramatic increase of the gravity gradient errors at ground level as a result of

820 downward continuation.

821

822

GOCO05C (solid black curve), is necessary to resolve smaller-scale 823 geological structures. This becomes immediately clear if looking at the series of Figs.

82414 through 21: most of the anomaly sizes at the margins of the South Atlantic are 825 smaller than $80 \mathrm{~km}$. On the other hand we state that the regional gravity field caused

826 at the ocean-continent transition can satisfyingly be resolved by satellite only models

827 (S models). Fig. 13a also shows the major step forward due to satellite missions 828 compared to pre-GOCE models such as EGM2008 (black dot-and-dashed line) 829 especially in the long to medium wavelengths for gross interpretations at a 830 continental scale.

831

832 Fig. 13b shows a similar representation when using gravity gradients at 833 satellite altitude as basis information for geophysical modelling of geological 834 structures. Pure GOCE-only models such as GOCE-TIM-R5 (dashed black curve) 835 provide gravity gradients at satellite altitude with standard deviations of $0.45 \mathrm{mE}$ for 836 gravity signals with a spatial resolution of $100 \mathrm{~km}$. These values can be decreased 837 further to $0.25 \mathrm{mE}$ by combination with GRACE information, as it was done, e.g., in 838 the GOCO05S model (solid grey curve). Evidently, GRACE alone (dashed grey 839 curve) results in very high error amplitudes in the higher degrees, demonstrating the 840 dominant impact of GOCE at shorter wavelengths. Modern combined gravity models 841 such as GOCO05C (solid black curve) further increase the performance in the short- 
842 wavelength range by complementing the satellite data by ground data over the

843 continents and satellite altimetry over the oceans. Also here the improvement

844 compared to pre-GOCE combined models such as EGM2008 (black dot-and-dashed

845 line curve) is significant. Recently gradients of the satellite gravity field came into the

846 focus for modelling purposes which can support interdisciplinary interpretations

847 (Ebbing et al., 2013; Schaller et al., 2015; Götze, 2015).

848 In Fig. 13b a very interesting feature is the flat curve of the combined gravity

849 model GOCO05C beyond degree 250. This results from the fact that beyond this

850 degree the signal amplitude of gravity gradients is already below the mE level, i.e.,

851 due to signal attenuation with altitude there is no significant gradient signal left in orbit

852 altitude beyond this degree, because most parts have been "filtered out" due to

853 upward continuation. Inversely, this also means that GOCE has captured $97 \%$ of the

854 amplitude of the gradient signal that exists in orbit altitude.

855 The picture changes completely (Fig. 13c) when continuing the gradient 856 information down to ground level. Here the GOCE model (black dashed curve) and 857 the GOCE+GRACE combination (solid grey curve) perform practically identical, again

858 showing the dominance of GOCE compared to GRACE at shorter scales. However,

859 also here for gravity signals with spatial scales below $80-100 \mathrm{~km}$ a combination with

860 terrestrial/airborne gravity information is necessary to achieve acceptable accuracies

861 (solid black curve), so that the gravity field information can be used for local

862 geophysical modelling of short-scale density structures.

863

8643.3 Not always in focus: the omission error

866 In order to perform a complete evaluation of the impact of modern satellite 867 missions for deriving density structure of continental margins, one of the most 868 important aspects is the evaluation of the omission error. It results from high869 frequency signals, which cannot be resolved by satellite gravimetry due to the 
870 exponential signal attenuation with altitude. These missing signals of satellite-only

871 models are an important issue for the determination of near-surface density

872 variations, but also shallow lithospheric structures.

873 Fig. 14 shows gravity anomaly fields for the South Atlantic region. Fig. 14 a is

874 based on the GOCO05S model resolved up to its maximum resolution of degree $n=$

$875280(\sim 70 \mathrm{~km})$, while Fig. $14 \mathrm{~b}$ displays the free-air gravity anomalies based on

876 EIGEN-6C4 with its maximum resolution of degree $n=2160(10 \mathrm{~km})$. Comparing

877 these two figures, the current limits of satellite-only models regarding their spatial

878 resolution becomes evident, and can only be coped with by combination with

879 complementary data sources from terrestrial/airborne/shipborne gravimetry, and

880 satellite altimetry over the oceans, as it was done in EIGEN-6C4. An estimate of the

881 omission error (Fig. 14 c) for satellite gravity models is given by the difference of

882 EIGEN-6C4 and GOCO05S, being equivalent to the difference of the Figs. 14 a and

883 b. Evidently, very rough topographic and bathymetric structures, generating high-

884 frequency gravity field anomalies and steep slopes, cannot be resolved by the

885 satellite data. However, usually these topographic features are not the main focus of 886 geophysical modelling and interpretation, but rather sub-surface lithospheric

887 structures. Therefore, a topographic reduction was applied, using the

888 RWI_TOPO_2015 topographic potential model (Grombein et al., 2015) and thus

889 taking away the effect of topographic masses up to zero level: $\delta g_{\text {TOP }}+\delta g_{\text {BPL }}$. The so

890 called "mass reduction effect" was already introduced in Fig. 6. The result is a

891 significantly reduced omission error (Fig. 14 d).

892 This difference field in Figs. $14 \mathrm{c}$ and $\mathrm{d}$ can be considered as errors made

893 when computing Bouguer anomalies from pure satellite models, which are then

894 further used for lithospheric modelling. Table 1 gives an overview of the main

895 statistical parameters of the gravity anomaly fields shown in Fig. 14.

896

897 Figure 14: Full page width 
899 Fig. 14. Free-air gravity anomalies (mGal) of the South Atlantic region based on

900 satellite-only model GOCO05S (a) resolved up to degree 280 , combined gravity

901 model EIGEN-6C4 (b) resolved up to degree 2160, omission error of a satellite-only

902 model (c) and omission error after reduction of topographic signals (d).

903

904 Table 1: Main statistical parameters of gravity fields of the South Atlantic region.

905

906

\begin{tabular}{|l|c|c|c|c|}
\hline Gravity field & Figure & $\begin{array}{c}\min \\
\text { (mGal) }\end{array}$ & $\max$ (mGal) & $\begin{array}{c}\text { std.dev. } \\
\text { (mGal) }\end{array}$ \\
\hline GOCO05S (d/o 280) & $14 \mathrm{a}$ & -199.8 & 116.1 & 18.8 \\
\hline EIGEN-6C4 (d/o 2160) & $14 \mathrm{~b}$ & -227.7 & 453.8 & 21.3 \\
\hline GOCO05S omission error & $14 \mathrm{c}$ & -166.7 & 415.1 & 10.8 \\
\hline $\begin{array}{l}\text { GOCO05S omission error, } \\
\text { topo-reduced }\end{array}$ & $14 \mathrm{~d}$ & -143.1 & 112.8 & 7.1 \\
\hline
\end{tabular}

907

908 4. Benefits for combined interpretations

909

$910 \quad$ However, in relation with the two key questions asked in Section 2.3

911 (processing, quality and secondly availability for interpretations at continental

912 margins) we have to respond to them in the light of interpretations of solid Earth

913 structures. For example a precise geoid can be used to identify global and deep

914 anomalies related to mantle lithosphere and deeper structures. Gravity anomalies,

915 being first order radial derivatives of the gravitational potential, are sensitive to gravity

916 effects of the entire lithosphere, and in particular to the crustal and upper crustal

917 structures and density variations e.g. at active and passive continental margins. As it

918 has been shown above (Fig. 14), each combination of satellite gravity data with 
919 terrestrial gravity data can be used for all interdisciplinary interpretations techniques,

920 e.g., "back stripping" in basin modelling at the African continental margin (Dressel et

921 al. 2015) which also includes thermal subsidence in the reconstruction of the passive

922 margins through time or 3D modelling of Moho undulations. The new database was

923 also used to reconstruct the Gondwana continent (Braitenberg, 2015). Fig. 15 refers

924 to the isostatic residual anomaly in the Southern Atlantic. It was calculated by Klinge

925 (2016) on base of the corresponding formula for "ISA" in Section 2.3 and the EIGEN-

$9266 \mathrm{C} 4$ model also portrayed in Fig. 14 (b).

$927 \quad$ Both anomaly maps are rather similar and caused by the main tectonic

928 features of the South Atlantic: the "highs" which are caused by the Mid Atlantic ridge,

929 the extended "lows" of the four basins in front of South America (Argentinean and

930 Brazilian basins) and South Africa (Cape and Angola basins). The hotspot trail (e.g.

931 Torsvik et al., 2009 among others) is visible in the structure of the SW-NE trending

932 Walvis Ridge offshore South Africa and the corresponding trace of the Rio Grande

933 Rise at the western side. To the North of the Romanche Fracture Zone between

934 Fortaleza in the west and Lagos in the East the Sierra Leone Rise is located. Even

935 the regions of salt deposits offshore Brazil and West Africa (blueish colors indicating

936 low gravity values) and the magmatic margins at both sides of the margins (reddish

937 colors and high gravity values) can be distinguished in the satellite derived fields. The

938 very short wavelengths in the gravity field correspond to masses that are located in

939 the crust and lithosphere - they were already mentioned in the sketch of Fig. 8 and

940 mark places of different density contrast at the margins. Other examples were given

941 in Bouman et al. (2014), Gutknecht et al. (2014), and Hosse et al. (2014).

942

943 Figure 15: one and a half page width

944

945 Fig. 15. The isostatic residual field was calculated by Klinge (2016) in the framework 946 of his MSc thesis. Reference depth $T_{0}=30 \mathrm{~km}$ and $\mathrm{T}_{\mathrm{e}}=20 \mathrm{~km}$ (elastic thickness 
947 which was kept constant over the entire area). The figure shows the residual gravity

948 field in the Southern Atlantic Ocean of the combined EIGEN-6C4 model (Förste et al.,

949 2014). It correlates well with bathymetric/topographic structures e.g. the Mid Atlantic

950 Rift (MAR) and portrays also the effect of geological bodies: the positive anomalies in

951 the area of Windhoek and Buenos Aires. Along the Mid-ocean rift axes positive

952 anomalies of up to $40 \mathrm{mGal}$ exist. MAR = Mid Atlantic rift.

953

954 4.1 The continental margins of the South Atlantic

955

956 New light can be shed on the gravity structures of South Atlantic oceanic

957 margins at regional (Figs. 16, 17, 19 and 20) and more local scales (Figs. 18 and 21).

958 By the help of these new compiled maps we will show that modern satellite gravity

959 fields described in Section 4 can support (1) interpretations of the lithospheric

960 structures in the South Atlantic and its passive margins and (2) provide much more

961 details in the gravity field than it was showed along the oversimplified profiles of Figs.

9627 and 8.

963 With reference to the Fig. 14, the following sequence of Figs. $(16-21)$ contains

964 always the same information for comparative reasons: the two gravity fields based on

965 the "satellite only" model GOCO05S (a) and the "combined model" EIGEN-6C4 (b),

966 and additionally Figs. 18 and 19 include the omission errors without (c) and with (d)

967 calculated topographic reductions.

968 Table 2 provides a summary of the standard deviations of the gravity fields

969 shown in these figures. $\mathbf{d} / \mathbf{o}$ refer to the spherical harmonic analysis: to degree and

970 order of the expansion.

971

972 Table 2: Standard deviations (mGal) of the gravity fields shown in Figures 16 to 21.

\begin{tabular}{|l|l|l|l|l|l|}
\hline Region & Figure & GOCO05S & EIGEN-6C4 & GOCO05S & GOCO05S \\
\hline
\end{tabular}


973

\begin{tabular}{|l|c|c|c|c|c|}
\hline & & $(\mathrm{d} / \mathrm{o} 280)$ & $(\mathrm{d} / \mathrm{o} 2160)$ & $\begin{array}{c}\text { omission } \\
\text { error }\end{array}$ & $\begin{array}{c}\text { omission } \\
\text { error, topo- } \\
\text { reduced }\end{array}$ \\
\hline $\begin{array}{l}\text { Argentinean } \\
\text { coast }\end{array}$ & 16 & 22.4 & 24.6 & 9.8 & 7.1 \\
\hline Brazilian coast & 17 & 15.9 & 18.8 & 10.8 & 6.3 \\
\hline Falkland Bank & 18 & 24.4 & 25.3 & 7.3 & 5.9 \\
\hline African coast & 19 & 19.3 & 21.5 & 10.6 & 7.3 \\
\hline $\begin{array}{l}\text { Equatorial } \\
\text { African margin }\end{array}$ & 20 & 19.3 & 23.9 & 14.3 & 9.8 \\
\hline $\begin{array}{l}\text { Tristan da Cunha } \\
\text { isle }\end{array}$ & 21 & 6.9 & 12.3 & 10.3 & 4.8 \\
\hline
\end{tabular}

974

975

Continental gravity edge effects indicate a fast change from positive to

976 negative anomalies as it is normal for the transition from oceanic to continental crust.

977 In Fig. 16 the positive anomalies indicate in the offshore area the seaward dipping

978 reflectors (SDR) which are of magmatic origin (e.g. Blaich, 2011; Franke et al. 2006;

979 Section 2). The negative anomalies (greenish and blueish colors) offshore are

980 caused by the sedimentary infill of the margin basins e.g. Colorado and Salado (e.g.

981 Autin et al., 2013; 2016). Onshore positive anomalies follow W-E trending

982 topographic features (Salado and Colorado Basin) and in the western continental part

983 of the maps the topography of the Southern Central Andes.

984

985 Figure 16: Full page width

986

987 Fig. 16. Detailed picture of the free-air gravity field along the Argentinean coast

988 compiled by the GOCO05S (a) and the EIGEN-6C4 (b) models. The lower two 
989 figures indicate the omission errors without (c) and with topographic correction (d).

990 For more information refer to manuscript. The continental areas are marked by

991 transparent overlays.

992

993 In general the series of the following figures will portray similar gravity

994 anomalies (both magnitude and trend of anomalies). It is no wonder that all EIGEN-

$9956 \mathrm{C} 4$ compilations consist of more structural details than the GOCO05S models which

996 base on data in the orbit height of some $250 \mathrm{~km}$ where small local gravity anomalies

997 are not detectable.

998 Figs. 17 (a) and (b) shows that the "central Atlantic segment" is dominated by

999 high density rocks which cause positive anomalies. The positive gravity offshore

1000 between $40^{\circ}-30^{\circ}$ longitude is caused by the "Rio Grande High" which marks the

1001 most western edge of the hot spot trace which starts at the position of the Tristan da

1002 Cunha hotspot area. The negative gravity anomalies close to the Brazilian coast are

1003 caused by negative densities of salt accumulation here (Mohriak, 2014). The SDRs

1004 with their high rock densities (Section 2.2) of the southern segment are not

1005 documented here with high resolution; they are too small to be resolved in detail as

1006 we show already in Fig. 3. However, at a larger scale the belt of positive gravity

1007 marks the area of SRDs quite well.

1008

1009 Figure 17: Full page width

1010

1011 Fig. 17. The gravity fields (a) GOCO5S and (b) EIGEN6C4 along the Brazilian coast

1012 and offshore regions of the "central segment" of the southern Atlantic. Figures

1013 content is equal to Figs. 14 and 16. However the omission errors are not portrayed

1014 here.

1015 
1016 The resolution of gravity anomaly in the off-shore area of the Falkland Bank

1017 and the Scotia Plate with the Eastern Sandwich trench allows the separation of

1018 subduction related trench lithosphere, the eastern border of the Sandwich Plate, and

1019 the southern rim with the Antarctic Plate (low gravity corresponding to blueish colors

1020 in Fig. 18) from high density rocks of the Scotia Plate and Sandwich Isles (yellow and

1021 reddish colors in Fig. 18 ( $a$ and b). Exactly here in a region with rather complex

1022 interplay of different plates the resolution of gravity fields before the era of the

1023 modern satellite missions was extremely low and often hindered a tectonic

1024 interpretation of lithosphere at medium scale. The Scotia Plate in the center (reddish

1025 colors in Fig. 18) is clearly separated from the other plates of the region (South

1026 American plate to the North, Antarctic plate to the South, Scotia plate to center.

1027

1028 Figure 18: One and a half page width

1029

1030 Fig. 18. The gravity field of the Falkland bank and the Scotia plate with the eastern

1031 South Sandwich trench after the processing of new satellite gravity (GOCO5S: (a)

1032 and EIGEN6C4: (b). Figures content is equal to Fig. 14.

1033

1034 Due to the symmetry of evolution of the South American and South African

1035 margins also the gravity field of the western African margin shows the same general

1036 features as it was exemplified for the South American margin: in the southern

1037 segment the magma dominated structures cause small positive gravity anomalies

1038 and North of the Walvis Ridge the area of salt layers is characterized by negative

1039 anomalies (blueish colors) in Fig. 19. The SW - NE trending Walvis Ridge separates

1040 the domains of magmatic material from salt layers. Positive gravity anomalies of the

1041 ridge clearly indicate the Tristan da Cunha hotspot trace - as it was already

1042 explained for the western part of the Southern Atlantic. More to the South at the

1043 South African tip of the Cape a second ridge (Agulhas Ridge) can be identified. 
1044 Onshore at the African continent close to the equator the extended gravity low (-50

$1045 \mathrm{mGal}$ ) of the Congo Basin with its thick sediments dominates the gravity picture.

1046

1047 Figure 19: full page width

1048

1049 Fig. 19. The gravity field of the African margin in the central and southern segment

1050 (Fig.15) after the GOCE gravity (a) and the EIGEN-6C4 data (b) processing. The

1051 series of maps correspond to the displayed formats of figures before; transparent

1052 overlay mark continental area.

1053 One of the most spectacular fracture zones in the Equatorial and Northern

1054 South Atlantic connecting Africa and South America is illustrated in Fig. 20 (a and b).

1055 Fairhead and Wilson (2005) explain the formation of the fracture system with

1056 processes which were related with the opening of the Central and South Atlantic.

1057 They state that a differential motion between plate segments was absorbed in the

1058 Caribbean and West and Central African rift systems. The fracture system developed

1059 due to the temporal different opening phases of the northern and southern Atlantic.

1060 Then the two independent spreading centers joined a major shear zone developed

1061 between West Africa and the northern margin of Brazil. The maps of satellite gravity

1062 image impressively this major shear zone. The gravity map of the EIGEN6C4 model

1063 provides a clear and sharp picture of the fractures zones.

1064

1065 Figure 20: One a a half page width

1066

1067 Fig. 20. The two gravity fields (GOCO5S (a) and EIGEN (b)) of the Equatorial Atlantic

1068 Ocean map major transform structures offshore the African margin. Sequence of

1069 maps corresponds with displayed formats of figures before; transparent overlay mark

1070 continental area.

1071 
1072 The limits of resolution of modern satellite only gravity fields (S models) can

1073 nicely be demonstrated by the gravity field of the Tristan da Cunha Isle, whose

1074 gravity field signal is at the edge of the spatial resolution of current satellite gravity

1075 missions. Fig. 21 shows that although GOCE is able to detect the gravity field signal

1076 of this island, it is significantly damped. It should be emphasized, that a constraint

1077 has been applied to the GOCO05S model in the frame of the gravity modelling

1078 procedure in order to improve the signal-to-noise ratio at higher degrees, i.e. noise is

1079 filtered out at the cost of damping also the signal. As already discussed in

1080 Section 3.2, the strength of constraining the solution was optimized on a global scale.

1081 Therefore, it is not tailored to small regions with strong gravity field signal, where a

1082 weaker constraint would be preferable due to a larger signal-to-noise ratio in this

1083 region compared to the global average. If the satellite gravity solution were optimized

1084 for this specific region, it can be expected that in such a regionally tailored solution

1085 slightly more signal could be retained. The series of Figs. 21 (a) -21 (d) shows that

1086 the satellite gravity fields of both GOCE and EIGEN-6c4 are mainly caused by the

1087 topography of the island. Perfectly seen is the "ring" of negative anomalies in Fig. 21

1088 (b) which can be explained by the flexure of oceanic lithosphere due to isostatic

1089 response of the loaded isle masses. After calculating a topographic correction (Fig.

$109021(\mathrm{~d}))$ an anomaly of some 20 mGal appears. One may speculate if this negative

1091 anomaly is caused by a mass deficit which is related to the hot spot or to crustal

1092 thickening..

1093 The statistics in Table 2 shows that for such rather small-scale structures the

1094 amplitude of the omission error can be larger than the signal captured by GOCE.

1095 However, Fig. 21d shows that significant parts of this high-frequency gravity signal

1096 result from topography.

1097

1098 Figure 21: one a half page width 
1100 Fig. 21. The Free Air gravity field of the Tristan de Cunha area after the GOCE (a)

1101 gravity and EIGEN-6C4 (b) data processing. Sequence of the four maps corresponds

1102 with displayed formats of figures before; omission error without (c) and (d) with

1103 topographic correction. The limits of resolution of satellite observations can nicely be

1104 demonstrated by these gravity fields.

1105

1106 Figure 21a: Small column size

1107

1108 Fig. 21a. In addition to what we interpret in Fig. 21 this sketch can explain the typical 1109 negative ring around the positive anomaly in the last figure: the central mass causes

1110 the positive anomaly while the sediments around the central mass cause a

1111 symmetrical gravity low. The extent of deformed crust below the mass crust depends

1112 on the rigidity of the surrounding crust: the left situation (rigidity R1) demonstrates a

1113 case with extreme high rigidity, on the right a lower crustal rigidity R2 was assumed.

11154.2 Validation of terrestrial gravity by GOCE data

1117 The GOCE mission provided not only new geoid and gravity fields, but also

1118 gravity gradient data. Representing the second derivatives of the gravitational 1119 potential, they are more sensitive to the density structures of the upper crust than 1120 gravity data normally are. Additionally, gravity gradients provide a better resolution of 1121 flanks of geological structures, faults, lineaments or even large intrusions at 1122 continental margins. Gradient data from satellite missions have the potential to 1123 identify the extent of different structures with varying densities even in the lower crust 1124 (e.g. Ebbing et al., 2013). Panet et al. (2014) even identify correlations of certain 1125 components of the gravity gradient tensor with lower mantle structures.

1126 For gravity interpretations at larger wavelengths the new satellite gravity 1127 database will help to identify a density zonation and segmentation in horizontal and 
1128 vertical directions in the lithosphere. As shown in Section 3.2, GOCE satellite-only

1129 gradient data provide a spatial (horizontal) resolution in the range of less than 100

$1130 \mathrm{~km}$. However, for many structures - in particular for offshore studies of Applied

1131 Geophysics - this spatial resolution is not yet sufficient, because smaller crustal

1132 structures cause anomalies with smaller spatial wavelengths. Therefore, terrestrial

1133 and airborne gravity measurements have not become obsolete even in the modern

1134 satellite era, but on the contrary they complement satellite observations on the short-

1135 wavelength scale where satellite data lack sensitivity.

1136 In addition to their very high accuracy in the long to medium wavelength 1137 range, modern satellite gravity data definitely provide significant added value in the 1138 geophysical gravity fields processing domain, especially for:

1139 a) Validation of heterogeneous terrestrial gravity data bases and identification $1140 \quad$ of outliers;

1141 b) Fill-in of regions with sparse terrestrial data coverage or even data gaps.

1142 As an example of the first task (a), Fig. 22 a shows the difference between a

1143 terrestrial gravity data base of South America and GOCO05S, resolved up to

1144 degree 200. To bring them to the same spatial resolution, the terrestrial data have

1145 been expanded as part of a global $0.25^{\circ} \times 0.25^{\circ}$ terrestrial gravity anomaly grid into a

1146 spherical harmonic series to degree 720 , and then have been cut at degree 200. Fig.

114722 a clearly indicates systematic differences, which can be attributed to errors of the

1148 terrestrial data, because of the globally homogeneous accuracy of less than $1 \mathrm{mGal}$

1149 for the satellite model. Based on this result, the terrestrial database can be further

1150 screened for outliers and suspicious observations (either of the gravity value itself or

1151 the attached height information, Hosse et al., 2014 ). This information can then be

1152 used to derive empirical error estimates of the terrestrial dataset, which can be further

1153 used for a spatially depending weighting scheme in the frame of a combined solution

1154 with satellite data (Fecher et al., 2013, 2016). The implicit assumption is that the data

1155 quality of a terrestrial observation is already reflected in its long-wavelength 
1156 component. By means of this procedure, satellite data get a higher weight in regions

1157 where a lower accuracy of terrestrial data is suspected.

1158

1159 Figure 22: Full page width

1160

1161 Fig 22. (a) Gravity anomaly differences (mGal) between a South American terrestrial

1162 database (kindly provided by the US National Geospatial-Intelligence Agency) and

1163 GOCO05S, consistently resolved up to degree 200; b) empirical error estimates

1164 (mGal) derived from the difference field (after: Fecher et al. (2015), modified).

1165

1166 It should be emphasized, that this validation procedure can be applied in any

1167 region on Earth. Thereby, a globally uniform satellite gravity model provides the

1168 chance to estimate a-posteriori the accuracy and reliability even of historical gravity

1169 data bases (terrestrial, ship- and air-borne), for which only incomplete or even no

1170 meta-information about the measurement process and conditions is available.

1171 Also Bomfim et al. (2013) describe how gradients of the GOCE mission can

1172 help to estimate systematic errors in terrestrial gravity data in the cratonal basins

1173 (e.g. Amazon and Parnaiba Basins) in Brazil. Here they calculate an average value of

1174 terrestrial gravity anomaly and compare its long-and medium-wavelength content of

1175 the terrestrial gravity with the GOCE gravity field. The analysis shows that where

1176 terrestrial data are sparse and therefore require an improvement in data coverage,

1177 satellite data can be substituted in order to represent the gravity field correctly. The

1178 method they proposed can be used directly to control other gravity databases and

1179 constitutes as a tool for the quality assessment of terrestrial gravity observations,

1180 both on- and offshore.

1181 The second task (b) also addressed the heterogeneity of terrestrial gravity 1182 data. There are many regions worldwide where terrestrial data are of very bad quality 
1183 or not available/accessible at all (refer to Fig. 2). In these regions, data from satellite

1184 gravity missions are the only available data source.

1185 These examples demonstrate, that although satellite missions provide (only)

1186 long to medium wavelength gravity field data, they are able to provide new gravity

1187 field information especially in regions where up to now the gravity field has been

1188 practically unknown. This regional model can then been used as constraint for an

1189 improved lithospheric density model and the derivation of the state of stress of the

1190 subduction zone (Gutknecht et al., 2014), clearly demonstrating the added value of

1191 GOCE especially in these data-critical onshore regions.

1192

1193 5. Conclusions and outlook

1194

1195 The resolution of "satellite only data" up to now does not fall below a resolution of

$119680-100 \mathrm{~km}$. This is still the borderline for studies presented in the above mentioned

1197 Sections. In summary we have to say that rather small complex structures related

1198 e.g. to the "seaward dipping reflectors at passive continental margins (SDR)" with

1199 small size and density contrast cannot be resolved as separated anomalies in the

1200 orbit heights of recent satellite missions (e.g. Schaller et al. 2015). For this purpose

1201 terrestrial gravity data have to be combined with satellite data in gravity models e.g.

1202 GOCO5C. The interpretations of Section 4.1. showed that gravity and its gradients

1203 from the modern satellite missions support interpretations at a medium scale - at

1204 passive continental margins and elsewhere.

1205 Modelers of lithospheric structures at continental margins hope that medium scale

1206 gravity data from the recent and future satellite missions (GRACE and/or GOCE;

1207 GRACE follow on) can support combined interpretation together with seismological

1208 and gravity studies. For rather local models (wavelengths of gravity anomalies are

1209 smaller than $20 \mathrm{~km}$ ) both resolution and quality of satellite only gravity data have to

1210 be seen still reluctant until today. However, there is no doubt that combinations with 
1211 terrestrial gravity data bases and satellite gravity with a spatial resolution of $10-20$

$1212 \mathrm{~km}$ can provide detailed insight in the structural behavior of continental margins.

1213 For modelling at continental scales Fig. 2 demonstrated that terrestrial databases

1214 often are of inhomogeneous distribution (e.g. in South America), just if gravity data

1215 are sampled over long time-consuming field campaigns with big human efforts: there

1216 remain big gaps in the data base. They are mainly caused by limited access to the

1217 terrain in remote areas of the world - high mountains, deserts, swamps and jungle.

1218 Even more field procedures and technical instrumentation varied over time and

1219 together with missing other metadata a homogeneous data base can be established

1220 only with big effort and high costs. Here the new data bases already helped in a

1221 spectacular way: Hosse et al. (2014) and Gutknecht et al. (2014) replaced the

1222 incomplete terrestrial gravity data base by homogeneously measured satellite gravity

1223 and gravity gradient data for lithospheric modelling. New data were applied to the

1224 calculation of GPE (gravity potential energy), stress distributions and combined

1225 interpretation of complex geologic structures. Satellite gravity information was also

1226 used for validation and cleaning of inhomogeneous gravity databases taking the

1227 benefit of very homogeneous error characteristics and accuracy of global satellite

1228 gravity data (Hosse et. al, 2014; Bomfim et al., 2013). The high spatial resolution of

1229 terrestrial gravity combined with the homogeneous lower-orbit satellite data leads to

1230 more detailed and better-constrained lithospheric density models, and hence

1231 improves our knowledge about structure, evolution and state of stress in the

1232 lithosphere basing on the consistency in the long-to-medium wavelengths, down to $123310-50 \mathrm{~km}$.

1235 At the beginning (Section 1.1) we mentioned the calculation/recalculation of the

1236 COB from an integrated interpretation of gravity, magnetic, seismic, electrical

1237 methods and geology (Torsvik et al., 2009). We did not deal with the calculation of 1238 COB, however, we think that the combined satellite fields can successfully replace 
1239 the terrestrial gravity data which have to be used in former times. Because we

1240 analyzed Free Air gravity from the GOCE mission, in Fig. 23 topographic features on-

1241 and offshore are enhanced. These enhancements indicate clearly the slopes of the

1242 continental shelf regions of the Southern Atlantic.

1243

1244 Figure 23: Full page width

1245

1246 Fig. 23. The third derivations of the gravitational potential and the resulting total

1247 gradient of the vertical gravity gradient were calculated from the GOCO5C model

1248 (expansion to degree 720). It provides already good insight into local gravity field

1249 structures particularly at the margins by the derivations of the vertical gradient $\left(V_{z z}\right)$.

1250

1251 In the near future complementary information from seismic and magnetics

1252 could be included in a joint inversion for lithospheric modelling also at passive

1253 continental margins. ESA's magnetic field mission Swarm was successfully launched

1254 in November 2013 and provides valuable information of the long to medium

1255 wavelength Earth's magnetic field and its temporal variations with an accuracy on the

1256 nT- (nano tesla) level (http://esamultimedia.esa.int/multimedia/publications/BR-302/).

1257 The value of the mission for the determination of the crustal remanent magnetic field

1258 will increase in the future, because the three satellites will continuously lower their

1259 orbit altitudes during mission lifetime, thus also increasing their sensitivity for detail

1260 magnetic field structures. However, a joint interpretation of remanent magnetic and

1261 gravity field is only possible in the case of common sources, i.e. similar contrasts in

1262 density and magnetization. In this case Poisson's equation can be applied, which

1263 links the magnetic and gravity potential fields. Swarm is already now a very valuable

1264 tool to determine the electric conductivity of the Earth's mantle and thus provides very

1265 important information on the thermochemical and compositional structure of the

1266 Earth. 
1267 Several concepts for future satellite mission constellations to explore the

1268 Earth's potential fields are under development and investigation. A strong need by

1269 the user communities was expressed in terms of a joint IUGG resolution adopted at

1270 the IUGG General Assembly 2015 (IUGG, 2015). The science requirements and user

1271 needs for a future gravity field mission constellation were consolidated (Pail et al.,

1272 2015a) also under active participation of the geophysical user community. In addition

1273 to an improved temporal resolution for the detection of co- and post-seismic

1274 deformation, an increased spatial resolution together with an improved accuracy will

1275 shift the capabilities to use satellite-based gravity observations for geophysical

1276 interpretation in passive continental margins, and elsewhere, to even more small-

1277 scale structures.

1278

\section{Acknowledgements}

1280

1281 The research partly described here in this paper was part of the Priority Program

1282 SAMPLE (South Atlantic Margin Processes and Links with onshore Evolution). It is

1283 financed by the Deutsche Forschungsgemeinschaft (DFG), Bonn which is thankfully

1284 acknowledged. HJG thanks M. Scheck-Wenderoth and members of her research

1285 team at GeoForschungsZentrum Potsdam for their continuous interest and many

1286 fruitful discussions over the last years. The satellite part of the paper was elaborated

1287 in a second DFG Priority Program "Mass Transport and Mass Distribution". HJG and

1288 RP are deeply grateful to their research teams at the Christian Albrechts Universität

1289 Kiel, Technische Universität München and Friedrich-Schiller-Universität, Jena. We

1290 thank Reiner Rummel and Jörg Ebbing for their intensive "test reading" and fruitful

1291 suggestions. Carla Braitenberg, Bruno Meurers and an anonymous reviewer

1292 improved an earlier version of the paper by their careful reviews. 


\section{References}

1295

1296 Autin, J., Scheck-Wenderoth, M., Loegering, M.J., Anka, Z., Vallejo, E., Rodriguez,

1297 J.F.,Dominguez, F., Marchal, D., Reichert, C., di Primio, R., Götze, H.-J., 2013.

1298 Colorado Basin 3D structure and evolution, Argentine passive margin.

1299 Tectonophysics 604, 264-279, doi:10.1016/j.tecto.2013.05.019

1300 Autin, J., Scheck-Wenderoth, M., Götze, H.-J., Reichert, Ch., Marchal, D., 2016.

1301 Deep structure of the Argentine margin inferred from 3D gravity and temperature

1302 modelling, Colorado Basin. Tectonophysics 676, pp. 198-210,

1303 doi.org/10.1016/j.tecto.2015.11.023.

1304 Baeschlin, C. F., 1948. Lehrbuch der Geodäsie. Verlag Orell Füssli, Zürich.

1305 Bauer, K., Neben, S., Schreckenberger, B., Emmermann, R., Hinz, K., Fechner, N., 1306 Gohl, K., Schulze, A., Trumbull, R.B., Weber, K., 2000. Deep structure of the Namibia 1307 continental margin as derived from integrated geophysical studies. Journal of

1308 Geophysical Research 105, pp. 25829 - 25,853.

1309 Basile, C., 2015. Transform continental margins - Part 1: Concepts and models.

1310 Tectonophysics, Elsevier, no. 661, pp.1-10. 10.1016/j.tecto.2015.08.034

1311 Benioff, H., 1954. Orogenesis and deep crustal structure - additional evidence from

1312 seismology, Bulletin of the Seismological Society of America, 66, 385-400.

1313 Blaich, O. A., Faleide, J. I., Tsikalas, F., 2011. Crustal breakup and continent-ocean

1314 transition at South Atlantic conjugate margins, Journal of Geophysical Research. 116,

1315 B01402, doi:10.1029/2010JB007686.

1317 Boltwood, B., 1907. The Ultimate Disintegration Products of the Radio-active 1318 Elements. Part II. The disintegration products of uranium. American Journal of 1319 Science series, 4, 23, 77-88. doi:10.2475/ajs.s4-23.134.78.

1320 Bomfim, E.P., Braitenberg, C. and Molina, E.C., 2013. Mutual evaluation of global 1321 gravity models (EGM2008 and GOCE) and terrestrial data in Amazon Basin, Brazil. 1322 Geophysical Journal International, 14 pages, doi: 10.1093/gj/ggt283.

1323 Bond, G.C., Nickelson, P.A., Kominz, M. A., 1984. Breakup of supercontinent 1324 between $625 \mathrm{Ma}$ and $55 \mathrm{Ma}$, New evidence and implicationes for continental 1325 histories. Earth and Planetary Science Letters, 70, 325-345.

1326 Bouman J., Ebbing J., Meekes S., Fattah R.A., Fuchs M., Gradmann S., Haagmans 1327 R., Lieb V., Schmidt M., Dettmering D., Bosch W., 2015. GOCE gravity gradient data 1328 for lithospheric modeling. International Journal of Applied Earth Observation and 1329 Geoinformation 35(A): 16-30, Elsevier, 10.1016/j.jag.2013.11.001. 
1330 Bouman, J., Fuchs, M., Lieb, V., Schmidt, M., Ebbing, J., Holzrichter, N., Gradmann,

1331 S., Abdul Fattah, R., Meekes, S., Novak, P., Sebera, J., 2014. GOCE+ GeoExolore -

1332 Final Report ESA, RP-GOCE+-DNT-11, 2.1, 1 - 443.

1333 Braitenberg, C., 2015. Exploration of tectonic structures with GOCE in Africa and 1334 across continents. International Journal of Applied Earth Observation and 1335 Geoinformation, 35, pp. 88-95.

1336 Brockmann, J.M., Zehentner, N., Höck, E., Pail, R., Loth, I., Mayer-Gürr, T., Schuh, 1337 W.-D., 2014. EGM_TIM_RL05: An independent Geoid with Centimeter Accuracy 1338 purely based on the GOCE Mission. Geophysical Research Letters, Wiley, doi: 1339 10.1002/2014GL061904.

1340 Bruinsma, S.L., C. Foerste, O. Abrikosov, J.M. Lemoine, J.C. Marty, S. Mulet, M.H. 1341 Rio und S. Bonvalot. 2014. ESA's satellite-only gravity field model via the direct 1342 approach based on all GOCE data. Geophysical Research Letters, 41(21), 75081343 7514, DOI: 10.1002/2014GL062045.

1344 Cappelletti, A., Salvi, F., Meda, M., Cavozzi, C., Chowdhury, B.R., Nestola, Y., 1345 Argnani, A., Tsikalas, F., Magistroni, M., Dalla, S., Roveri, M., Bevilacqua, N., 2011. 1346 Tectono-Stratigraphic Evolution of South Atlantic Extensional Rifted Margins: 1347 Constraints from Sandbox Analogue Modeling. Search and Discovery Article, no. 134830204.

1349 Colli, L., Ghelichkhan, S. and Bunge, H. -P., 2016. Geophysical Research Letters, 1350 Volume 43 Issue 6, pp. 2510-2516.

1351 Dressel, I., Scheck-Wenderoth, M., Cacace, M., Lewerenz, B., Götze, H.-J., Reichert, 1352 Ch., 2015. Reconstruction of the southwestern African continental margin by 1353 backward modeling. Marine and Petroleum Geology, 67, DOI:

1354 10.1016/j.marpetgeo.2015.06.006.

1355 Drinkwater, M.R., Floberghagen, R., Haagmans, R., Muzi, D., Popescu, A., 2003. 1356 GOCE: ESA's first Earth Explorer Core mission. In Beutler, G., Drinkwater, M.R., 1357 Rummel, R., von Steiger, R. (eds.), Earth Gravity Field from Space - From Sensors 1358 toEarth Sciences, Space Sciences Series of ISSI, vol. 17. Kluwer Academic 1359 Publishers,Dordrecht, The Netherlands, S. 419-432, ISBN: 1-4020-1408-2.

1360 Ebbing J., Bouman J., Fuchs M., Lieb V., Haagmans R., Meekes J.A.C., Fattah R.A., 1361 2013. Advancements in satellite gravity gradient data for crustal studies. Leading 1362 Edge, 32 (8), pp. 900-906.

1363 Ebbing, J., Lundin, E., Olesen, O., Hansen, E.K., 2006. The mid-Norwegian margin: 1364 A discussion of crustal lineaments, mafic intrusions, and remnants of the Caledonian 1365 root by 3D density modelling and structural interpretation. Journal of the Geological 1366 Society, 163, 47-60.

1367 Eldholm, O., Gladczenko, T.P, Skogseid, J., Planke, S., 2000. Atlantic volcanic 1368 margins: a comparative study. In: Nøttvedt, A., Larsen, B.T., Olaussen, S., 1369 Tørudbakken, B., Skogseid, J., Gabrielsen, R.H., Brekke, H.,Ø. Birkeland (eds.), 1370 Dynamics of the Norwegian Margin. Geological Society of London, Special 1371 Publication 167, 411-428. 
1372 Fairhead, J.D. and Wilson, M. 2005. Plate tectonic processes in the South Atlantic 1373 Ocean: do we need deep mantle plumes? In: G.R. Foulger, J.H. Natland, D.C.

1374 Presnall, D.L. Anderson (Eds.), Plates, Plumes, and Paradigms, Geological Society 1375 of America Special Paper, 388, pp. 537-553.

1376 Fecher T., Pail R., Gruber T., 2013. Global gravity field modeling based on GOCE 1377 and complementary gravity data. International Journal of Applied Earth Observation 1378 and Geoinformation, doi: 10.1016/j.jag.2013.10.005.

1379 Fecher T., Pail R., Gruber T. 2016. GOCO05c - A new combined gravity field model 1380 based on full normal equations and regionally varying weighting. Surveys in 1381 Geophysics, in review.

1382 Fecher T., Pail R., Gruber Th., Holmes S., 2015. Validation of South American 1383 Terrestrial Gravity Anomalies by GOCE. Geophysical Research Abstracts, 17, 1384 EGU2015-4859-1 European Geosciences Union General Assembly 2015, Vienna, 1385 14.04.2015.

1386 Flament, N., Gurnis, M. and Müller, R.D., 2013. A review of observations and models 1387 of dynamic topography, Lithosphere, vol. 5, no. 2, pp. 189-210. doi: 10.1130/L245.1

1388 Förste, C., Bruinsma, S. L., Abrikosov, O., Lemoine, J.-M., Marty, J. C., Flechtner, F., 1389 Balmino, G., Barthelmes, F., Biancale, R., 2014. EIGEN-6C4 The latest combined 1390 global gravity field model including GOCE data up to degree and order 2190 of GFZ 1391 Potsdam and GRGS Toulouse. GFZ Data Services.

1392 http://dx.doi.org/10.5880/icgem.2015.1

1393 Franke, D., Neben, S., Schreckenberger, B., Schulze, A., Stiller, M., and Krawczyk, 1394 C.M., 2006. Crustal structure across the Colorado Basin, offshore Argentina.

1395 Geophys. J.Int., 165, $850-864$.

1396 Franke, D., Ladage, S., Schnabel, M., Schreckenberger, B., Reichert, C., Hinz, 1397 K.,Paterlini, M., de Abelleyra, J., Siciliano, M., 2010. Birth of a volcanic margin off 1398 Argentina, South Atlantic. Geochemistry, Geophysics, Geosystems 11,Q0AB04.

1399 Frisch, W. und Meschede, M., 2005. Plattentektonik. Kontinentverschiebung und 1400 Gebirgsbildung. Primus Verlag GmbH, 208 Seiten. ISBN-10: 3896785257.

1401 Gatti, A., Reguzzoni, M., 2015. Comparison of the space-wise grids with other GOCE 1402 solutions. Geophysical Research Abstracts, Vol. 17, EGU2015-11112, EGU General 1403 Assembly 2015.

1404 Geoffroy, L.C.R., 2005. Volcanic passive margins. Geoscience 337, 1395 -1408. 1405 doi:10.1016/j.crte.2005.10.006.

1406 Gernigon, L., Lucazeau, F., Brigaud, F., Ringenbach, J.-C., Planke, S., Le Gall, B., 1407 2006. A moderate melting model for the Vøring margin (Norway) based on structural 1408 observations and a thermo-kinematical modelling: Implication for the meaning of the 1409 lower crustal bodies. Tectonophysics 412 (3-4), 255-278.

1410 Götze, H.-J., 2015. Potential Methods and Geoinformation Systems. In: Freeden, W., 1411 Nashed, M.Z., Sonar, T. (Eds.): Handbook of Geo-Mathematics. Berlin, Heidelberg, 
1412 Springer Verlag, S. 1-21. - ISBN 978-3-642-27793-1, (doi>10.1007/978-3-642-277931413 1_52-2)

1414 Grombein, T.; Seitz, K.; Heck, B. 2015. RWI_TOPO_2015: An update of the Rock-

1415 Water-Ice topographic gravity field model of the Earth, available from

1416 http://www.gik.kit.edu/rwi_model.php

1417 Gutknecht, B.D., Götze, H.-J., Jahr, T., Jentzsch, G., Mahatsente, R., Zeumann, S., 1418 2014. Surveys of Geophysics, 35, 1417-1440. DOI 10.1007/s10712-014-9296-9.

1419 Gutknecht, B.D., Köther, N., Mahatsente, R., Götze, H.J., 2011. Utilisation of Gravity 1420 Gradients and Invariants for 3D Density Modelling. Proc. General Assembly of the 1421 International Union of Geodesy and Geophysics (IUGG), Melbourne, Australia.

1422 Hackney, R. I. and Featherstone, W. E., 2003. Geodetic versus geophysical 1423 perspectives of the 'gravity anomaly'. Geophysical Journal International 154 (1), 351424 43. doi: 10.1046/j.1365-246X.2003.01941.x

1425 Heit, B., Sodoudi, f., Yuan, X., Bianchi, M., Kind, R., 2007. An S- Receiver Function 1426 Analysis of the Lithospheric Structure in South America, Geophyical. Resarch Letters, 1427 34, L14307, doi:10.1029/2007GL030317.

1428 Hess, H. H., 1962. History of Ocean Basins. In A. E. J. Engel, Harold L. James, and 1429 B. F. Leonard. Petrologic studies: a volume in honor of A. F. Buddington. Boulder, 1430 CO: Geological Society of America. pp. 599-620.

1431 Hinz, K., Neben, S., Schreckenberger, B., Roeser, H.A., Block, M., Goncalves de 1432 Souza, K., Meyer, H., 1999. The Argentine continental margin north of $48^{\circ} \mathrm{S}$ :

1433 sedimentary successions, volcanic activity during break-up. Mar. \& Petrol. Geol.,16, 1 $1434-25$.

1435 Hinze, W.J., Aiken, C., Brozena, J., Coakley, B., Dater, D., Flanagan, G., Forsberg, 1436 R., Hildenbrand, T., Keller, G.R., Kellogg, J., Kucks, R., Li, X., Mainville, A., Morin, R., 1437 Pilkington, M., Plouff, D., Ravat, D., Roman, D., Urrutia-Fucugauchi, J., Véronneau, 1438 M., Webring, M., Winester, D., 2006. New standards for reducing gravity 1439 observations: The Revised North American Gravity Database:

1440 http://paces.geo.utep.edu/research/gravmag/PDF/Final\%20NAGDB\%20Report\%200 $1441 \quad$ 91403.pdf

1442 Hirsch, K.K., Bauer, K., Scheck-Wenderoth, M., 2009. Deep structure of the western 1443 South African passive margin e results of a combined approach of seismic, gravity 1444 and isostatic investigations. Tectonophysics 470, 57 - 70.

1445 http://dx.doi.org/10.1016/j.tecto.2008.04.028.

1446 Holzrichter, N., 2013. Processing and interpretation of satellite and ground based 1447 gravity data at different lithospheric scales. Dissertation, 126 pages. Christian1448 Albrechts-Universität zu Kiel. Fakultät für Mathematik und Naturwissenschaften.

1449 Hopper, J.R., Funck, T., Tucholke, B.E., Larsen, H.C., Holbrook, W.S., Louden, K.E., 1450 Shillington, D., Lau, H., 2004. Geological Society of America. Geology, 32, (1), 93 1451 96. DOI 10.1130/G19694.1. 
1452 Hosse, M., Pail, R., Horwath, M., Holzrichter, N., Gutknecht, B.D., 2014. Combined

Regional Gravity Model of the Andean Convergent Subduction Zone and Its

1454 Application to Crustal Density Modelling in Active Plate Margins. Surveys in

1455 Geophysics, 35, (6), 1393-1415.

1456 Isacks, B., Oliver, J.,Sykes, L. R., 1968. Seismology and the New Global Tectonics.

1457 Journal of Geophysical Research, 73, (18), 5855.

1458 IUGG, 2015. Resolutions adpoted by the IUGG Council at the XXVI General

1459 Assembly, Prague, Czech Republic, 22 June - 2 July 2015;

1460 http://www.iugg.org/resolutions/IUGGResolutions2015.pdf

1461 Kalberg, T., 2016. Interpretation tektonomagmatischer Prozesse basierend auf 3D

1462 Potentialfeldmodellierungsergebnissen. Dissertation 185 pages. Fachbereich für

1463 Geowissenschaften, Universität Bremen.

1464 Klinge, L., 2016. Gravitational potential energy (GPE) und Stress im südlichen

1465 Atlantik (in German). Master Arbeit, 89 pages. Institut für Geowissenschaften,

1466 Mathematisch-naturwissenschaftliche Fakultät der Christian-Albrechts-Universität

1467 Kiel.

1468 Köther, N., Götze, H.-J., Gutknecht, B.G., Jahr, T., Jentzsch, G., Lücke, O.H.,

1469 Mahatsentea, R., Sharma, R., Zeumann, S., 2012. The seismically active Andean

1470 and Central American margins: Can satellite gravity map lithospheric structures?

1471 Journal of Geodynamics, 59-60, 207-218.

1472 LaFehr, T.R., 1991. An exact solution for the gravity curvature (Bullard B) correction:

1473 Geophysics, 56, (8), 1179-1184, doi: 10.1190/1.1443138.

1474 Lallemand S., 2014. Active continental margin. In Encyclopedia of Marine

1475 Geosciences, Springer Science, Eds.: Harff, J., Meschede, M., Petersen, S. and

1476 Thiede, J., 7 pages, DOI 10.1007/978-94-007-6644-0_102-2.

1477 Li, X. and Götze, H.-J., 2001. Ellipsoid, Geoid, Gravity, Geodesy, and Geophysics - A

1478 Tutorial. Geophysics, vol. 66, no. 6, 1660-1668.

1479 Maus, S., Barckhausen, U., Berkenbosch, H., Bournas, N., Brozena, J., Childers, V., 1480 Dostaler, F., Fairhead, J.D., Finn, C., von Frese, R. R. B., Gaina, C., Golynsky, S., 1481 Kucks, R., Lühr, H., Milligan, P., Mogren, S., Müller, R.D., Olesen, O., Pilkington, M., 1482 Saltus, R., Schreckenberger, B., Thébault, E. and Caratori Tontini, F., 2009. EMAG2: 1483 A 2-arc min resolution Earth Magnetic Anomaly Grid compiled from satellite, airborne, 1484 and marine magnetic measurements. Geochemistry, Geophysics, Geosystems, vol. 1485 10, no. 8. doi: 10.1029/2009GC002471.

1486 Mayer-Gürr, T., Zehentner, N., Klinger, B., Kvas, A., 2014. ITSG-Grace2014: a new 1487 GRACE gravity field release computed in Graz. Presented at GRACE Science Team 1488 Meeting (GSTM), Potsdam, 29.09.2014.

1489 Maystrenko, Y.P., Scheck-Wenderoth, M., Hartwig, A., Anka, Z., Watts, A.B., Hirsch, 1490 K.K, Fishwick, S. 2013. Salt as a 3D element in structural modeling - Example from 1491 the Central European Basin System. Tectonophysics,

1492 doi:10.1016/j.tecto.2012.06.030 
1493 Mikuška, J., Pašteka, R., Marušiak, I., 2006. Estimation of distant relief effect in gravimetry. GEOPHYSICS, 71, (6), J59-J69, doi: 10.1190/1.2338333.

1495

Mohriak, W., 2014. Birth and development of continental margin basins: analogies from the South Atlantic, North Atlantic and the Red Sea. Search and Discovery article, http://www.searchanddiscovery.com/pdfz/documents /2014/41502mohriak/ndx mohriak.pdf.html

Müller, R. D., Sdrolias, M., Gaina, C. and Roest, W.R., 2008. Age, spreading rates, and spreading asymmetry of the world's ocean crust. Geochemistry, Geophysics, Geosystems, vol. 9, no. 4., 19 pages, doi: 10.1029/2007GC001743.

Naudy, H. and Neumann R., 1965. Sur la définition de l'anomalie de Bouguer et ses conséquences pratiques, Geophys. Prosp., vol 13, 1-110'Connor, J.M., Jokat, W., le Roex, A.P., Class,C., Wijbrans,J.R., Keßling, S., Kuiper, K.F. and Nebel, O., 2012. Hotspot trails in the South Atlantic controlled by plume and plate tectonic processes. Nature Geoscience 5, pp. 735-738, doi:10.1038/ngeo1583.

Oliver, J., Isacks, B., 1967. Deep earthquake zones, anomalous structures in the upper mantle, and the lithosphere. Journal of Geophysical Research, 72 (16), pp. 4259-4275.

Oncken, O., Chong, G., Franz, G., Giese, P., Götze, H.-J., Ramos, V., Strecker, M. and Wigger, P., (Eds), 2006: The Andes - Active Subduction Orogeny., Frontiers in Earth Sciences, 1, Springer Verlag, pp. 570.

Pail R., Fecher T., Rexer M. 2015b. Validation of GOCE gravity gradient grids for geophysical applications. Geophysical Research Abstracts, Vol. 17, EGU2015-1652, Poster presented at EGU General Assembly 2015, Vienna.

Pail, R., Bingham, R., Braitenberg, C., Dobslaw, H., Eicker, A., Güntner, A., Horwath, M., Ivins, E., Longuevergne, L., Panet, I., Wouters, B. 2015a. Science and User Needs for Observing Global Mass Transport to Understand Global Change and to Benefit Society. Surveys in Geophysics, 36(6): 743-772, Springer Netherlands, doi: 10.1007/s10712-015-9348-9.

Pail, R., Goiginger, H., Schuh, W.-D., Höck, E., Brockmann, J. M., Fecher, T., Gruber, T., Mayer-Gürr, T., Kusche, J., Jäggi, A., Rieser, D. 2010. Combined satellite gravity field model GOCO01S derived from GOCE and GRACE. Geophysical Research Letters, Vol. 37, L20314, doi:10.1029/2010GL044906.

Pail, R., S. Bruinsma, F. Migliaccio, C. Förste, H. Goiginger, W.-D. Schuh, E. Höck, M. Reguzzoni, J. M. Brockmann, O. Abrikosov, M. Veicherts, T. Fecher, R. Mayrhofer, I. Krasbutter, F. Sansò, and C. C. Tscherning 2011. First GOCE gravity field models derived by three different approaches, Journal of Geodesy, 85(11), 819843, doi: 10.1007/s00190-011-0467-x.

Panet I., G. Pajot-Métivier, M. Greff-Lefftz, L. Métivier, M. Diament \& M. Mandea 2014. Mapping the mass distribution of Earth's mantle using satellite-derived gravity gradients, Nature Geoscience 7, 131-135, doi:10.1038/ngeo2063. 
1533 Pavlis, N.K., Holmes, S.A., Kenyon, S.C., Factor, J.K., 2008. An Earth Gravitational Model to Degree 2160: EGM2008. In: Proceedings of the European Geosciences

1535 Union General Assembly, April 13-18, Vienna, Austria.

1536 Pavlis, N.K., Holmes, S.A., Kenyon, S.C., Factor, J.K., 2012. The development and 1537 evaluation of the Earth Gravitational Model 2008 (EGM2008). Journal of Geophysical 1538 Research, 117, (B4), 2156 - 2202, doi: 10.1029/2011JB008916.

1539 Prange, L., 2011. Global Gravity Field Determination Using the GPS Measurements 1540 Made Onboard the Low Earth Orbiting Satellite CHAMP. PhD Thesis, Geodätisch1541 geophysikalische Arbeiten in der Schweiz, vol. 81. http://www.sgc.ethz.ch/sgc1542 volumes/sgk-81.pdf

1543 Reigber, C., Balmino, G., Schwintzer, P., Biancale, R., Bode, A., Lemoine, J.-M., 1544 Koenig, R., Loyer, S., Neumayer, H., Marty, J.C., Barthelmes, F., Perossanz, F., 1545 2002. A high quality global gravity field model from CHAMP GPS tracking data and 1546 accelerometry (EIGEN-1S). Geophysical Research Letters, 29, 14, 1547 dx.doi.org/10.1029/2002GL015064

1548 Reston, T.J., 2009. The structure, evolution and symmetry of the magma-poor rifted 1549 margins of the North and Central Atlantic: A synthesis. Tectonophysics 468, 6-27. 1550 doi:10.1016/j.tecto.2008.09.002.

1551 Rudenko S., Dettmering D., Esselborn S., Schoene T., Foerste C., Lemoine J-M, 1552 Ablain M, Alexandre D, Neumayer K.-H., 2014. Influence of time variable geopotential 1553 models on precise orbits of altimetry satellites, global and regional mean sea level 1554 trends. Advances in Space Research, doi: 10.1016/j.asr.2014.03.010.

1555 Salomon, A., Koehn, D., Passchier, C., Hackspacher, P.C. and Glasmacher, U.A., 1556 2014. Contrasting stress fields on correlating margins of the South Atlantic, 1557 Gondwana Research, doi.org/10.1016/j.gr.2014.09.006.

1558 Schaller. T., Andersen, J., Götze, H.-J., Koproch, N., Schmidt, S., Sobiesiak, M., 1559 Splettstößer,S., 2015. Segmentation of the Andean margin by isostatic models and 1560 gradients. Journal of South American Earth Sciences, 59, 69-85.

1561 Scheck-Wenderoth, M., Maystrenko, Y., 2008. How warm are passive continental 1562 margins? A 3D lithosphere-scale study from the Norwegian margin. Geology, 36, (5), 1563 419-422, DOI: 10.1130/G24545A.1.

1564 Skogseid, J., Planke, S., Faleide, J.I., Pedersen, T., Eldholm, O., Neverdal, F., 2000. 1565 NE Atlantic continental rifting and volcanic margin formation, in Nottvedt, A.e.a., Ed., 1566 Dynamics of the Norwegian Margin, 167: London, Geological Society of London, 1567 Special Publications, p. 55-82.

1568 Sobiesiak, M., Meyer U., Schmidt S., Götze H.-J., Krawczyk C.M., 2007. Asperity 1569 generating upper crustal sources revealed by b value and isostatic residual anomaly 1570 grids in the area of Antofagasta, Chile. Journal of Geophysical Research, v. 112, 1571 B12308, doi: 10.1029/2006JB004796. 
1572 Stadler, G., Gurnis,M., Burstedde, C., Wilcox, L.C., Alisic, L., Ghattas, O., 2010. The

1573 Dynamics of Plate Tectonics and Mantle Flow: From Local to Global Scales. Science,

1574 Vol. 329, Issue 5995, pp. 1033-1038, DOI: 10.1126/science.1191223.

1575 Szwillus, W., Ebbing, J. and Holzrichter, N., 2016. Importance of far-field topographic 1576 and isostatic corrections for regional density modelling. Geo- physical Journal

1577 International, 207 (1), pp. 274-287, doi:10.1093/gji/ggw270

1578 Szwillus, W., Götze, H.-J., 2016. Efficient mass correction using an adaptive method.

1579 In: R, Pasteka et al., Proceedings of the workshop on Bouguer Anomaly, Bratislava

1580 (Slowak Republic). Accepted.

1581 Tapley, B.D., Bettadpur, S., Watkins, M., Reigber, C., 2004. The gravity recovery and

1582 climate experiment: mission overview and early results. Geophysical Research

1583 Letters, 31(9), L09607, AmericanGeophysical Union,

1584 http://dx.doi.org/10.1029/2004GL019920.

1585 Tašárová, Z., 2007. Towards understanding the lithospheric structure of the southern 1586 Chilean subduction zone $\left(36^{\circ} \mathrm{S}-42^{\circ} \mathrm{S}\right)$ and its role in the gravity field. Geophysical

1587 Journal International, 170, (3), 995-1014. doi:10.1111/j.1365-246X.2007.03466.x

1588 Torge W., 2001. Geodesy, 3rd edition, 416 pages. De Gruyter Berlin, ISBN 3-111589 017072-8.

1590 Torsvik, T. H., Rousse, S., Labails, C. and Smethurst, M.A., 2009. A new scheme for 1591 the opening of the South Atlantic Ocean and the dissection of an Aptian salt basin.

1592 Geophysical Journal International, 177, 3, pp. 1315-1333. doi: 10.1111/j.1365-

1593 246X.2009.04137.x.

1594 Vine, F. J.; Matthews, D. H., 1963. Magnetic Anomalies Over Oceanic Ridges. Nature 1595199 (4897), 947-949.

1596 Wadati, K., 1929. Shallow and deep earthquakes (2nd paper): Geophysical

1597 Magazine, 2, 1-36.

1598 Wefer,G., Billet, D., Hebbeln, D., Barker Jorgensen, B., Schlüter, M., van Weering, 1599 T.C.E., 2003. Eds. Ocean Margin Systems. Springer, pp. 495. Doi.10.007/978/-31600 662-05127-6

1601 Wegener, A., 1920. Die Entstehung der Kontinente und Ozeane. In: E. Wiedemann 1602 (Herausgeber), Die Wissenschaft, Friedrich Vieweg und Sohn, Braunschweig, 2.

1603 Auflage, 66, 1-135.

1604 Wenzel H., 1985: Hochauflösende Kugelfunktionsmodelle für das

1605 Gravitationspotential der Erde: Wissenschaftliche Arbeiten der Fachrichtung 1606 Vermessungswesen der Universität Hannover, 137, 1-155.White, R. S., Smith,L.K., 1607 2009. Crustal structure of the Hatton and the conjugate east Greenland rifted volcanic 1608 continental margins, NE Atlantic. Journal of Geophysical Research, 114. B02305. 1609 DOI 10.1029/2008JB005856 
CHRISTIAN-ALBRECHTS-UNIVERSITÄT ZU KIEL

INSTITUT FÜR GEOWISSENSCHAFTEN

Prof. Dr. H.-J. Götze

Abteilung Geophysik, Otto-Hahn-Platz 1, 24118 Kiel

Datum:March 24, 2017

Telefon: $\quad+49(0) 431880-3805$
FAX: $\quad+49(0) 431880-1387$
mail: hajo@geophysik.uni-kiel.de
//www.gravity.uni-kiel.de

Ladies and Gentlemen,

This an invited manuscript by me and Roland Pail for the "Passive margin" issue.

Please, start with the review process.

Regards,

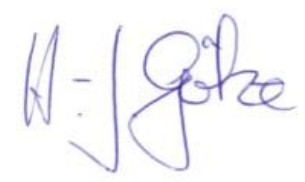

H.-J. Götze 